Prepared for the U.S. Department of Energy

under Contract DE-AC05-76RL01830

\title{
Simulant Development for Hanford Double-Shell Tank Mixing and Waste Feed Delivery Testing
}

PA Gauglitz

DN Tran

WC Buchmiller

September 2012

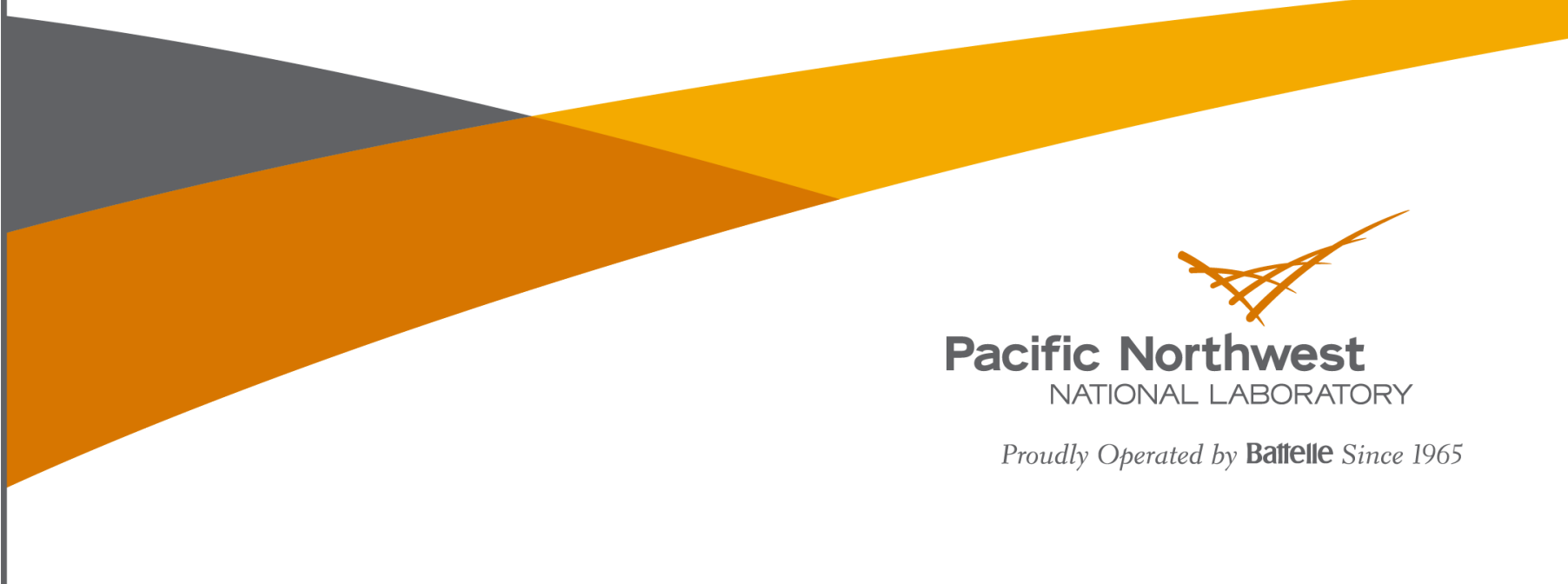




\title{
DISCLAIMER
}

This report was prepared as an account of work sponsored by an agency of the United States Government. Neither the United States Government nor any agency thereof, nor Battelle Memorial Institute, nor any of their employees, makes any warranty, express or implied, or assumes any legal liability or responsibility for the accuracy, completeness, or usefulness of any information, apparatus, product, or process disclosed, or represents that its use would not infringe privately owned rights. Reference herein to any specific commercial product, process, or service by trade name, trademark, manufacturer, or otherwise does not necessarily constitute or imply its endorsement, recommendation, or favoring by the United States Government or any agency thereof, or Battelle Memorial Institute. The views and opinions of authors expressed herein do not necessarily state or reflect those of the United States (iovernment or any agency thereof.

\author{
PACIFIC NORTHWEST NATIONAL LABORATORY \\ operated by \\ BATTELLE \\ for the \\ UNITED STATES DEPARTMENT OF ENERGY \\ under Contract DE-AC05-76RL01830 \\ Printed in the United States of America
Available to DOF and DOF contractors from the
Office of Scientific and 'Technical Information,
P.O. Box 62, Oak Ridge, I'N 37831-0062;
ph: (865) 576-8401
fax: $(865) 576-5728$ \\ email: reports@adonis.osti.gov

\footnotetext{
Available to the public from the National Technical Information Service,

U.S. Department of Commerce, 5285 Port Roy al Rd., Springfield, VA 22161

ph: (800) $553-6847$

fax: $(703) 605-6900$

email: orders@ntis.fedworld.gov

online ordering: http://www.ntis.gov/ordering.htm
}

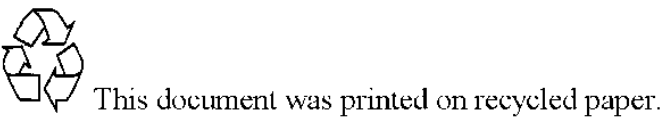

$(9 / 2003)$ 


\section{Simulant Development for Hanford Double-Shell Tank Mixing and Waste Feed Delivery Testing}

PA Gauglitz

DN Tran

WC Buchmiller

September 2012

Prepared for

the U.S. Department of Energy

under Contract DE-AC05-76RL01830

Pacific Northwest National Laboratory

Richland, Washington 99352 



\section{Executive Summary}

The U.S. Department of Energy Office of River Protection manages the River Protection Project, which has the mission to retrieve and treat the Hanford tank waste for disposal and close the tank farms. Washington River Protection Solutions, LLC, is responsible for a primary objective of this mission: to retrieve and transfer tank waste to the Hanford Waste Treatment and Immobilization Plant (WTP). A mixing and sampling program with four separate demonstrations is currently being conducted to support this objective and also to support activities in a plan for addressing safety concerns identified by the Defense Nuclear Facilities Safety Board related to the ability of the WTP to mix, sample, and transfer fast-settling particles.

Previous studies have documented the objectives, criteria, and selection of nonradioactive simulants for these four demonstrations. The identified simulants include Newtonian suspending liquids with densities and viscosities that span the range expected in waste feed tanks. The identified simulants also include non-Newtonian slurries with Bingham yield stress values that span a range that is expected to bound the Bingham yield stresses of waste in the feed delivery tanks. The previous studies identified candidate materials for the Newtonian and non-Newtonian suspending fluids, but did not provide specific recipes for obtaining the target properties, and information was not available to evaluate the compatibility of the fluids and particles or the potential for salt precipitation at lower temperatures.

The purpose of this study is to prepare small batches of simulants in advance of the demonstrations to determine specific simulant recipes, to evaluate the compatibility of the liquids and particles, and to determine whether the simulants are stable for the potential range of test temperatures. The objective of the testing, which is focused primarily on the Newtonian and non-Newtonian fluids, is to determine the composition of simulant materials that gives the desired density and viscosity or rheological parameters.

Recipes for five Newtonian liquids were developed to match low and high targets for density and viscosity and to match a typical density and typical viscosity target. The recipes were developed using aqueous solutions of sodium thiosulfate or sodium thiosulfate and glycerol to match the density and viscosity targets for four of the five targets. Sodium thiosulfate was the preferred salt because it is nonhazardous and inexpensive. An aqueous solution of sodium bromide, which gives lower viscosities in concentrated solutions, was selected as a preferred material for a high-density/low-viscosity target. The effect of temperature on viscosity was determined for all the solutions; the solutions including glycerol are the most temperature sensitive. All of these solutions were stable (no salt precipitation after about a day) down to $10^{\circ} \mathrm{C}$. There was only one liquid/particle compatibility issue observed during the testing, and this was when a specific gibbsite material was added to a solution of glycerol in water (lowdensity/high-viscosity target). For this mixture, slurries always stayed cloudy during settling and would form settled layers that were difficult to resuspend. This recipe was reformulated by adding $0.1 \mathrm{wt} \%$ sodium thiosulfate, which altered the particle behavior, and the settling and resuspension results were much improved.

For the non-Newtonian slurries, simulant recipes were developed using slurries of kaolin clay in water or kaolin clay in sodium thiosulfate solutions. For the kaolin in sodium thiosulfate solutions, the proportions of both the sodium thiosulfate and kaolin were adjusted to obtain slurries with Bingham yield stresses of 1, 3 and $10 \mathrm{~Pa}$ having a constant density (matching the high-density Newtonian target). For the kaolin-in-water slurries, the density was not adjusted but was comparable to the low-density 
Newtonian target. The effect of temperature on the Bingham yield stress and consistency were determined and slurries were stable (no salt precipitation) down to $10^{\circ} \mathrm{C}$. 


\section{Acknowledgments}

The authors would like to acknowledge K. Pat Lee and Mike Thien of Washington River Protection Solutions for their technical involvement in defining simulant targets and evaluating candidate recipes, and also thank Matthew Ahrendt for his support in providing samples of the simulant materials from the batches obtained for the demonstration tests. The authors also would like to thank Beric Wells for his technical peer review and Maura Zimmerschied for her technical editing. 



\section{Acronyms and Abbreviations}

DI

EPK

$\mathrm{g}$

in

KA

$\mathrm{m}$

MB

$\min$

$\mathrm{mL}$

$\mathrm{Pa}$

PSD

QA

$\mathrm{S}$

SS

VSR

WTP deionized

Edgar plastic kaolin, from Edgar Minerals division of The Feldspar Corporation gram

inch

KitchenAid ${ }^{\circledR}$

meter

Magic Bullet ${ }^{\circledR}$

minute

milliliter

Pascal

particle size distribution

quality assurance

second

stainless steel

variable speed re-cycling

Hanford Waste Treatment and Immobilization Plant 



\section{Contents}

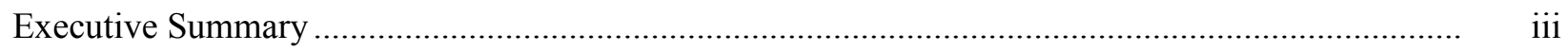

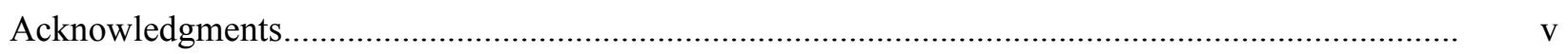

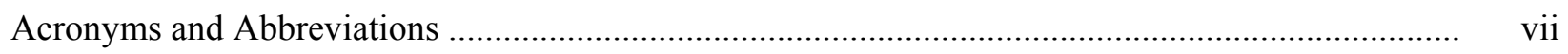

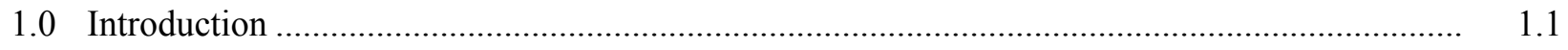

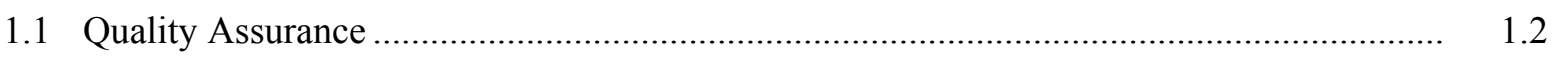

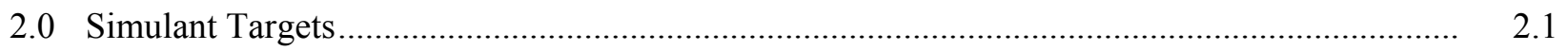

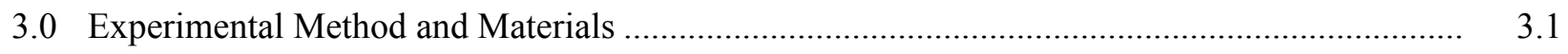

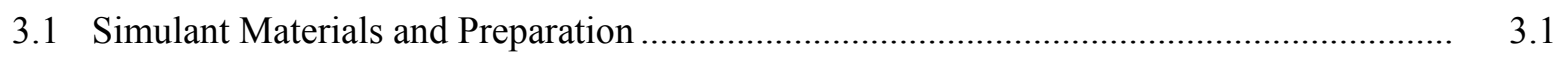

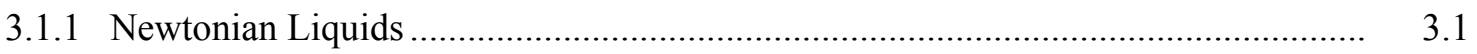

3.1.2 Non-Newtonian Fluids ................................................................................... 3.3

3.1.3 Base and Spike Simulant Particles .............................................................. 3.4

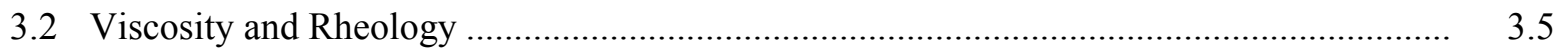

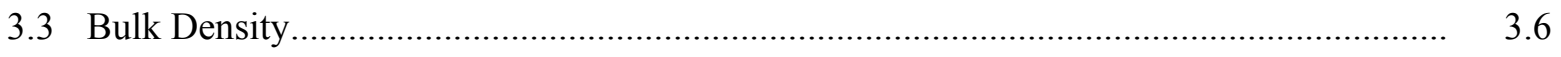

3.4 Compatibility of Suspending Fluids and Particles ….................................................... 3.7

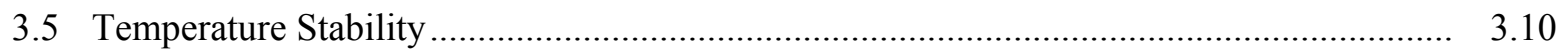

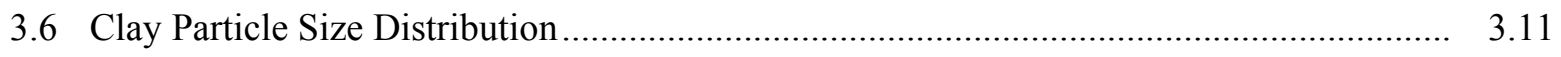

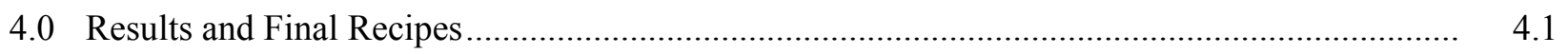

4.1 Newtonian Simulant Density and Viscosity .............................................................. 4.3

4.2 Compatibility of Base and Spike Particles in Newtonian Simulants ............................... 4.6

4.3 Non-Newtonian Simulant Density and Rheology ....................................................... 4.8

4.4 Compatibility of Spike Simulant Particles in Non-Newtonian Slurries ............................ 4.14

4.5 Non-Newtonian Kaolin Slurry Particle Size Distributions ….......................................... 4.15

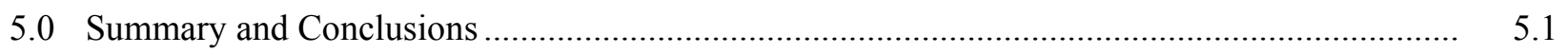

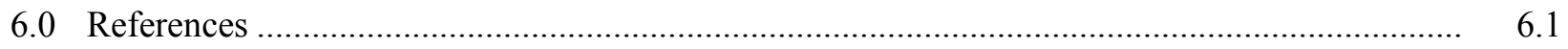

Appendix A - Simulant Materials Provided to Pacific Northwest National Laboratory ................... A. A.1

Appendix B - Rheograms for Kaolin Clay Slurries.................................................................. B. B 1

Appendix C - Particle Size Distributions for Kaolin Clay in Simulant Recipes ............................... C.1 


\section{Figures}

4.1 Effect of Temperature on Viscosity for Newtonian Simulants ..............................................

4.2 Experimental Results and Model Fit for the Effect of Temperature on Viscosity with the Solution Composition Adjusted to give a Density of $1.37 \mathrm{~g} / \mathrm{mL}$........................................... 4.6

4.3 Settling Behavior of Low-Base Simulant Particles in the Newtonian Liquids ......................... 4.7

4.4 Bingham Yield Stress for Aqueous Slurries of Kaolin and Sodium Thiosulfate with a Slurry Density of $1.37 \mathrm{~g} / \mathrm{mL}$

4.5 Bingham Consistency for Aqueous Slurries of Kaolin and Sodium Thiosulfate with a Slurry Density of $1.37 \mathrm{~g} / \mathrm{mL}$

4.6 Bingham Yield Stress for Aqueous Slurries of Kaolin with Slurry Densities that Vary from 1.13 to $1.19 \mathrm{~g} / \mathrm{mL}$

4.7 Bingham Consistency for Aqueous Slurries of Kaolin with Slurry Densities that Vary from 1.13 to $1.19 \mathrm{~g} / \mathrm{mL}$

4.8 Comparison of Bingham Yield Stresses for Kaolin Slurries in Water and with Sodium Thiosulfate and Sodium Bromide

4.9 Comparison of Bingham Consistencies for Kaolin Slurries in Water and with Sodium Thiosulfate and Sodium Bromide

4.10 Bingham Consistency versus Yield Stress for Kaolin Slurries in Water and with Sodium Thiosulfate or Sodium Bromide.

4.11 Kaolin PSDs for all Sonicated Slurries having Different Preshearing for Slurries of Kaolin in Water and Kaolin in Sodium Thiosulfate Solutions.

4.12 Effect of Sodium Thiosulfate on Kaolin PSDs for Unsonicated Kaolin Slurries with Different Preshearing

4.13 Effect of Preshearing on Kaolin PSDs for Unsonicated Slurries of Kaolin in Water and Kaolin in Sodium Thiosulfate Salt Solution

4.14 Effect of Sonication on Kaolin PSDs for Slurries of Kaolin in Water and Kaolin in Sodium Thiosulfate Salt Solution.

4.15 Effect of Sonication on Kaolin PSDs for Slurries of Kaolin in Water Presheared with the Magic Bullet Mixer. 


\section{Tables}

$2.1 \quad$ Targets for Newtonian-Liquid Simulants.................................................................... 2.2

2.2 Bingham Yield Stress and Density Targets for Non-Newtonian Suspending Fluid ................. 2.2

3.1 Materials Used in Newtonian Liquid Simulants ............................................................ 3.2

3.2 Materials used in Non-Newtonian Liquid Simulants .......................................................... 3.3

3.3 Materials Used as Base Simulant Particles in Newtonian Liquids ......................................... 3.4

3.4 Materials Used as Spike Particles in Newtonian and Non-Newtonian Fluids .......................... 3.5

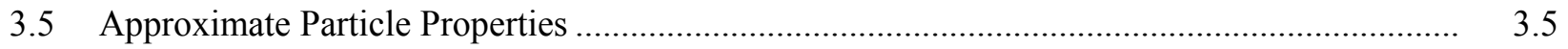

3.6 Compositions of Newtonian Liquids used for Evaluating Particle and Liquid Compatibility.... $\quad 3.8$

3.7 Compositions of Slurries of Newtonian Liquids and Base and Spike Particles for

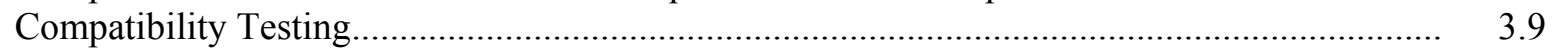

3.8 Compositions of Non-Newtonian Slurries used for Evaluating Particle and Liquid

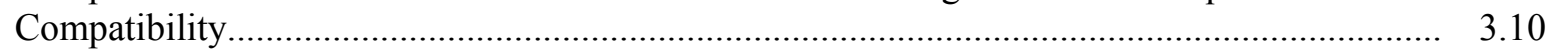

3.9 Compositions of Non-Newtonian Slurries and Spike Particles for Compatibility Testing........ 3.10

3.10 Kaolin Slurries for PSD Analysis................................................................................ 3.11

3.11 Preshearing and Sonication for Kaolin Slurry Samples ..................................................... 3.12

3.12 Microtrac Instrument Parameters for PSD Measurements of Kaolin in Water and in a Sodium Thiosulfate Solution..................................................................................... 3.12

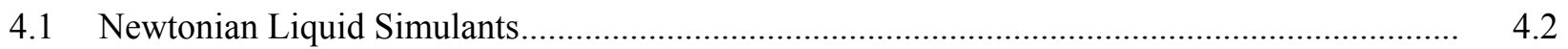

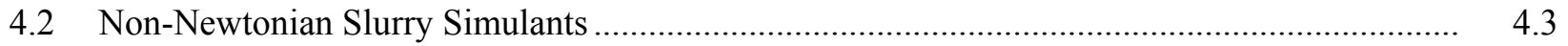

4.3 Densities of Aqueous Solutions of Glycerol, Sodium Thiosulfate and Water and Comparison to Calculated Density....................................................................................... 4.4

4.4 Effect of Temperature on the Viscosity of Aqueous Solutions of Glycerol and Water ............. 4.5

4.5 Resuspension Results for Newtonian Liquids with Base and Spike Particles ......................... 4.8

4.6 Effect of Temperature on Bingham Yield Stress and Consistency for Slurries of Kaolin and

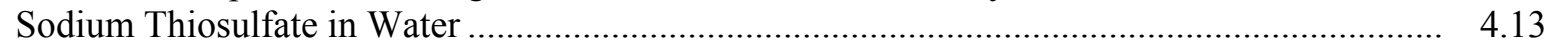

4.7 Effect of Temperature on Bingham Yield Stress and Consistency for Slurries of Kaolin in Water.

4.8 Resuspension Results for Spike Particles in Non-Newtonian Simulant 



\subsection{Introduction}

The U.S. Department of Energy Office of River Protection manages the River Protection Project, which has the mission to retrieve and treat the Hanford tank waste for disposal and close the tank farms (Certa et al. 2011). Washington River Protection Solutions, LLC is responsible for a primary objective of this mission: to retrieve and transfer tank waste to the Hanford Waste Treatment and Immobilization Plant. Washington River Protection Solutions is currently conducting a mixing and sampling program to support this objective (Thien and Sexton 2012). The mixing and sampling program is also being conducted to support the activities identified in the implementation plan for addressing comments from the Defense Nuclear Facilities Safety Board on waste mixing (DOE 2011). This program includes four experimental demonstrations that use nonradioactive simulants: a small-scale mixing demonstration, a remote sampler demonstration, scouting studies at the Savannah River National Laboratory, and full-scale transfer pump testing (Thien and Sexton 2012).

Lee et al. (2012) documents the objectives, criteria, and selection of simulants for use in these demonstrations. Further definition of the simulant targets and materials for specific testing is given in individual test plans (Lee 2012a, 2012b, 2012c). The identified simulants include Newtonian suspending liquids with densities and viscosities that span the range expected in waste feed tanks based on an evaluation of actual waste data and planned blending in the feed delivery tanks. A variety of particles with different size distributions and densities were specified for addition to the Newtonian liquids to create appropriate slurries for testing. The identified simulants also include non-Newtonian slurries with Bingham yield stress values that span a range that is expected to bound the Bingham yield stresses of waste in the feed delivery tanks. Specific large and dense particles were again specified for addition to the non-Newtonian materials to create slurries for testing. Lee et al. (2012) identified candidate materials for the Newtonian and non-Newtonian suspending fluids and the added particles, but did not provide specific recipes for obtaining the target properties for the Newtonian and non-Newtonian suspending fluids. In addition, existing information was not available to evaluate the compatibility of all the fluids and particles or the potential for salt precipitation at lower test temperatures for the candidate materials.

The purpose of this study is to prepare small trial batches of simulants in advance of the demonstration tests to determine specific simulant recipes, to evaluate the compatibility of the liquids and particles, and to determine whether the simulants are stable for the potential range of test temperatures.

The objective of the testing, which is focused primarily on the Newtonian and non-Newtonian suspending fluids, is to determine the composition of selected simulant materials that give the desired density and viscosity or rheological parameters. Results will also be shown for the evaluation of the compatibility of the fluids and particles and the effect of temperature on the simulants.

In the following subsections we discuss the quality assurance (QA) level for these scoping tests and the simulant recipes. Section 2 discusses the target values for the bulk density and viscosity or Bingham properties for the simulants. Section 3 describes the experimental method and materials used in developing the simulant recipes and characterizing the simulants. Section 4 summarizes the final recipes and results of testing, and Section 5 provides an overall summary. 


\subsection{Quality Assurance}

In conducting this work, Pacific Northwest National Laboratory (PNNL) followed the basic requirements that are implemented for all work conducted in accordance with the U.S. Department of Energy Prime Contract DE-AC05-76RL01830 at PNNL. The demonstrations described in Section 1.0 are conducted using a higher level of QA requirements and the testing conducted in this study does not meet this higher QA level. Accordingly, the intent of this simulant development effort is to provide recipes as guidance for the demonstration tests; the demonstrations will need to mix and characterize simulant batches according to the appropriate QA procedures for those demonstrations. 


\subsection{Simulant Targets}

Target values of density and viscosity for Newtonian liquids and Bingham parameters for nonNewtonian fluids are given in Lee et al. (2012). Following simulant selection guidelines for tank waste (ASTM 2010), the target values were determined from an evaluation of actual waste data and planned waste blending in the feed delivery tanks for the parameters that are important for the planned testing. Table 2.1 shows the Newtonian-liquid targets and also describes the priority property for the simulant to match. For the typical-density/typical-viscosity target, the selection in the table is identified in Lee (2012b) and represents a multicomponent caustic salt solution used in previous mixing studies (Adamson et al. 2010) that is representative of Hanford supernatant liquid. For the two low-viscosity targets and the typical-density/typical-viscosity target, the priority is to match the target density because the fluid density is likely to have a more significant role in jet mixing than the viscosity (Wells et al. 2012). For the lowdensity/high-viscosity target, while the fluid density is certainly important, the purpose of this simulant is to explore the impact of elevated viscosity. For this simulant, the priority is to match the target viscosity and be reasonably close to the low-density target.

Aqueous solutions of salts and glycerol were specified in Lee et al. (2012) as candidates for producing Newtonian liquids with the target densities and viscosities. In general, glycerol was selected for increasing the viscosity (it also changes the density) and salts were selected for adjusting the density (salts also affect the viscosity). A variety of salts are candidates, but for the planned demonstration tests a preference was given to salts solutions that are nonhazardous and readily available at a reasonable cost. Sodium thiosulfate $\left(\mathrm{Na}_{2} \mathrm{~S}_{2} \mathrm{O}_{3}\right)$ and sodium bromide $(\mathrm{NaBr})$ were identified as specific candidates in Lee et al. (2012). Because of the lower purchase and disposal costs, sodium thiosulfate was the preferred salt and was used for all the recipes with one exception. For the high-density/low-viscosity target, a sodium thiosulfate solution at the target density would give a viscosity that is significantly higher than the target of $1 \mathrm{mPa} \cdot \mathrm{s}$ (CRC 2011). A sodium bromide solution for the same target density gives much lower viscosity and was selected for the high-density/low-viscosity simulant.

Table 2.2 gives the target densities and Bingham yield stresses for the non-Newtonian slurries. The overall range for the Bingham yield stress is described in Lee et al. (2012) and the specific $3 \mathrm{~Pa}$ target is given by Lee (2012a). Lee et al. (2012) do not give specific values for the Bingham consistency, but note that the consistency should be appropriate for the yield stress based on the actual waste data presented in their Appendix B. For the majority of the data in Appendix B of Lee et al. (2012), the Bingham consistency is between 1 and $10 \mathrm{mPa} \cdot \mathrm{s}$. The high-density target for the non-Newtonian slurries was selected by Lee (2012a) to match the high-density Newtonian fluid. The low-density target was selected to be comparable to the low-density Newtonian liquid as comparable as can be achieved with kaolin-in-water slurries (Lee 2012a).

Lee et al. (2012) and Lee (2012a) specified slurries of kaolin clay in water and kaolin clay in sodium thiosulfate solutions as candidates for giving the target densities and Bingham parameters. In general, kaolin was selected for increasing the Bingham yield stress (kaolin also affects the density) and sodium thiosulfate was selected for adjusting the density (it also changes how the kaolin increases the yield stress). Some limited testing was done with kaolin in sodium bromide solutions, but the lower purchase and disposal cost of sodium thiosulfate made it the preferred salt for these recipes. 
Table 2.1. Targets for Newtonian-Liquid Simulants

\begin{tabular}{|c|c|c|c|}
\hline \multirow[b]{2}{*}{$\begin{array}{c}\text { Simulant } \\
\text { (Density/Viscosity) }\end{array}$} & \multicolumn{2}{|c|}{$\begin{array}{l}\text { Targets from Tank } \\
\text { Waste Data }^{(\mathrm{a})}\end{array}$} & \multirow[b]{2}{*}{ Comments } \\
\hline & $\begin{array}{r}\text { Density } \\
(\mathrm{g} / \mathrm{mL})\end{array}$ & $\begin{array}{l}\text { Viscosity } \\
(\mathrm{mPa} \cdot \mathrm{s})\end{array}$ & \\
\hline Low/Low ${ }^{(a)}$ & 1.1 & 1 & $\begin{array}{l}\text { Simulant priority is to match } \\
\text { target density }\end{array}$ \\
\hline Low/High $^{(a)}$ & 1.1 & 8 & $\begin{array}{l}\text { Simulant priority is to match } \\
\text { target viscosity }\end{array}$ \\
\hline High/Low ${ }^{(a)}$ & 1.37 & 1 & $\begin{array}{l}\text { Simulant priority is to match } \\
\text { target density }\end{array}$ \\
\hline $\operatorname{High} \operatorname{High}^{(\mathrm{a})}$ & 1.37 & 15 & $\begin{array}{l}\text { Simulant target is to match both } \\
\text { density and viscosity }\end{array}$ \\
\hline Typical/Typical $^{(\mathrm{b})}$ & 1.29 & 2.6 & $\begin{array}{l}\text { Simulant priority is to match } \\
\text { target density }\end{array}$ \\
\hline
\end{tabular}

(a) Targets as defined in Lee et al. (2012) except the Typical/Typical simulant

(b) Typical/Typical target is to match multicomponent caustic salt solution used in previous mixing studies (Adamson et al. 2010) that is representative of Hanford supernatant liquid

Table 2.2. Bingham Yield Stress and Density Targets for Non-Newtonian Suspending Fluid

\begin{tabular}{ccc}
\hline \multirow{2}{*}{ Simulant } & \multicolumn{2}{c}{ Targets from Tank Waste Data } \\
\cline { 2 - 3 } $\begin{array}{c}\text { Bingham } \\
\text { Yield Stress })\end{array}$ & $\begin{array}{c}\text { Density } \\
(\mathrm{g} / \mathrm{mL})\end{array}$ & $\begin{array}{c}\text { Bingham } \\
\text { Yield Stress } \\
(\mathrm{Pa})\end{array}$ \\
\hline Low $^{(\mathrm{a})}$ & $1.37^{(\mathrm{b})}$ & 1 \\
Middle $^{(\mathrm{a})}$ & $1.37^{(\mathrm{b})}$ & 3 \\
High $^{(\mathrm{a})}$ & $1.37^{(\mathrm{b})}$ & 10 \\
\hline Low $^{(\mathrm{a})}$ & $1.1^{(\mathrm{c})}$ & 1 \\
Middle $^{(\mathrm{a})}$ & $1.1^{(\mathrm{c})}$ & 3 \\
High $^{(\mathrm{a})}$ & $1.1^{(\mathrm{c})}$ & 10 \\
\hline
\end{tabular}

(a) overall range described in Lee et al. (2012) and specific 3 Pa target given by Lee (2012a)

(b) density target selected to match the high-density Newtonian fluid (Lee 2012a)

(c) density target is to be comparable to low-density Newtonian liquid (as comparable as can be achieved with kaolin-in-water slurries) (Lee 2012a) 


\subsection{Experimental Method and Materials}

Trial batches of simulants were prepared to develop simulant recipes to match the target properties for specific Newtonian and non-Newtonian simulants given in Section 2. The primary properties measured were the density and viscosity or Bingham parameters. The materials for these tests were obtained as subsamples from large batches that will be used in the planned demonstration tests. In addition to measuring the primary parameters, tests were conducted to evaluate the compatibility of the suspending fluids with the planned base and spike simulant particles. For the non-Newtonian simulants, one suite used the addition of salt to kaolin slurries to achieve a high-density target while a second suite used kaolin in water. For these tests, the presence of the salt significantly increased the Bingham parameters in addition to increasing the density. For these kaolin slurries, the particle size distribution (PSD) of the kaolin was determined to evaluate whether the presence of salt changed the kaolin particle size in a way that might make it difficult to compare the behavior of the kaolin slurries with and without salt in the demonstration tests. Testing results are summarized in Section 4.

\subsection{Simulant Materials and Preparation}

Various solutions and slurries were prepared to evaluate rheological properties and to observe process characteristics in an attempt to determine potential large-scale slurry preparation, mixing, and/or suspension problems. Additional particles were also added as needed for compatibility studies. The preparation was different for the Newtonian and non-Newtonian fluids and the specifics are discussed below.

\subsubsection{Newtonian Liquids}

The chemicals used for mixing the Newtonian liquids are given in Table 3.1. See Appendix A for specific details about the materials used for evaluation. Most of the solutions were hand mixed (shaken) in both nominal $250 \mathrm{~g}$ and nominal $500 \mathrm{~g}$ batches using $250 \mathrm{~mL}$ and $500 \mathrm{~mL}$ clear acrylic bottles, respectively. In all cases, when a solution contained glycerol, an attempt was made to dissolve all chemical additives in the water component of the solution prior to the addition of the glycerol. During early scoping tests, warm tap water was run over mixing containers to help attain $100 \%$ dissolution of sodium thiosulfate pentahydrate. Note that in a few cases, chemical additives that did not go into solution in the low-weight-percent water fraction went into solution without additional heat when sufficient glycerol was added.

Both sodium thiosulfate pentahydrate and anhydrous sodium thiosulfate salts were evaluated. Endothermic and exothermic reactions were experienced respectively, though not to the same degree. The endothermic reaction of the hydrated sodium thiosulfate was much more discernable than the exothermic reaction of the anhydrous form. It is reasonable to believe that the relatively easy dissolution of the solutions containing anhydrous sodium thiosulfate may have been enhanced by the exothermic dissolution of this salt. 
Table 3.1. Materials Used in Newtonian Liquid Simulants

\begin{tabular}{lccl}
\hline \multicolumn{1}{c}{ Material } & Supplier & $\begin{array}{c}\text { Chain of Custody } \\
\text { Identification }\end{array}$ & \multicolumn{1}{c}{$\begin{array}{c}\text { Sample } \\
\text { Identification }\end{array}$} \\
\hline Pasco City Water & N/A & $\begin{array}{l}\text { ES-RSD-051 } \\
\text { ES-SSMD-062 }\end{array}$ & $\begin{array}{l}\text { RSD-272 } \\
\text { SSMD-792, -793, } \\
\text {-794, and -795 }\end{array}$ \\
Glycerol & Silver Fern & ES-SSMD-062 & SSMD-791 \\
Sodium Thiosulfate (anhydrous) & Brainerd Chemical & ES-SSMD-062 & SSMD-790 \\
Company & Elbemarle Corporation & ES-SSMD-063 & SSMD-799 \\
ES-RSD-051 & RSD-273 \\
\hline
\end{tabular}

For the high-viscosity/high-density Newtonian-liquid target given in Table 2.1, an aqueous singlecomponent solution of sodium thiosulfate, sodium bromide, or glycerol will not match both the density and viscosity targets (CRC 2011). To match both of these targets, the approach will be to add both glycerol and sodium thiosulfate to water and then adjust their proportions to match both the density and viscosity targets. Information is not available in the literature to estimate viscosity as a function of composition; viscosity results for various mixtures will be discussed in Section 4. A simple model for density of glycerol and sodium thiosulfate mixtures can be estimated by assuming an ideal mixture of pure glycerol with a salt solution whose composition is given by the water and salt content of the mixture. The bulk density of the combination of glycerol and sodium thiosulfate solution is given by the following:

$$
\rho_{g-s}=\frac{1}{\left(1-x_{g}\right) / \rho_{s s}+x_{g} / \rho_{g}}
$$

where

$\rho_{\mathrm{g}-\mathrm{s}}=$ the density of the glycerol/ sodium thiosulfate solution

$\mathrm{x}_{\mathrm{g}}=$ the mass fraction of glycerol in the bulk mixture

$\rho_{\mathrm{g}}=$ the density of pure glycerol

$\rho_{\mathrm{ss}}=$ the density of the sodium thiosulfate solution whose composition is given by the water and salt content of the mixture

The density for the solution of water and sodium thiosulfate can be determined from literature data (CRC 2011), and the following linear equation fits the data for sodium thiosulfate mass fractions between 0.2 and 0.4:

$$
\rho_{\mathrm{ss}}=0.9638+1.044 \mathrm{x}_{\text {salt in ss }}
$$

where $\mathrm{x}_{\text {salt in ss }}$ is the mass fraction of sodium thiosulfate in the salt solution whose composition is given by the water and salt content of the mixture. The target density for the high-viscosity/high-density simulant is $1.37 \mathrm{~g} / \mathrm{mL}$ and Equations 3.1 and 3.2 can be used to calculate the concentrations of glycerol and sodium thiosulfate that will give this density. The measured density of various mixtures used for viscosity testing will be compared to the model estimates in Section 4 . 


\subsubsection{Non-Newtonian Fluids}

Testing was conducted with simulants that are slurries of Pasco City water and Edgar plastic kaolin (EPK, Feldspar Corporation) with sodium thiosulfate or sodium bromide. Table 3.2 shows the materials used in this study and also refers to chain of custody documentation containing additional product information, which is located in Appendix A.

Most of the non-Newtonian slurries were prepared using a 300 watt UltraPower KichenAid ${ }^{\circledR}$ mixer in nominally $500 \mathrm{~g}$ batches that were transferred primarily to $500 \mathrm{~mL}$ clear acrylic bottles after mixing. A standard approach for mixing the slurries was developed during testing. Typically, dry components were added to the mixing bowl followed by fluid components. The mixer was then turned on to a mixing speed set point of 2 (maximum speed set point is 10) for 5 minutes. The mixing set point was increased to 4 and mixing continued for an additional 15 minutes. The mixer arrangement utilized a stainless steel mixing bowl and a compatible ceramic coated paddle.

Prior to measuring rheological properties, the slurry was presheared. The preeminent method of preshearing involved returning the slurry to the KichenAid mixer for an additional 5 minutes at a mixing speed set point of 4 .

As can be expected, the intensity of the mixing and the subsequent preshearing has an impact on rheology. An alternate, a more intense, method of preshearing involving a 250 watt, model MB1001C, Magic Bullet ${ }^{\circledR}$ blender was also evaluated prior to analysis. The previously mixed slurry was placed in the Magic Bullet and processed for 1 minute at high speed (the Magic Bullet has only one speed, which is higher than speeds of the KitchenAid mixer). It should be noted that other mixing techniques were used during testing and that all mixing and preshearing steps are identified for each specific experiment. In test and/or sample nomenclature, "KA" refers to use of the KichenAid mixer and "MB" refers to the use of the Magic Bullet. "KA/MB" indicates initial mixing with the KichenAid and preshearing with the Magic Bullet.

Table 3.2. Materials used in Non-Newtonian Liquid Simulants

\begin{tabular}{cccc}
\hline Material & Supplier & $\begin{array}{c}\text { Chain of Custody } \\
\text { Identification }\end{array}$ & $\begin{array}{c}\text { Sample } \\
\text { Identification }\end{array}$ \\
\hline \multirow{2}{*}{ Pasco City Water } & N/A & ES-RSD-051 & RSD-272 \\
& ES-SSMD-062 & $\begin{array}{c}\text { SSMD-792, -793, } \\
\text {-794, and -795 }\end{array}$ \\
& $\begin{array}{c}\text { Feldspar Corporation } \\
\text { ZEMEX Industrial } \\
\text { EPK Kaolin }\end{array}$ & $\begin{array}{c}\text { Minerals, Inc. } \\
\text { ES-SSMD-063 }\end{array}$ & SSMD-796 \\
Sodium Thiosulfate (anhydrous) & $\begin{array}{c}\text { Brainerd Chemical } \\
\text { Company }\end{array}$ & ES-SSMD-062 & SSMD-790 \\
& Albemarle Corp. & ES-SSMD-063 & SSMD-799 \\
Sodium Bromide & & & RSD-273 \\
\hline
\end{tabular}

For the high-density non-Newtonian fluid target given in Table 2.2, mixtures of only kaolin in water will not match the target density. To match the density and Bingham yield stress targets, the approach will be to add both kaolin and sodium thiosulfate to water and then adjust their proportions to match both targets. Information is not available in the literature to estimate Bingham yield as a function of both salt 
and kaolin concentration; rheology results for various mixtures will be discussed in Section 4. The density of a composite slurry of kaolin and sodium thiosulfate can be estimated by assuming an ideal mixture of the kaolin particles with a salt solution whose composition is given by the water and salt content of the mixture. The bulk density of the slurry is given by the following (Gauglitz et al. 2010):

$$
\rho_{\mathrm{k}-\mathrm{s}}=\frac{1}{\left(1-\mathrm{x}_{\mathrm{k}}\right) / \rho_{\mathrm{ss}}+\mathrm{x}_{\mathrm{k}} / \rho_{\mathrm{k}}}
$$

where

$\rho_{\mathrm{k}-\mathrm{s}}=$ density of the kaolin-sodium thiosulfate slurry

$\mathrm{X}_{\mathrm{k}}=$ the mass fraction of kaolin in the bulk mixture

$\rho_{\mathrm{k}}=$ kaolin particle density $(2.65 \mathrm{~g} / \mathrm{mL}$, Gauglitz et al. 2010)

$\rho_{\mathrm{ss}}=$ the density of the sodium thiosulfate solution whose composition is given by the water and salt

content of the composite slurry

The density, $\rho_{\mathrm{ss}}$, for an aqueous solution of sodium thiosulfate can be determined from literature data (CRC 2011). Equation 3.2 can be used to estimate the density of an aqueous solution of sodium thiosulfate that has a mass fraction, $\mathrm{x}_{\text {salt in ss, }}$ in the range of 0.2 and 0.4 . The target density for the highdensity non-Newtonian slurries is $1.37 \mathrm{~g} / \mathrm{mL}$ and Equations 3.3 and 3.2 can be used to calculate the concentrations of kaolin and sodium thiosulfate that will give this density. For the non-Newtonian simulants, the measured densities for the specific simulant recipes are given Section 4.

\subsubsection{Base and Spike Simulant Particles}

Table 3.3 and Table 3.4 show the base and spike particles used in this study to evaluate the compatibility of the particles in the Newtonian and non-Newtonian fluids. The base particles are the components given in Lee et al. (2012) for the low-base simulant and the high-base simulant. The spike particles in Table 3.4 are a single size from each of materials planned for use as spike particles in the demonstration testing (Lee 2012a). The compatibility experiments included observing the settling behavior of the base and spike particles. Table 3.5 lists the particle densities and estimates of the median particle diameter, $\mathrm{d}_{50}$.

Table 3.3. Materials Used as Base Simulant Particles in Newtonian Liquids

\begin{tabular}{lccc}
\hline \multicolumn{1}{c}{ Material } & Supplier & $\begin{array}{c}\text { Chain of Custody } \\
\text { Identification }\end{array}$ & $\begin{array}{c}\text { Sample } \\
\text { Identification }\end{array}$ \\
\hline Gibbsite 3431 (large) & Huber & ES-SSMD-067 & SSMD-833 \\
Gibbsite (small) & Nalbatec & ES-SSMD-064 & SSMD-801 \\
Sand (small, Sil-Co-Sil 250) & US Silica & ES-SSMD-063 & SSMD-797 \\
Sand (Large, NJ6) & US Silica & ES-SSMD-064 & SSMD-800 \\
Zirconium Oxide & Washington Mills & ES-SSMD-063 & SSMD-798 \\
Stainless Steel Powder & Electro Corp & ES-SSMD-064 & SSMD-802 \\
\hline
\end{tabular}


Table 3.4. Materials Used as Spike Particles in Newtonian and Non-Newtonian Fluids

\begin{tabular}{lccc}
\hline \multicolumn{1}{c}{ Material } & Manufacture & $\begin{array}{c}\text { Chain of Custody } \\
\text { Identification }\end{array}$ & $\begin{array}{c}\text { Sample } \\
\text { Identification }\end{array}$ \\
\hline Soda Lime Glass Beads & Walter Stern, Inc. & ES-SSMD-064 & SSMD-803 \\
Stainless Steel (1/16”) & Pellets LLC & ES-SSMD-064 & SSMD-804 \\
Tungsten Carbide Balls (1/16”) & $\begin{array}{c}\text { Tungsten Heavy } \\
\text { Powder, Inc. }\end{array}$ & ES-SSMD-068 & SSMD-834 \\
\hline
\end{tabular}

Table 3.5. Approximate Particle Properties

\begin{tabular}{|c|c|c|c|}
\hline Particle & $\mathrm{d}_{50}$ & $\begin{array}{l}\text { Density } \\
(\mathrm{g} / \mathrm{mL})\end{array}$ & Reference \\
\hline $\begin{array}{l}\text { Gibbsite (small) } \\
\text { APYRAL® 40CD }\end{array}$ & $1.3 \mu \mathrm{m}$ & 2.42 & Lee et al. (2012) \\
\hline Gibbsite 3431 (large) & $10 \mu \mathrm{m}$ & 2.42 & Lee et al. (2012) \\
\hline Sand (small, Sil-Co-Sil 250) & $40 \mu \mathrm{m}$ & 2.65 & $\begin{array}{l}\mathrm{d}_{50} \text { estimated from vendor data } \\
\text { Density from vendor data }\end{array}$ \\
\hline Sand (Large, NJ6) & $520 \mu \mathrm{m}$ & 2.65 & $\begin{array}{l}d_{50} \text { estimated from vendor data } \\
\text { Density for typical sand }\end{array}$ \\
\hline Zirconium Oxide & $6 \mu \mathrm{m}$ & 5.7 & Lee et al. (2012) \\
\hline Stainless Steel Powder & $112 \mu \mathrm{m}$ & 8 & Lee et al. (2012) \\
\hline EPK Kaolin & $5 \mu \mathrm{m}$ & 2.65 & $\begin{array}{l}\mathrm{d}_{50} \text { from Figure C. } 2 \\
\text { Density - Gauglitz et al. (2010) }\end{array}$ \\
\hline Soda Lime Glass Beads & $2 \mathrm{~mm}$ & 2.49 & Vendor Data \\
\hline Stainless Steel (1/16”) & $1 / 16$ in. & 8 & $\begin{array}{l}d_{50} \text { from vendor data } \\
\text { Density from Lee et al. (2012) }\end{array}$ \\
\hline Tungsten Carbide Balls (1/16") & $1 / 16$ in. & 14 & $\begin{array}{l}d_{50} \text { from vendor data } \\
\text { Density from Lee et al. (2012) }\end{array}$ \\
\hline
\end{tabular}

\subsection{Viscosity and Rheology}

Viscosity and rheological measurements were performed using a Haake RS600 rheometer operated with RheoWin software (Thermo Electron Corporation). The RS600 rheometer was equipped with a low-inertia torque motor and coaxial cylinder measurement geometry. The drive shaft of the motor was centered by an air bearing, which provides virtually frictionless transmission of the applied torque to the sample. Viscosity and rheological analyses were conducted at various temperatures ranging from 15 to $30^{\circ} \mathrm{C}$, which was the estimated potential range of test temperatures. Each rheogram (flow curve) was obtained by shearing the sample at a controlled rate increasing from 0 (zero) to $1000 \mathrm{~s}^{-1}$ for 5 minutes, holding constant at $1000 \mathrm{~s}^{-1}$ for 1 minute, following by shearing at a controlled rate decreasing from 1000 to $0 \mathrm{~s}^{-1}$ (zero) for 5 minutes. Prior to measuring a flow curve, each sample was gently shaken by hand and sheared at a constant rate of $250 \mathrm{~s}^{-1}$ for 3 minutes. The purpose of pre-measurement mixing was to make sure that the material being analyzed was homogenized and representative of the sample. 
Typically, for Newtonian simulants, one rheogram (flow curve) was obtained from one sample aliquot. For non-Newtonian simulants, two or three rheograms were obtained from one sample aliquot. A flow curve represents shear stress as a function of shear rate. For Newtonian simulants, the Newtonian Model, shown in Equation 3.4, was used to fit the data. For non-Newtonian simulants, the Bingham Plastic Model, shown in Equation 3.5, was used for data quantification (Mewis and Wagner 2012). Unless specified otherwise, all of the Newtonian simulant data was fitted to the entire range of testing shear rates of 0 to $1000 \mathrm{~s}^{-1}$. For the non-Newtonian simulants, the selected shear rate range for data fitting was 250 to $700 \mathrm{~s}^{-1}$, unless specified otherwise. For non-Newtonian simulants, the Bingham yield stress and Bingham consistency values from the down-ramp of the second flow curve are reported and discussed in this document.

$$
\tau=\eta * \gamma
$$

where $\tau=$ shear stress in $\mathrm{Pa}$

$\gamma=$ shear rate in $\mathrm{s}^{-1}$

$\eta=$ viscosity in $\mathrm{Pa} \cdot \mathrm{s}$

$$
\tau=\tau_{0}+\eta_{p} * \gamma
$$

where $\tau=$ shear stress in Pa

$\tau_{0}=$ critical shear stress or Bingham yield stress in $\mathrm{Pa}$

$\gamma=$ shear rate in $\mathrm{s}^{-1}$

$\eta_{\mathrm{p}}=$ Bingham consistency in $\mathrm{Pa} \cdot \mathrm{s}$

\subsection{Bulk Density}

Bulk density of the selected simulants was measured using certified glass pycnometers (Wilmad LabGlass) and a calibrated balance. A pycnometer is a volumetric flask with a known volume that is specifically designed for density measurements. Prior to density measurements, a performance check of the balance was performed using a $10 \mathrm{~g}$ and/or a $50 \mathrm{~g}$ certified check weight (manufactured by Rice Lake and calibrated and certified by Quality Control Services, Inc.). The balance performance-check result was recorded in a density measurement bench sheet. After the balance performance check, the tare weight of the pycnometer to be used was obtained and recorded in the density measurement bench sheet. The pycnometer was then filled with the simulant fluid to be measured. The gross weight of the pycnometer containing the simulant fluid was obtained and recorded in the density measurement bench sheet. The net weight of the simulant fluid was calculated by subtracting the pycnometer tare weight from the gross weight of the pycnometer containing the simulant. The bulk density of the simulant fluid was calculated using Equation 3.6. Unless specified otherwise, all density measurements were carried out at room temperature. Room temperature associated with each density measurement was also measured using a calibrated thermocouple and thermocouple readout and recorded in the density measurement bench sheet.

$$
\rho=\frac{M}{V}
$$

where

$\rho=$ bulk density in $\mathrm{g} / \mathrm{mL}$

$\mathrm{M}=$ net weight of the simulant fluid in $\mathrm{g}$

$\mathrm{V}=$ volume of the simulant fluid in $\mathrm{mL}$ 


\subsection{Compatibility of Suspending Fluids and Particles}

Two types of qualitative tests were conducted to evaluate the compatibility of the base and spike particles with the Newtonian and non-Newtonian suspending fluids. The first evaluation was to determine the settling behavior of the particles in the suspending fluids. The second evaluation was to determine the intensity of mixing required to re-suspend layers of particles that had settled overnight, or for seven days. For the first evaluation, approximately $200 \mathrm{~mL}$ of each simulant mixture of suspending fluid and base and spike particles, at concentrations that are described below in Table 3.6 through Table 3.9, were added to a $250 \mathrm{~mL}$ graduated cylinder. The cylinder was then closed and shaken and the settling rate of the simulant particles was observed over a period of about 8 hours. The settling measurements were conducted for four consecutive days for each sample to determine whether there were changes in settling behavior over this duration. For the second evaluation, each graduated cylinder was allowed to continue settling undisturbed overnight after the last settling measurement was recorded each day. The intensity of shaking needed to resuspend the settled layer was determined for each graduated cylinder on the following day prior to continuing settling measurements. For the resuspension testing, in addition to the daily re-suspension measurement from each graduated cylinder that was also used for settling evaluation, one additional graduated cylinder of each simulant mixture was prepared and allowed to settle undisturbed for seven days prior to performing the same resuspension evaluation. The intensity of shaking was controlled by progressing through the following sequential steps until the settled layer and large spike particles were observed to move.

Level 0 Swirl in a circular motion - heavy stainless steel (SS) beads are not stuck to the bottom (applicable to bottle 7 day test only).

Level 1 Rock vertical to horizontal gently at least 20 times - heavy SS beads are not stuck to the bottom.

Level 2 Shake gently side to side $\sim 2$ shakes per second, at least 20 times - heavy SS beads are not stuck to the bottom.

Level 3 Shake vigorously side to side $\sim 4$ shakes per second, at least 20 times - heavy SS beads are not stuck to the bottom.

Table 3.6 shows the composition of the Newtonian liquids used for the compatibility evaluation. The compositions of these solutions are the same as the final recipes discussed in Section 4. Each of these liquids was combined with the solid particles for the low-base simulant and high-base simulant given by Lee (2012a). Lee (2012a) also specifies the total quantity of base and spike particles, and the compatibility tests used $15 \mathrm{wt} \%$ solids loading to match the high-solids loading tests. Table 3.7 provides the compositions of slurries of the base and spike particles in Newtonian suspending fluids that were used in compatibility tests. For simplification, the first row of the table lists the short name for each simulant mixture that will be used when discussing the testing results in Section 4. 
Table 3.6. Compositions of Newtonian Liquids used for Evaluating Particle and Liquid Compatibility

\begin{tabular}{|c|c|c|c|c|c|c|}
\hline \multirow[b]{2}{*}{ Component } & \multicolumn{6}{|c|}{ Newtonian Simulant } \\
\hline & $\begin{array}{c}\text { Low } \\
\text { Density } \\
\text { Low } \\
\text { Viscosity }\end{array}$ & $\begin{array}{c}\text { Low } \\
\text { Density } \\
\text { High } \\
\text { Viscosity }\end{array}$ & $\begin{array}{c}\text { Low } \\
\text { Density } \\
\text { High } \\
\text { Viscosity } \\
\left(\mathrm{w} / \mathrm{Na}_{2} \mathrm{~S}_{2} \mathrm{O}_{3}\right)\end{array}$ & $\begin{array}{c}\text { High } \\
\text { Density } \\
\text { Low } \\
\text { Viscosity }\end{array}$ & $\begin{array}{c}\text { High } \\
\text { Density } \\
\text { High } \\
\text { Viscosity }\end{array}$ & $\begin{array}{c}\text { Typical } \\
\text { Density } \\
\text { Typical } \\
\text { Viscosity }\end{array}$ \\
\hline $\begin{array}{c}\text { Sodium } \\
\text { Thiosulfate } \\
\text { Anhydrous }\end{array}$ & $12.0 \%$ & - & $0.1 \%$ & - & $33.4 \%$ & $31.5 \%$ \\
\hline Glycerol & - & $53.0 \%$ & $53.0 \%$ & - & $19.5 \%$ & - \\
\hline $\begin{array}{l}\text { Sodium } \\
\text { Bromide }\end{array}$ & - & - & - & $37.0 \%$ & - & - \\
\hline $\begin{array}{c}\text { Pasco City } \\
\text { Water }\end{array}$ & $88.0 \%$ & $47.0 \%$ & $46.9 \%$ & $63.0 \%$ & $47.1 \%$ & $68.5 \%$ \\
\hline
\end{tabular}

Table 3.8 shows the compositions of the non-Newtonian slurries used for the compatibility evaluation. The compositions of these slurries are the same as the final recipes discussed in Section 4 for the simulants with a target Bingham yield stress of $3 \mathrm{~Pa}$. Each of these slurries was combined with quantities of spike particles, as described in Lee (2012a), to have the same quantity of spike particles as the Newtonian liquids with the same density. Table 3.9 provides the compositions of slurries and spike particles for these tests, including one test that had a higher quantity of spike particles to make observation easier. 
Table 3.7. Compositions of Slurries of Newtonian Liquids and Base and Spike Particles for Compatibility Testing

\begin{tabular}{|c|c|c|c|c|c|c|c|c|c|c|}
\hline & \multicolumn{10}{|c|}{ Short Names for Simulant and Base Particle Mixtures ${ }^{(a)}$} \\
\hline & $\mathrm{Lo} / \mathrm{Lo} / \mathrm{Lo}$ & $\mathrm{Lo} / \mathrm{Lo} / \mathrm{Hi}$ & $\mathrm{Lo} / \mathrm{Hi} / \mathrm{Lo}$ & $\mathrm{Lo} / \mathrm{Hi} / \mathrm{Hi}$ & $\mathrm{Hi} / \mathrm{Lo} / \mathrm{Lo}$ & $\mathrm{Hi} / \mathrm{Lo} / \mathrm{Hi}$ & $\mathrm{Hi} / \mathrm{Hi} / \mathrm{Lo}$ & $\mathrm{Hi} / \mathrm{Hi} / \mathrm{Hi}$ & Typ/Typ/Lo & Тур/Тур/Hi \\
\hline $\begin{array}{l}\text { Newtonian } \\
\text { Liquid }\end{array}$ & $\begin{array}{l}\text { Lo Density } \\
\text { Lo Visc. }\end{array}$ & $\begin{array}{l}\text { Lo Density } \\
\text { Lo Visc. }\end{array}$ & $\begin{array}{c}\text { Lo Density } \\
\text { Hi Visc. }\end{array}$ & $\begin{array}{c}\text { Lo Density } \\
\text { Hi Visc. }\end{array}$ & $\begin{array}{l}\text { Hi Density } \\
\text { Lo Visc. }\end{array}$ & $\begin{array}{l}\text { Hi Density } \\
\text { Lo Visc. }\end{array}$ & $\begin{array}{l}\text { Hi Density } \\
\text { Hi Visc. }\end{array}$ & $\begin{array}{l}\text { Hi Density } \\
\text { Hi Visc. }\end{array}$ & $\begin{array}{l}\text { Typ Dens. } \\
\text { Typ Visc. }\end{array}$ & $\begin{array}{l}\text { Typ Dens. } \\
\text { Typ Visc. }\end{array}$ \\
\hline & & & $\begin{array}{r}\text { both with } \\
0.1 \mathrm{wt} \%\end{array}$ & $\begin{array}{l}\text { ad without } \\
\mathrm{Na}_{2} \mathrm{~S}_{2} \mathrm{O}_{3}\end{array}$ & & & & & & \\
\hline $\begin{array}{l}\text { Newtonian } \\
\text { Liquid }^{(b)}\end{array}$ & $85 \%$ & $85 \%$ & $85 \%$ & $85 \%$ & $85 \%$ & $85 \%$ & $85 \%$ & $85 \%$ & $85 \%$ & $85 \%$ \\
\hline $\begin{array}{c}\text { Small } \\
\text { Gibbsite }\end{array}$ & $14.25 \%$ & - & $14.25 \%$ & - & $14.25 \%$ & - & $14.25 \%$ & - & $14.25 \%$ & - \\
\hline $\begin{array}{c}\text { Large } \\
\text { Gibbsite }\end{array}$ & - & $0.43 \%$ & - & $0.43 \%$ & - & $0.43 \%$ & - & $0.43 \%$ & - & $0.43 \%$ \\
\hline $\begin{array}{l}\text { Small } \\
\text { Sand }\end{array}$ & - & $4.99 \%$ & - & $4.99 \%$ & - & $4.99 \%$ & - & $4.99 \%$ & - & $4.99 \%$ \\
\hline $\begin{array}{l}\text { Large } \\
\text { Sand }\end{array}$ & - & $2.99 \%$ & - & $2.99 \%$ & - & $2.99 \%$ & - & $2.99 \%$ & - & $2.99 \%$ \\
\hline $\begin{array}{l}\text { Zirconium } \\
\text { Oxide }\end{array}$ & - & $1.14 \%$ & - & $1.14 \%$ & - & $1.14 \%$ & - & $1.14 \%$ & - & $1.14 \%$ \\
\hline $\begin{array}{c}\text { SS } \\
\text { Powder }\end{array}$ & - & $4.70 \%$ & - & $4.70 \%$ & - & $4.70 \%$ & - & $4.70 \%$ & - & $4.70 \%$ \\
\hline $\begin{array}{l}\text { Soda Lime } \\
\text { Glass }\end{array}$ & $0.25 \%$ & $0.25 \%$ & $0.25 \%$ & $0.25 \%$ & $0.25 \%$ & $0.25 \%$ & $0.25 \%$ & $0.25 \%$ & $0.25 \%$ & $0.25 \%$ \\
\hline $\begin{array}{c}\text { SS } \\
\text { Beads }\end{array}$ & $0.25 \%$ & $0.25 \%$ & $0.25 \%$ & $0.25 \%$ & $0.25 \%$ & $0.25 \%$ & $0.25 \%$ & $0.25 \%$ & $0.25 \%$ & $0.25 \%$ \\
\hline $\begin{array}{c}\text { Tungsten } \\
\text { Carbide } \\
\text { Beads }\end{array}$ & $0.25 \%$ & $0.25 \%$ & $0.25 \%$ & $0.25 \%$ & $0.25 \%$ & $0.25 \%$ & $0.25 \%$ & $0.25 \%$ & $0.25 \%$ & $0.25 \%$ \\
\hline
\end{tabular}

(a) Each short name specifies the density and viscosity of the Newtonian liquid, and type of base particle, respectively $(\mathrm{Lo}=\mathrm{Low}, \mathrm{Hi}=\mathrm{High}$, Typ $=\mathrm{Typical})$

(b) Each test mixture contained $85 \mathrm{wt} \%$ Newtonian liquid and $15 \mathrm{wt} \%$ solids loading to match the high-solids loading tests specified in Lee (2012a). 
Table 3.8. Compositions of Non-Newtonian Slurries used for Evaluating Particle and Liquid Compatibility

Non-Newtonian Simulant

\begin{tabular}{ccc}
\hline $\begin{array}{c}\text { Target Density } \\
\text { Target Yield Stress }\end{array}$ & $\begin{array}{c}1.37 \mathrm{~g} / \mathrm{mL} \\
3 \mathrm{~Pa}\end{array}$ & $\begin{array}{c}1.1 \mathrm{~g} / \mathrm{mL} \\
3 \mathrm{~Pa}\end{array}$ \\
\hline Component & & - \\
\hline $\begin{array}{c}\text { Sodium } \\
\text { Thiosulfate } \\
\text { Anhydrous }\end{array}$ & $24.9 \%$ & \\
Kaolin & $14.5 \%$ & $22.5 \%$ \\
\hline $\begin{array}{c}\text { Pasco City } \\
\text { Water }\end{array}$ & $60.6 \%$ & $77.5 \%$ \\
\hline
\end{tabular}

Table 3.9. Compositions of Non-Newtonian Slurries and Spike Particles for Compatibility Testing

\begin{tabular}{cccc} 
& \multicolumn{3}{c}{ Non-Newtonian Simulant } \\
\cline { 2 - 4 } $\begin{array}{c}\text { Target Density } \\
\text { Target Yield Stress }\end{array}$ & $\begin{array}{c}1.37 \mathrm{~g} / \mathrm{mL} \\
3 \mathrm{~Pa}\end{array}$ & $\begin{array}{c}1.37 \mathrm{~g} / \mathrm{mL} \\
3 \mathrm{~Pa} \\
(100 \mathrm{x} \text { each spike })\end{array}$ & $\begin{array}{c}1.1 \mathrm{~g} / \mathrm{mL} \\
3 \mathrm{~Pa}\end{array}$ \\
\hline $\begin{array}{c}\text { Non-Newtonian } \\
\text { Simulant }\end{array}$ & $99.04 \%$ & $51.7 \%$ & $99.04 \%$ \\
$\begin{array}{c}\text { Soda Lime Glass } \\
(2 \text { mm) }\end{array}$ & $0.32 \%$ & $16.1 \%$ & $0.32 \%$ \\
$\begin{array}{c}\text { Stainless Steel } \\
(1 / 16 ")\end{array}$ & $0.32 \%$ & $16.1 \%$ & $0.32 \%$ \\
$\begin{array}{c}\text { Tungsten Carbide } \\
\text { Spheres }(1 / 16 ")\end{array}$ & $0.32 \%$ & $16.1 \%$ & $0.32 \%$ \\
\hline
\end{tabular}

\subsection{Temperature Stability}

The effect of temperature on the final recipes of Newtonian and non-Newtonian simulants recommended for demonstration tests was observed down to $10^{\circ} \mathrm{C}$ to determine the stability of the selected simulants at the potential lowest test temperature. Temperature stability studies were carried out in a temperature-controlled water bath. The simulant fluids were placed in the water bath at $15^{\circ} \mathrm{C}$. The 
simulant slurries were visually checked for precipitation after 20 to 24 hours. After visual check for precipitation, the water bath temperature set point was lowered to $10^{\circ} \mathrm{C}$. Visual inspection was performed again after 20 to 24 hours to check for precipitation.

\subsection{Clay Particle Size Distribution}

PSD measurements were made using a Microtrac S3000 Particle Size Analyzer that has a full size range of 0.02 to $2000 \mu \mathrm{m}$ (Microtrac, Inc.). The Microtrac S3000 Particle Size Analyzer uses laser diffraction technology. Prior to performing analyses on slurry samples, a number of measurements were made at different instrument settings to determine the appropriate settings. Measurements were then made on three selected slurries using what were considered the best settings. As is typical for PSD measurements, the results are affected by the choice of instrument settings. The instrument analysis program was set up to analyze the particle size using volume distribution with standard progression. The analysis was performed between the size range of 0.021 and 1408 microns with a run time of 30 seconds and an average of 3 runs used to determine each analysis result.

Three kaolin clay slurries were prepared for PSD analysis as shown in Table 3.10. Samples 071012WCB01 and 071012WCB02 were stirred in a KitchenAid mixer at mixing speed set point of 2 for 5 minutes, followed by an additional 15-minute mixing at speed set point of 4. Sample 071012WCB03 was hand mixed by placing the kaolin and water in a poly bottle and shaking for about 2 minutes. All three samples were split equally into two containers for each sample. Preshearing was performed on Samples 071012WCB01 and 071012WCB02. One split sample was presheared using a Magic Bullet for 1 minute and the other split was presheared with the KitchenAid mixer at mixing speed set point of 4 .

Table 3.10. Kaolin Slurries for PSD Analysis

\begin{tabular}{ccccc}
\hline Slurry ID & $\begin{array}{c}\text { Kaolin } \\
(\mathrm{wt} \%)\end{array}$ & $\begin{array}{c}\mathrm{Na}_{2} \mathrm{~S}_{2} \mathrm{O}_{3} \\
(\mathrm{wt} \%)\end{array}$ & $\begin{array}{c}\text { Pasco City } \\
\text { Water } \\
(\mathrm{wt} \%)\end{array}$ & $\begin{array}{c}\text { DI Water } \\
(\mathrm{wt} \%)\end{array}$ \\
\hline 071012 WCB01 & 14.5 & 24.9 & 60.6 & - \\
071012 WCB02 & 22.5 & - & 77.5 & - \\
071012 WCB03 & 22.5 & - & - & 77.5 \\
\hline
\end{tabular}

Ten samples were analyzed. The samples were analyzed as provided and after sonication with an ultrasonic horn as indicated in Table 3.11. For those subsamples treated with the ultrasonic horn, an aliquot was prepared and then "sonicated" intermittently for a nominal 20 seconds with a MICROGON Ultrasonic Cell Disrupter (PNNL-assigned property \# R104106). The set point for the ultrasonic horn was 12 , resulting in 10 to 12 watts (root mean square) directed into the slurry of $\sim 0.2 \mathrm{~g}$ of sample material in $\sim 10 \mathrm{~mL}$ of deionized (DI) water, Pasco City water or $29 \mathrm{wt} \%$ sodium thiosulfate diluent contained in an $\sim 25 \mathrm{~mL}$ poly beaker. The diluent used was dependent upon the corresponding analytical carrier solution. Sample material was transferred from the poly beaker to the analyzer using a transfer pipette. The transfer pipette was also used to keep the sample material suspended in the poly beaker between analyses. The variable speed re-cycling (VSR) pump integral to the analyzer was set at 45 . 
Table 3.11. Preshearing and Sonication for Kaolin Slurry Samples

\begin{tabular}{|c|c|c|c|c|c|}
\hline Sample ID & Slurry ID & $\begin{array}{c}\text { MB } \\
\text { Pre-Shear }\end{array}$ & $\begin{array}{c}\text { KA } \\
\text { Pre-Shear }\end{array}$ & Sonicated & $\begin{array}{c}\text { Analytical Carrier } \\
\text { Solution }\end{array}$ \\
\hline KA/MB Salts/Sonicated & 071012WCB01 & $\mathrm{x}$ & & $\mathrm{x}$ & $29 \mathrm{wt} \% \mathrm{Na}_{2} \mathrm{~S}_{2} \mathrm{O}_{3}{ }^{(\mathrm{a})}$ \\
\hline KA/MB Salts & 071012WCB01 & $\mathrm{x}$ & & & $29 \mathrm{wt} \% \mathrm{Na}_{2} \mathrm{~S}_{2} \mathrm{O}_{3}{ }^{(\mathrm{a})}$ \\
\hline KA/KA Salts/Sonicated & 071012WCB01 & & $\mathrm{x}$ & $\mathrm{x}$ & $29 \mathrm{wt} \% \mathrm{Na}_{2} \mathrm{~S}_{2} \mathrm{O}_{3}{ }^{(\mathrm{a})}$ \\
\hline KA/KA Salts & 071012WCB01 & & $\mathrm{x}$ & & $29 \mathrm{wt} \% \mathrm{Na}_{2} \mathrm{~S}_{2} \mathrm{O}_{3}{ }^{(a)}$ \\
\hline KA/MB Kaolin/Sonicated & 071012WCB02 & $\mathrm{x}$ & & $\mathrm{x}$ & Pasco City Water \\
\hline KA/MB Kaolin & 071012WCB02 & $\mathrm{x}$ & & & Pasco City Water \\
\hline KA/KA Kaolin/Sonicated & 071012WCB02 & & $\mathrm{x}$ & $\mathrm{x}$ & Pasco City Water \\
\hline KA/KA Kaolin & 071012WCB02 & & $\mathrm{x}$ & & Pasco City Water \\
\hline Hand Kaolin/Sonicated & 071012WCB03 & & & $\mathrm{x}$ & DI Water \\
\hline Hand Kaolin & 071012WCB03 & & & & DI Water \\
\hline
\end{tabular}

(a) $29 \mathrm{wt} \%$ is the concentration of sodium thiosulfate in water within the slurry

Multiple runs were performed on each sample to evaluate potential particle breakdown or agglomeration during the analysis. In addition, the VSR pump speed set point was varied down to 30 and up to 60 in an effort to determine whether heavy particles were settling in the VSR pump. It was determined that there was minimal particle breakdown over time and the VSR pump speed had negligible effect on the PSD; these runs were not reported. Table 3.12 gives parameters used in the sample analysis setup.

Table 3.12. Microtrac Instrument Parameters for PSD Measurements of Kaolin in Water and in a Sodium Thiosulfate Solution

\begin{tabular}{ll}
\hline \multicolumn{1}{c}{ Setup Name: Kaolin } & \multicolumn{1}{c}{ Setup Name: Kaolin $\left(\mathrm{Na}_{2} \mathrm{~S}_{2} \mathrm{O}_{3}\right)$} \\
\hline Setzero time: 30 seconds & Setzero time: 30 seconds \\
Run time: 30 seconds & Run time: 30 seconds \\
Run number: 3 & Run number: 3 \\
Particle: Kaolin & Particle: Kaolin \\
\hline Particle transparency: Trans & Particle transparency: Trans \\
Particle refractive index: $1.57^{(\mathrm{a})}$ & Particle refractive index: $1.57^{(\mathrm{a})}$ \\
Particle shape: irregular & Particle shape: irregular \\
Fluid: water & Fluid: $29.1 \mathrm{wt} \% \mathrm{Na}_{2} \mathrm{~S}_{2} \mathrm{O}_{3}$ in water \\
Refractive index: $1.33^{\text {(b) }}$ & Refractive index: $1.40^{(\text {b) }}$ \\
Progression: geometric root 8 & Progression: geometric root 8 \\
\hline $\begin{array}{l}\text { (a) } \text { Malvern (2007) } \\
\text { (b) } \text { CRC (2011) }\end{array}$ & \\
\hline
\end{tabular}




\subsection{Results and Final Recipes}

Experiments were conducted to determine the compositions of aqueous solutions and slurries that have densities and viscosities or rheological parameters that match the simulant targets given in Section 2. For the Newtonian liquids, the mixtures were primarily single components in water and the desired targets were readily obtained by adjusting the concentrations of the single components. For these mixtures, the priority for the simulant was matching either the fluid density or viscosity target. For the parameter that was not specifically matched, testing was needed to confirm that the value was comparable to simulant target. One of the Newtonian simulants involved adding two components to water, and here both the density and viscosity targets could be matched. For this mixture, additional measurements and analyses were needed to determine how to vary the concentration of the two added components to match both properties. For the non-Newtonian simulants, the high-density target involved adding both kaolin clay and a salt to water to match both the density and Bingham yield stress targets.

The primary temperature for developing simulant recipes was $20^{\circ} \mathrm{C}$, which was selected as a representative value for the planned demonstration tests. The actual test temperature is expected to vary, so the viscosity or Bingham parameters were also measured at $15^{\circ}$ and $25^{\circ} \mathrm{C}$. For the high-viscosity/highdensity simulant that uses glycerol, the viscosity was also measured at $30^{\circ} \mathrm{C}$ because glycerol solutions are known to be somewhat temperature sensitive (CRC 2011). Because many of the simulants are concentrated salt solutions, there is a potential that the salt may precipitate at lower temperatures. Accordingly, the stability of the solutions was determined at $10^{\circ} \mathrm{C}$, which was selected as a temperature that should be lower than that of the demonstration tests. After the recipes were developed to match the target properties, tests were conducted to evaluate the interaction of base and spike simulant particles with the suspending Newtonian and non-Newtonian fluids. In one case, a combination of a specific type of base particle and Newtonian liquid formed overly strong settled layers, and the recipe for this Newtonian simulant was modified by adding a small concentration of sodium thiosulfate.

Table 4.1 gives a summary of the final recipes for the Newtonian simulants, the specific simulant targets, and the measured properties for these recipes at $20^{\circ} \mathrm{C}$. The table also shows the priorities for matching the specific density and/or viscosity targets. All of these recipes were stable down to $10^{\circ} \mathrm{C}$ as discussed below. Table 4.2 gives the final recipes for the non-Newtonian simulants, the specific simulant targets, and the measured properties at $20^{\circ} \mathrm{C}$. These slurries were also stable down to $10^{\circ} \mathrm{C}$ as discussed below. Specific tests were not conducted to evaluate long-term degradation of these simulants, but there was no indication of degradation in test samples over a period of a couple weeks. In the subsections below, detailed testing results for trial batches of these simulants are given. For the non-Newtonian simulants, the full rheograms are given in Appendix B. 
Table 4.1. Newtonian Liquid Simulants

\begin{tabular}{|c|c|c|c|c|c|}
\hline \multirow{2}{*}{$\begin{array}{c}\text { Simulant } \\
\text { (density/viscosity) }\end{array}$} & \multicolumn{2}{|c|}{$\begin{array}{l}\text { Targets from Tank } \\
\text { Waste Data }^{\text {(a) }}\end{array}$} & \multicolumn{2}{|c|}{$\begin{array}{c}\text { Simulant Properties } \\
\left(20^{\circ} \mathrm{C}\right)^{(\mathrm{c})}\end{array}$} & \multirow{2}{*}{ Simulant Recipes } \\
\hline & $\begin{array}{l}\text { Density } \\
(\mathrm{g} / \mathrm{mL})\end{array}$ & $\begin{array}{l}\text { Viscosity } \\
(\mathrm{mPa} \cdot \mathrm{s})\end{array}$ & $\begin{array}{l}\text { Density } \\
(\mathrm{g} / \mathrm{mL})\end{array}$ & $\begin{array}{l}\text { Viscosity } \\
(\mathrm{mPa} \cdot \mathrm{s})\end{array}$ & \\
\hline Low/Low ${ }^{(a)}$ & 1.1 & 1 & 1.098 & 1.62 & $\begin{array}{l}12 \mathrm{wt} \% \mathrm{Na}_{2} \mathrm{~S}_{2} \mathrm{O}_{3} \\
88 \mathrm{wt} \% \text { water } \\
\text { Simulant priority is to match } \\
\text { target density }\end{array}$ \\
\hline Low/High $^{(a)}$ & 1.1 & 8 & 1.135 & 7.96 & $\begin{array}{l}53 \mathrm{wt} \% \text { glycerol } \\
0.1 \mathrm{wt} \% \mathrm{Na}_{2} \mathrm{~S}_{2} \mathrm{O}_{3} \\
46.9 \mathrm{wt} \% \text { water } \\
\text { Simulant priority is to match } \\
\text { target viscosity }\end{array}$ \\
\hline High/Low ${ }^{(a)}$ & 1.37 & 1 & 1.370 & 2.00 & $\begin{array}{l}37 \mathrm{wt} \% \mathrm{NaBr} \\
63 \mathrm{wt} \% \text { water } \\
\text { Simulant priority is to match } \\
\text { target density }\end{array}$ \\
\hline $\operatorname{High} / \operatorname{High}^{(a)}$ & 1.37 & 15 & 1.368 & 14.6 & $\begin{array}{l}19.5 \mathrm{wt} \% \text { glycerol } \\
47.1 \mathrm{wt} \% \text { water } \\
33.4 \mathrm{wt} \% \mathrm{Na}_{2} \mathrm{~S}_{2} \mathrm{O}_{3} \\
\text { Simulant target is both } \\
\text { matched density and viscosity }\end{array}$ \\
\hline Typical/Typical $^{(\mathrm{b})}$ & 1.29 & 2.6 & 1.284 & 3.60 & $\begin{array}{l}31.5 \mathrm{wt} \% \mathrm{Na}_{2} \mathrm{~S}_{2} \mathrm{O}_{3} \text { in water } \\
\text { Simulant priority is to match } \\
\text { target density }\end{array}$ \\
\hline
\end{tabular}

(a) Targets as defined in Lee et al. (2012) except Typical/Typical simulant

(b) Target is to match multi-component caustic salt solution used in previous mixing studies (Adamson et al. 2010) that is representative of Hanford supernatant liquid

(c) Viscosity was measured at $20^{\circ} \mathrm{C}$; the density is expected to be insensitive to temperature and was measured at ambient temperature that varied between $17^{\circ}$ and $21^{\circ} \mathrm{C}$ 
Table 4.2. Non-Newtonian Slurry Simulants

\begin{tabular}{|c|c|c|c|c|c|c|}
\hline \multirow{2}{*}{$\begin{array}{c}\text { Simulant } \\
\text { (Bingham } \\
\text { Yield } \\
\text { Stress) }\end{array}$} & \multicolumn{2}{|c|}{$\begin{array}{c}\text { Targets from Tank } \\
\text { Waste Data }\end{array}$} & \multicolumn{3}{|c|}{$\begin{array}{c}\text { Simulant Properties } \\
\left(20^{\circ} \mathrm{C}\right)^{(\mathrm{d})}\end{array}$} & \multirow[b]{2}{*}{ Simulant Recipes } \\
\hline & $\begin{array}{l}\text { Density } \\
(\mathrm{g} / \mathrm{mL})\end{array}$ & $\begin{array}{l}\text { Bingham } \\
\text { Yield } \\
\text { Stress } \\
(\mathrm{Pa})\end{array}$ & $\begin{array}{l}\text { Density } \\
(\mathrm{g} / \mathrm{mL})\end{array}$ & $\begin{array}{l}\text { Bingham } \\
\text { Yield } \\
\text { Stress } \\
(\mathrm{Pa})\end{array}$ & $\begin{array}{c}\text { Bingham } \\
\text { Consistency } \\
(\mathrm{mPa} \cdot \mathrm{s})\end{array}$ & \\
\hline Low & $1.37^{(\mathrm{b})}$ & $1^{\text {(a) }}$ & 1.36 & 1.1 & 7.3 & $\begin{array}{l}9.5 \mathrm{wt} \% \text { Kaolin } \\
29.6 \mathrm{wt} \% \mathrm{Na}_{2} \mathrm{~S}_{2} \mathrm{O}_{3}\end{array}$ \\
\hline Middle & $1.37^{(\mathrm{b})}$ & $3^{(\mathrm{a})}$ & 1.36 & 3.7 & 8.1 & $\begin{array}{l}14.5 \mathrm{wt} \% \text { Kaolin } \\
24.9 \mathrm{wt} \% \mathrm{Na}_{2} \mathrm{~S}_{2} \mathrm{O}_{3}\end{array}$ \\
\hline High & $1.37^{(\mathrm{b})}$ & $10^{(\mathrm{a})}$ & 1.34 & 11 & 10 & $\begin{array}{l}20.0 \mathrm{wt} \% \text { Kaolin } \\
19.9 \mathrm{wt} \% \mathrm{Na}_{2} \mathrm{~S}_{2} \mathrm{O}_{3}\end{array}$ \\
\hline Low & $1.1^{(\mathrm{c})}$ & $1^{(\mathrm{a})}$ & 1.13 & 1.2 & 3.4 & $20 \mathrm{wt} \%$ Kaolin \\
\hline Middle & $1.1^{(\mathrm{c})}$ & $3^{(a)}$ & 1.15 & 2.6 & 4.0 & $22.5 \mathrm{wt} \%$ Kaolin \\
\hline High & $1.1^{(\mathrm{c})}$ & $10^{(\mathrm{a})}$ & 1.19 & 11 & 6.0 & $26.5 \mathrm{wt} \%$ Kaolin \\
\hline
\end{tabular}

(a) Lee et al. (2012) define range as up to $10 \mathrm{~Pa}$; target values of 1, 3, and $10 \mathrm{~Pa}$ are selected to span this range and to support planned testing (Lee 2012a)

(b) Density target selected to match High/High Newtonian liquid as part of planned testing (Lee 2012a)

(c) Density target is to be comparable to low-density Newtonian liquid; as comparable as can be achieved with kaolin-in-water slurries (Lee 2012a)

(d) Bingham parameters measured at $20^{\circ} \mathrm{C}$; the density is expected to be insensitive to temperature and was measured at ambient temperature that varied between $17^{\circ}$ and $21^{\circ} \mathrm{C}$

\subsection{Newtonian Simulant Density and Viscosity}

Simulant recipes to meet targets for the Newtonian liquids were obtained with single-component aqueous solutions for all but the high-density/high-viscosity target. The specific recipes for these four simulants at $20^{\circ} \mathrm{C}$ are given in Table 4.1. For the single-component solutions, the simulant target was achieved by adjusting the concentration of each single component. Figure 4.1 shows the effect of temperature on viscosity for these four of the simulant recipes. The most temperature-sensitive recipe is the low-density/high-viscosity simulant that is a mixture of glycerol in water. The final recipe for this simulant has a small amount of sodium thiosulfate added to improve the behavior of the small gibbsite base particle in this liquid (see Section 4.2). The temperature dependence of viscosity was measured for the initial recipe for this simulant without the sodium thiosulfate but this temperature dependence should be essentially the same for the final recipe. 


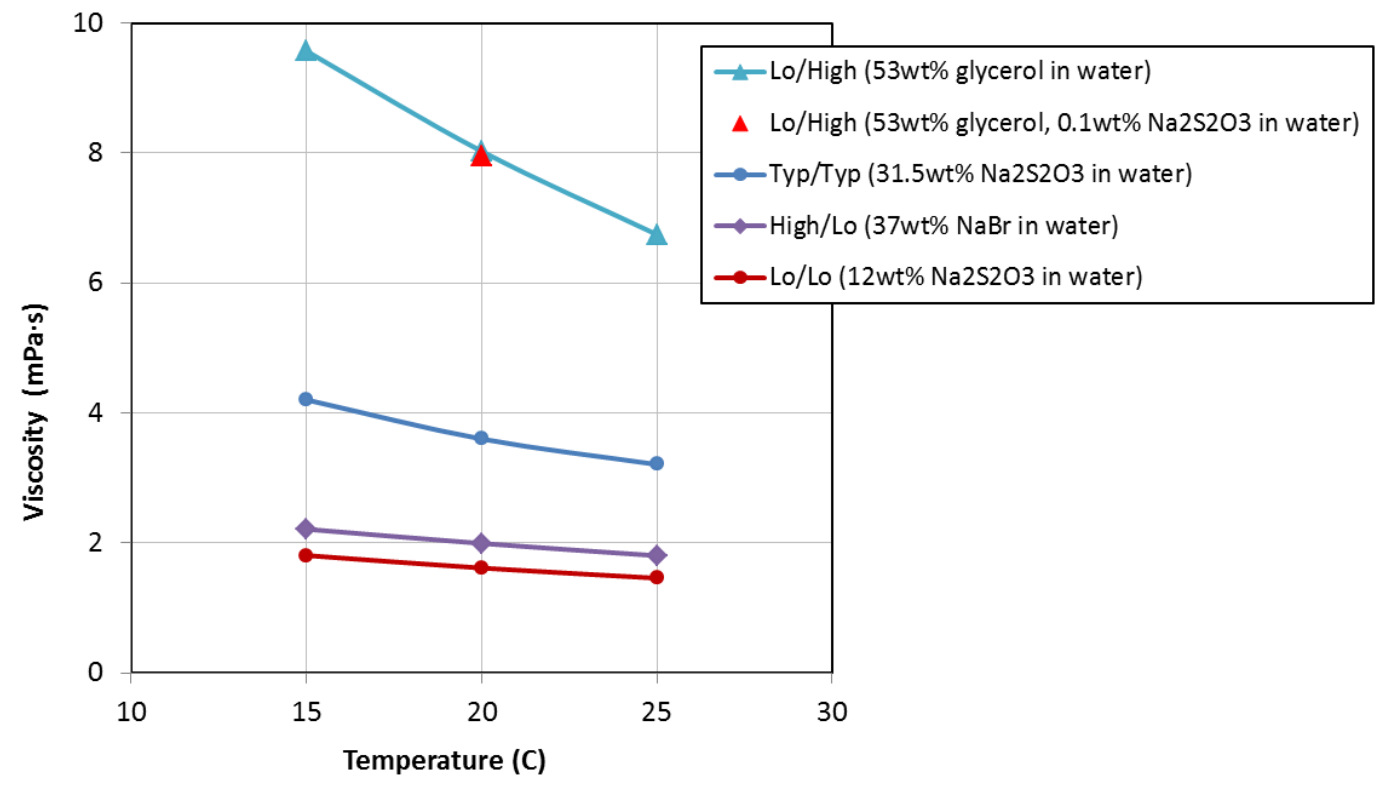

Figure 4.1. Effect of Temperature on Viscosity for Newtonian Simulants

For the high-density/high-viscosity target, glycerol and sodium thiosulfate were added to water to adjust both the viscosity and density. Four solutions were prepared that were selected to have progressively higher viscosities and also, by using Equations 3.1 and 3.2 to select compositions, have a density of $1.37 \mathrm{~g} / \mathrm{mL}$. Two additional solutions were prepared that have slightly higher or lower densities than the $1.37 \mathrm{~g} / \mathrm{mL}$ target value to get a better set of data for evaluating the density predictions and to support development of the viscosity model discussed below. Table 4.3 gives the measured densities of the solutions and shows a comparison to the calculated densities.

Table 4.3. Densities of Aqueous Solutions of Glycerol, Sodium Thiosulfate and Water and Comparison to Calculated Density

\begin{tabular}{lcccc}
\hline $\begin{array}{c}\text { Glycerol } \\
(\mathrm{wt} \%)\end{array}$ & $\begin{array}{c}\mathrm{Na}_{2} \mathrm{~S}_{2} \mathrm{O}_{3} \\
(\mathrm{wt} \%)\end{array}$ & $\begin{array}{c}\text { Calculated } \\
\text { Density } \\
(\mathrm{g} / \mathrm{mL})\end{array}$ & $\begin{array}{c}\text { Measured } \\
\text { Density } \\
(\mathrm{g} / \mathrm{mL})\end{array}$ & $\begin{array}{c}\text { Difference } \\
\text { Measured to } \\
\text { Calculated } \\
(\%)\end{array}$ \\
\hline 17 & 34.1 & 1.37 & 1.365 & -0.4 \\
19.5 & 33.4 & 1.37 & 1.368 & -0.1 \\
22 & 32.7 & 1.37 & 1.367 & -0.2 \\
25.5 & 31.8 & 1.37 & 1.367 & -0.2 \\
17 & 32.7 & 1.35 & 1.351 & +0.1 \\
\hline 22 & 34.1 & 1.38 & 1.381 & +0.1 \\
\hline
\end{tabular}

(a) The density is expected to be insensitive to temperature, provided there is no salt precipitation, and was measured at ambient temperature that varied between 17 and $21^{\circ} \mathrm{C}$

Table 4.4 gives the viscosities of the glycerol and sodium thiosulfate solutions as a function of temperature. To allow viscosities to be estimated for intermediate temperatures and concentrations, a 
simple model was used to correlate the viscosity data. Base on literature data for similar solutions, exponential dependencies were used for the glycerol and sodium thiosulfate concentrations and for the effect of temperature. This model was fit to the data in Table 4.4 using a least-squares method and the resulting correlation is given below.

$$
\mu_{g s}=0.2904\left(e^{7.838 x_{g}}\right)\left(e^{9.571 x_{s}}\right)\left(e^{-0.0398 T}\right)
$$

where $\quad \mu_{\mathrm{gs}}=$ viscosity of aqueous glycerol and sodium thiosulfate solutions

$\mathrm{x}_{\mathrm{g}}=$ mass fraction glycerol in bulk mixture

$\mathrm{x}_{\mathrm{s}}=$ mass fraction of sodium thiosulfate in bulk mixture

$\mathrm{T}=$ Temperature $\left({ }^{\circ} \mathrm{C}\right)$

Table 4.4. Effect of Temperature on the Viscosity of Aqueous Solutions of Glycerol and Water

\begin{tabular}{|c|c|c|c|}
\hline $\begin{array}{c}\text { Glycerol } \\
\text { (wt } \%)\end{array}$ & $\begin{array}{c}\mathrm{Na}_{2} \mathrm{~S}_{2} \mathrm{O}_{3} \\
(\mathrm{wt} \%)\end{array}$ & $\begin{array}{c}\text { Temp } \\
\left({ }^{\circ} \mathrm{C}\right)\end{array}$ & $\begin{array}{c}\text { Measured } \\
\text { Viscosity } \\
(\mathrm{mPa} \cdot \mathrm{s})\end{array}$ \\
\hline \multirow{4}{*}{17} & \multirow{4}{*}{34.1} & 15 & 15.88 \\
\hline & & 20 & 12.80 \\
\hline & & 25 & 10.61 \\
\hline & & 30 & 8.98 \\
\hline \multirow{4}{*}{17} & \multirow{4}{*}{32.7} & 15 & 13.70 \\
\hline & & 20 & 11.22 \\
\hline & & 25 & 9.38 \\
\hline & & 30 & 7.98 \\
\hline \multirow{3}{*}{22} & \multirow{3}{*}{34.1} & 20 & 19.39 \\
\hline & & 25 & 15.46 \\
\hline & & 30 & 12.95 \\
\hline \multirow{4}{*}{22} & \multirow{4}{*}{32.7} & 15 & 20.75 \\
\hline & & 20 & 16.61 \\
\hline & & 25 & 13.61 \\
\hline & & 30 & 11.59 \\
\hline \multirow{4}{*}{19.5} & \multirow{4}{*}{33.4} & 15 & 17.79 \\
\hline & & 20 & 14.63 \\
\hline & & 25 & 12.20 \\
\hline & & 30 & 10.04 \\
\hline \multirow{4}{*}{25.5} & \multirow{4}{*}{31.8} & 15 & 25.19 \\
\hline & & 20 & 19.90 \\
\hline & & 25 & 16.31 \\
\hline & & 30 & 13.58 \\
\hline
\end{tabular}

Figure 4.2 shows the viscosity data and correlation results for the four solutions with a density of $1.37 \mathrm{~g} / \mathrm{mL}$. The final recipe for the high-viscosity/high-density target is a solution of $19.5 \mathrm{wt} \%$ glycerol and $33.4 \mathrm{wt} \%$ sodium thiosulfate, and this solution gives a viscosity that matches the target of $15 \mathrm{mPa} \cdot \mathrm{s}$ at $20^{\circ} \mathrm{C}$. For higher or lower test temperatures, different recipes can be selected to achieve the $15 \mathrm{mPa} \cdot \mathrm{s}$ target. 


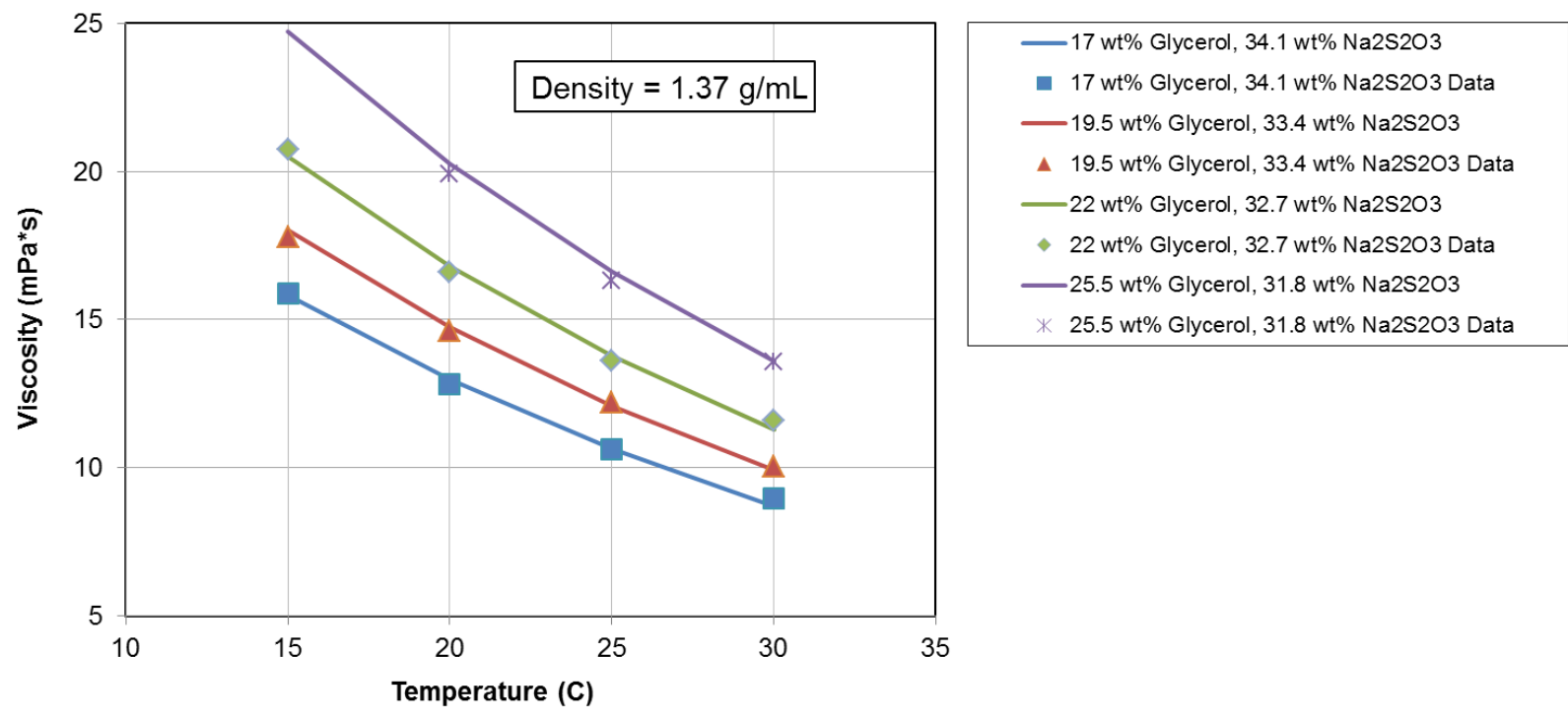

Figure 4.2. Experimental Results and Model Fit for the Effect of Temperature on Viscosity with the Solution Composition Adjusted to give a Density of $1.37 \mathrm{~g} / \mathrm{mL}$

\subsection{Compatibility of Base and Spike Particles in Newtonian Simulants}

Two qualitative evaluations were conducted to evaluate whether the base and spike particles are compatible with the Newtonian fluids. For the first evaluation, the settling behavior of the particles was measured in each Newtonian simulant. These settling tests were repeated for four successive days to detect any significant changes in settling behavior over time. Ideally, the base and spike particles will settle based on the size and density of the particles and the viscosity and density of the suspending fluid. For the second evaluation, the intensity of mixing needed to resuspend layers that had settled overnight, or for seven days, was determined. The resuspension tests give an indication of unexpectedly strong settled layers that might form in test tanks, piping, and pumps if the slurry is not continuously mixed.

Figure 4.3 shows an example of the settling behavior for the low base simulants for the first day of settling experiment (see Table 3.3 and Table 3.5 for small gibbsite). The low-base simulant particles all settle, though at different rates, in each of the Newtonian simulants with the exception of the lowdensity/high-viscosity liquid (curve labeled as lo_hi_lo), which did not show an observable settling layer. The addition of $0.1 \mathrm{wt} \%$ sodium thiosulfate to this glycerol-water solution changed the particle behavior and a settling layer below clear liquid was observed. The settling behavior of the final low-density/highviscosity recipe (curve labeled as lo_hi_lo+0.1 wt $\% \mathrm{Na}_{2} \mathrm{~S}_{2} \mathrm{O}_{3}$ ) is also shown in Figure 4.3. For the lowbase simulant and the five final Newtonian recipes (see Table 4.1), the settling behavior shows reasonable results for the low-base particle in the different viscosity and density liquids. The settling behavior was measured on four consecutive days and the settling results were essentially the same on each day. Equivalent settling tests were conducted with the high-base simulant in the five Newtonian liquids. For the high-base simulant, it was difficult to observe a settling upper layer though the rapidly settling 
particles were easily seen collecting at the bottom of the graduated cylinders. In these tests, the lowdensity/high-viscosity simulant again seemed unusual and always remained cloudy during the day-long settling tests. The revised recipe with $0.1 \mathrm{wt} \%$ sodium thiosulfate gave improved and more consistent behavior.

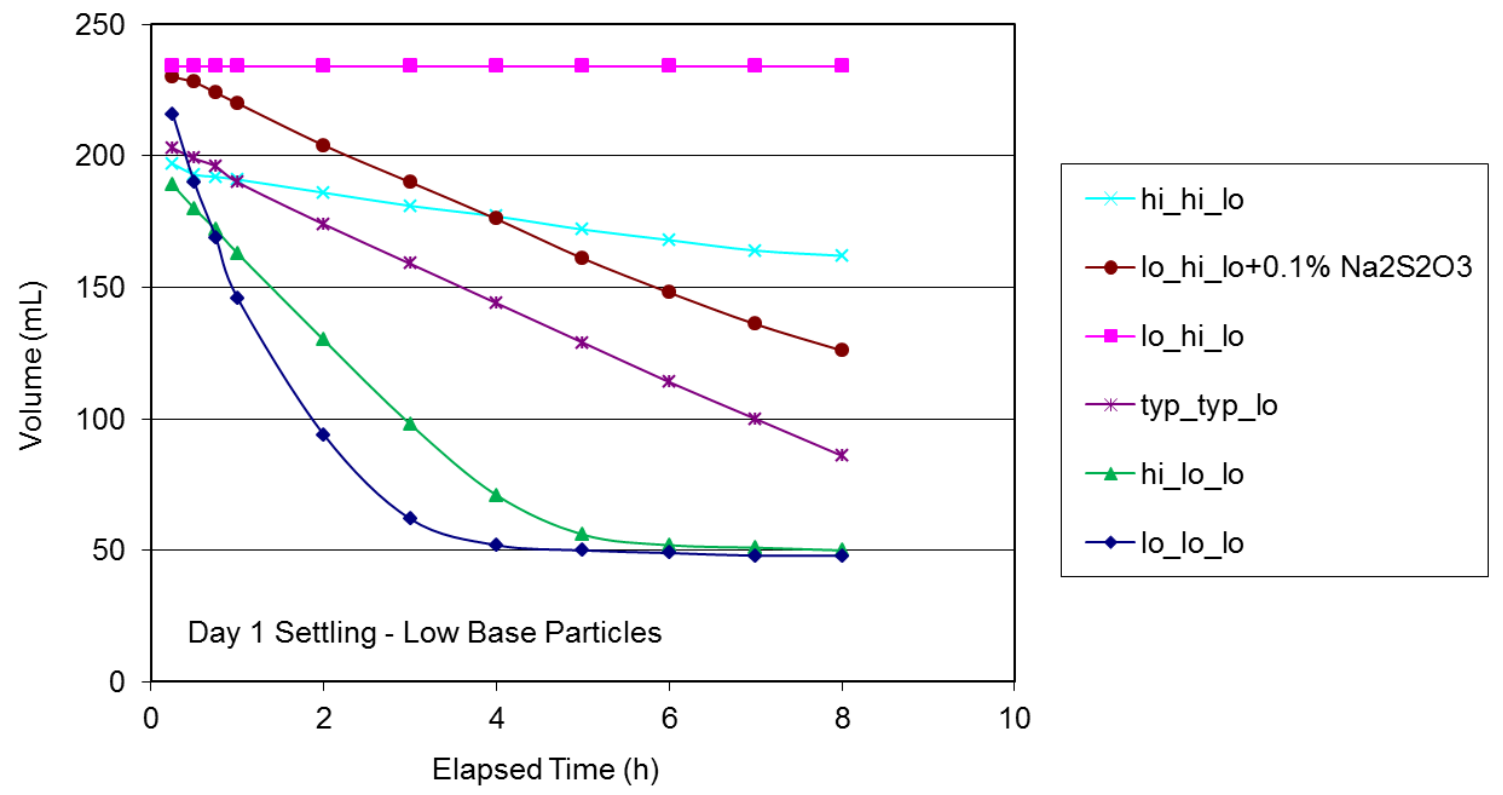

Figure 4.3. Settling Behavior of Low-Base Simulant Particles in the Newtonian Liquids

Table 4.5 shows the results of the resuspension tests for the base and spike particles in the Newtonian liquids. The results for the low-density/high-viscosity liquid without $0.1 \mathrm{wt} \%$ sodium thiosulfate show the difficulty in resuspending settled layers of both low-base and high-base particles in this liquid. The final recipe for the low-density/high-viscosity target with the addition of $0.1 \mathrm{wt} \%$ sodium thiosulfate has improved resuspending behavior, especially for the low-base particles. For the low-density/low-viscosity and low-density/high-viscosity fluids, the results show that it is more difficult to resuspend settled layers of the low-base particles than settled layers of the high-base particles. In contrast, the results for the typical-density/typical-viscosity liquid show that it is more difficult to resuspend a settled layer of the high-base particles. Overall, these resuspension testing results give a qualitative indication of the potential for strong settled layers that might form in tanks, piping, and pumps if the slurry is not continuously mixed. 
Table 4.5. Resuspension Results for Newtonian Liquids with Base and Spike Particles

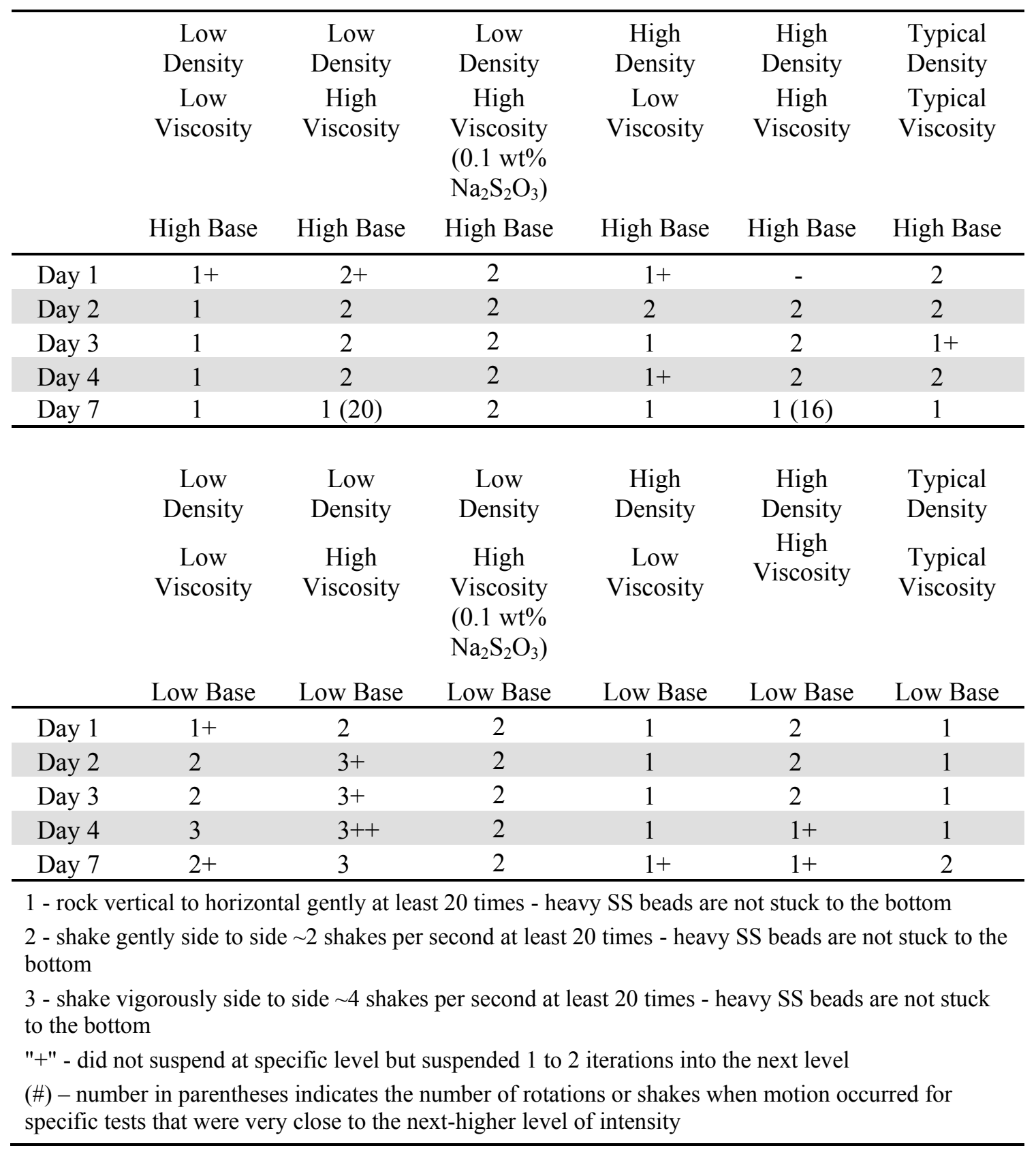

\subsection{Non-Newtonian Simulant Density and Rheology}

Figure 4.4 and Figure 4.5 compare the Bingham yield stress and Bingham consistency, respectively, as a function of weight percent of kaolin for various aqueous slurries of kaolin and sodium thiosulfate with a controlled slurry density of $1.37 \mathrm{~g} / \mathrm{mL}$ that were prepared by different mixing methods that varied the shear rate and mixing duration. The KitchenAid mixing represents a low-shear mixing method while the Magic Bullet mixing represents a high-shear mixing method. The recommended recipes of non-Newtonian kaolin-sodium thiosulfate simulants are represented by the green filled-triangles. The results in Figure 4.4 and Figure 4.5 show that increasing the mixing shear rate would noticeably increase 
the Bingham yield stress but would only slightly increase the Bingham consistency of these selected non-Newtonian kaolin-thiosulfate simulants. This implies that variations in measured Bingham yield stress of the demonstration testing samples using the recommended recipes may be expected due to different mixing shear rates. The intensity of shearing in the demonstration testing is not known, so changes to the slurry concentrations may be needed to achieve the desired Bingham yield stress targets.

Figure 4.6 and Figure 4.7 compare the Bingham yield stress and Bingham consistency, respectively, as a function of weight percent of kaolin, for various aqueous slurries of kaolin with a slurry density ranging from 1.13 to $1.19 \mathrm{~g} / \mathrm{mL}$ that were prepared by different mixing methods that varied the mixing shear rate. Unlike the case of the aqueous kaolin-thiosulfate simulants, increasing mixing shear rate would noticeably increase both the Bingham yield stress and the Bingham consistency of these selected non-Newtonian kaolin simulants. This implies that variations in measured Bingham yield stress and Bingham consistency of the demonstration testing samples using the recommended recipes may be expected due to different mixing shear rates. The intensity of shearing in the demonstration testing is not known, so changes to the slurry concentrations may be needed to achieve the desired Bingham yield stress targets.

Figure 4.8 and Figure 4.9 compare the Bingham yield stress and Bingham consistency, respectively, as a function of weight percent of kaolin for various slurries of kaolin in water, and with sodium thiosulfate and sodium bromide. For the kaolin slurries with salt, the bulk slurry density is near the high-density target of $1.37 \mathrm{~g} / \mathrm{mL}$. The results in Figure 4.8 and Figure 4.9 show that for an equal weight percent of kaolin in aqueous kaolin slurry, addition of sodium bromide or sodium thiosulfate salt increases the Bingham yield stress and Bingham consistency of the slurry. The sodium thiosulfate addition produces a greater increase in the Bingham properties of the kaolin slurry than the addition of sodium bromide.

Figure 4.10 shows the Bingham consistency as a function of Bingham yield stress for various slurries of kaolin in water, and with sodium thiosulfate and sodium bromide. This data shows that at the same Bingham yield stress, sodium thiosulfate addition gives a greater increase in the Bingham consistency than the addition of sodium bromide. Accordingly, additions of different salts would allow parametric testing to isolate the role of the Bingham consistency of aqueous kaolin clay slurries. 


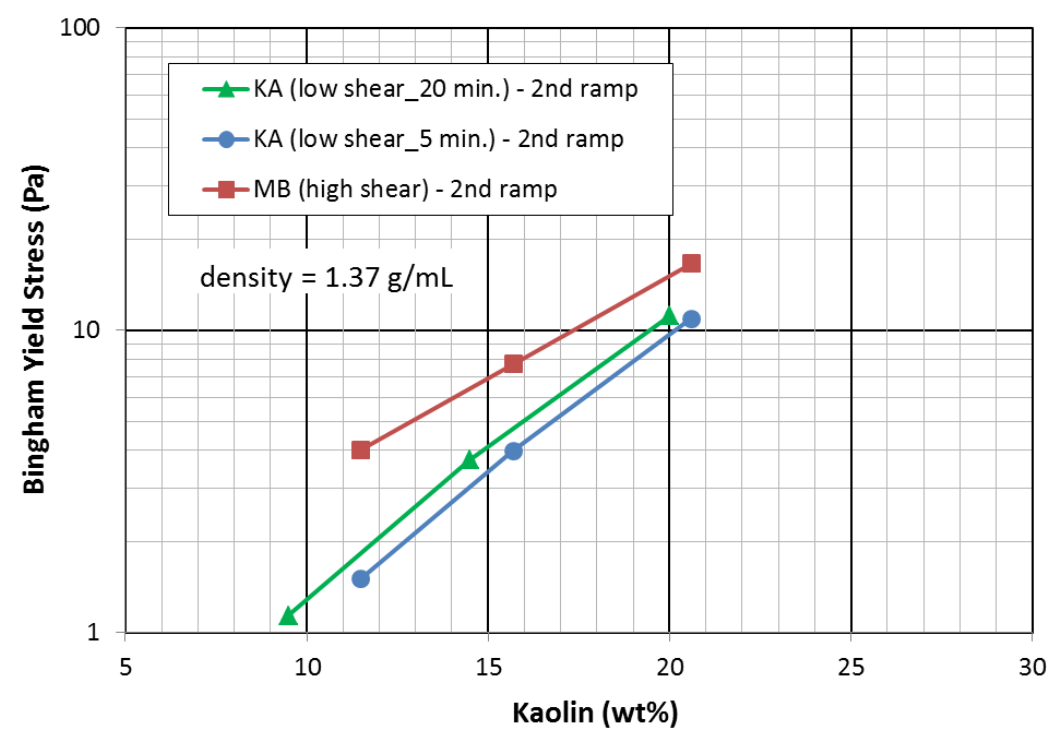

Figure 4.4. Bingham Yield Stress for Aqueous Slurries of Kaolin and Sodium Thiosulfate with a Slurry Density of $1.37 \mathrm{~g} / \mathrm{mL}$

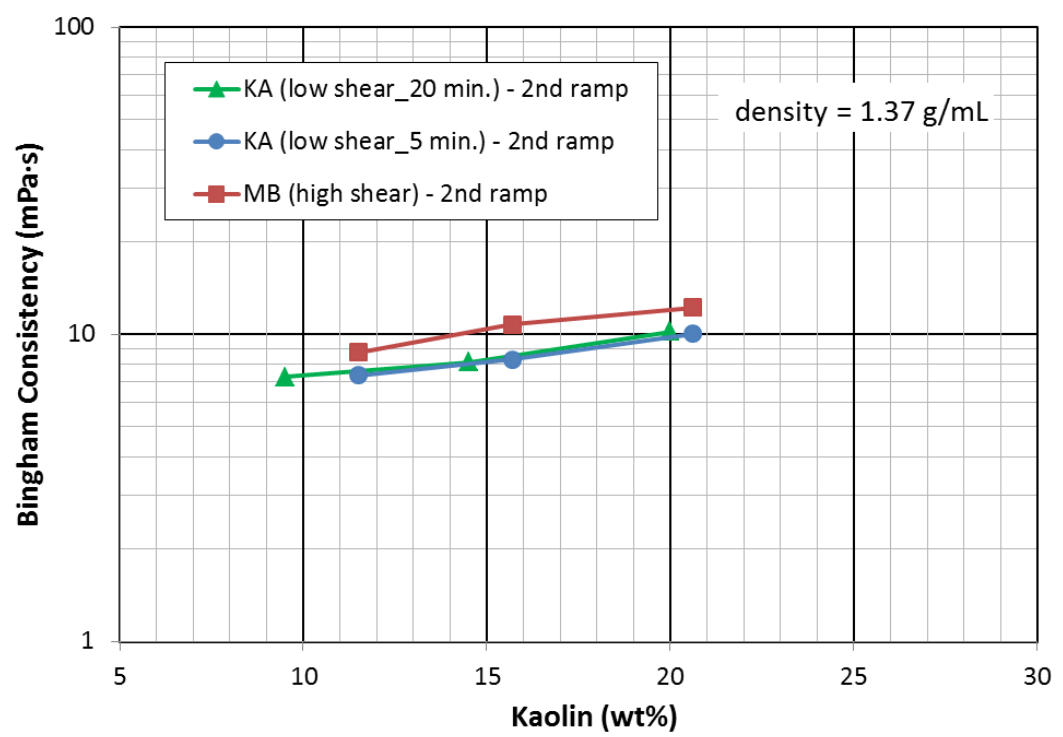

Figure 4.5. Bingham Consistency for Aqueous Slurries of Kaolin and Sodium Thiosulfate with a Slurry Density of $1.37 \mathrm{~g} / \mathrm{mL}$ 


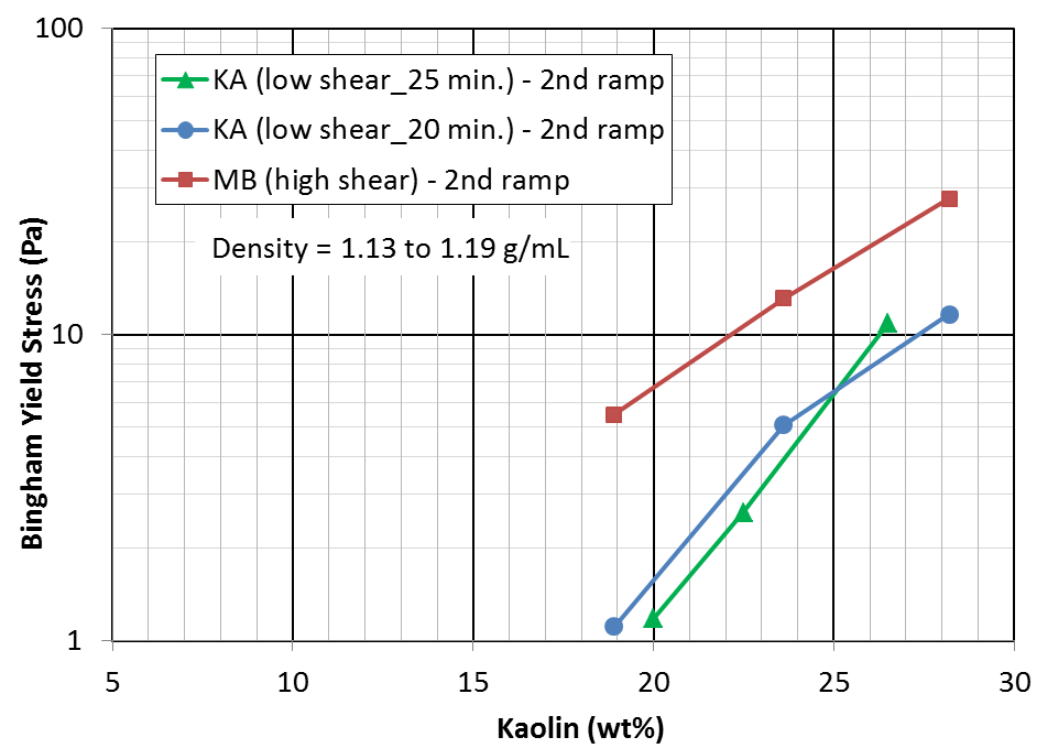

Figure 4.6. Bingham Yield Stress for Aqueous Slurries of Kaolin with Slurry Densities that Vary from 1.13 to $1.19 \mathrm{~g} / \mathrm{mL}$

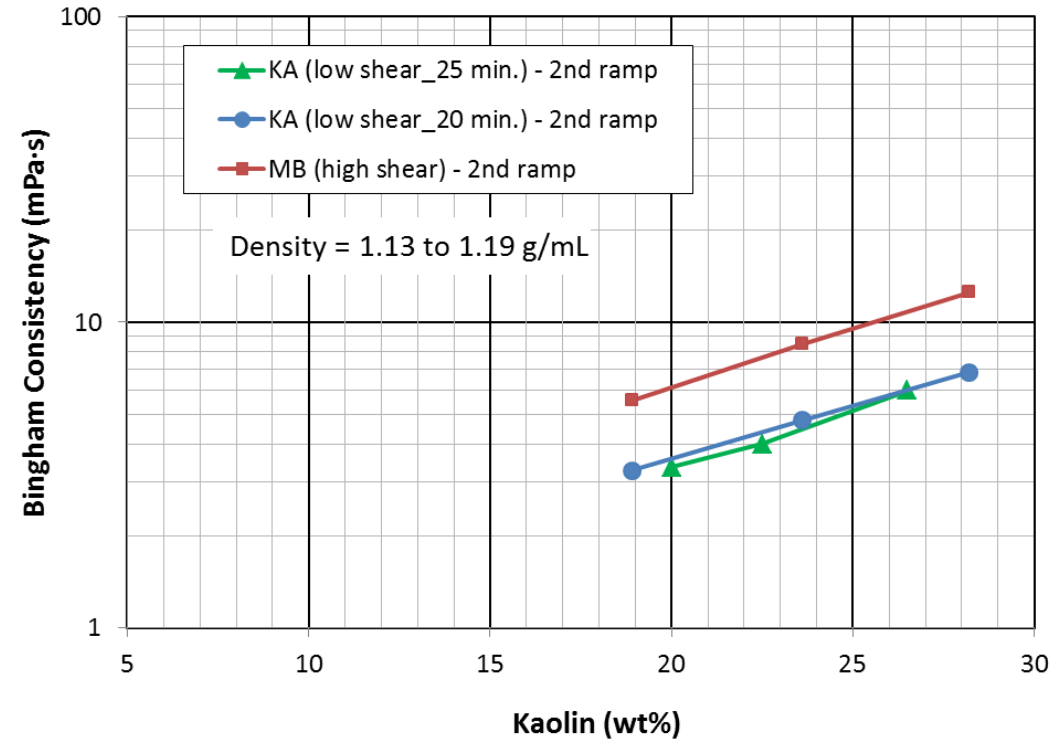

Figure 4.7. Bingham Consistency for Aqueous Slurries of Kaolin with Slurry Densities that Vary from 1.13 to $1.19 \mathrm{~g} / \mathrm{mL}$ 


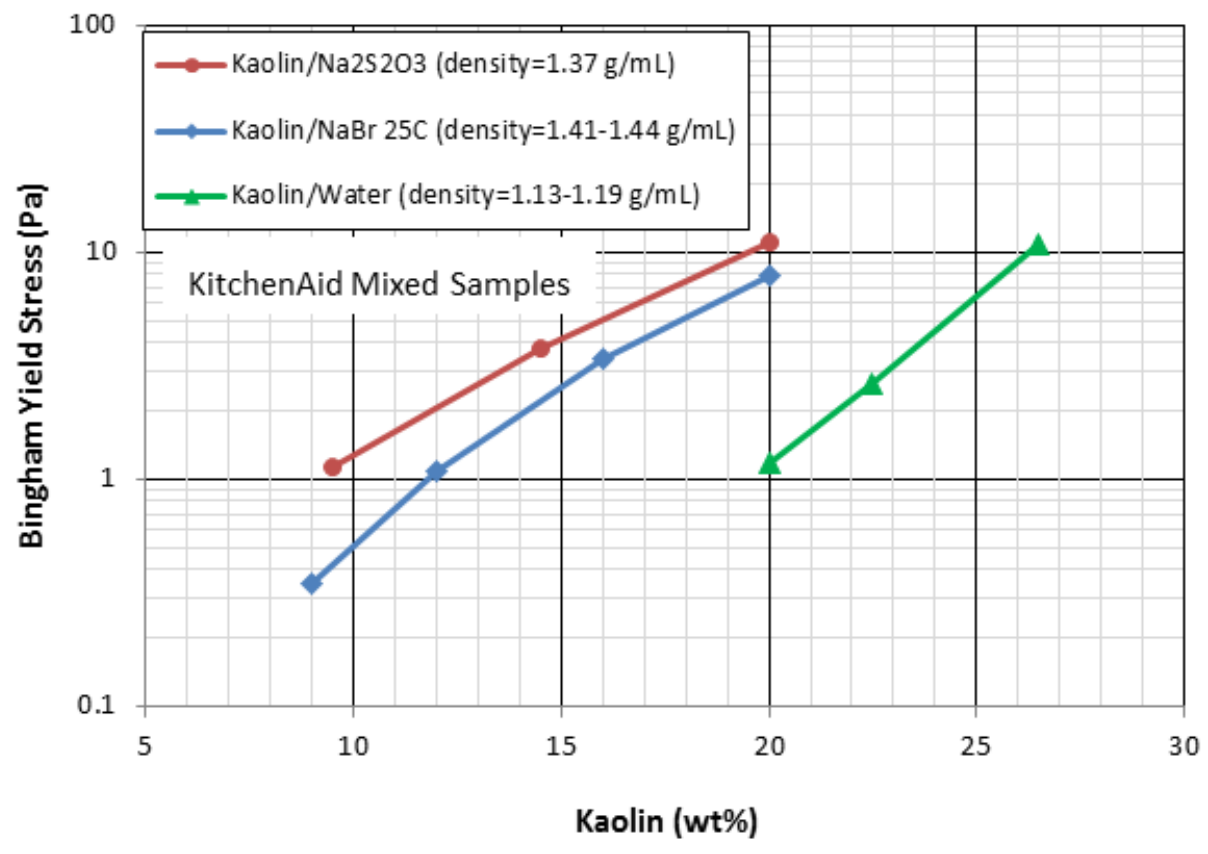

Figure 4.8. Comparison of Bingham Yield Stresses for Kaolin Slurries in Water and with Sodium Thiosulfate and Sodium Bromide

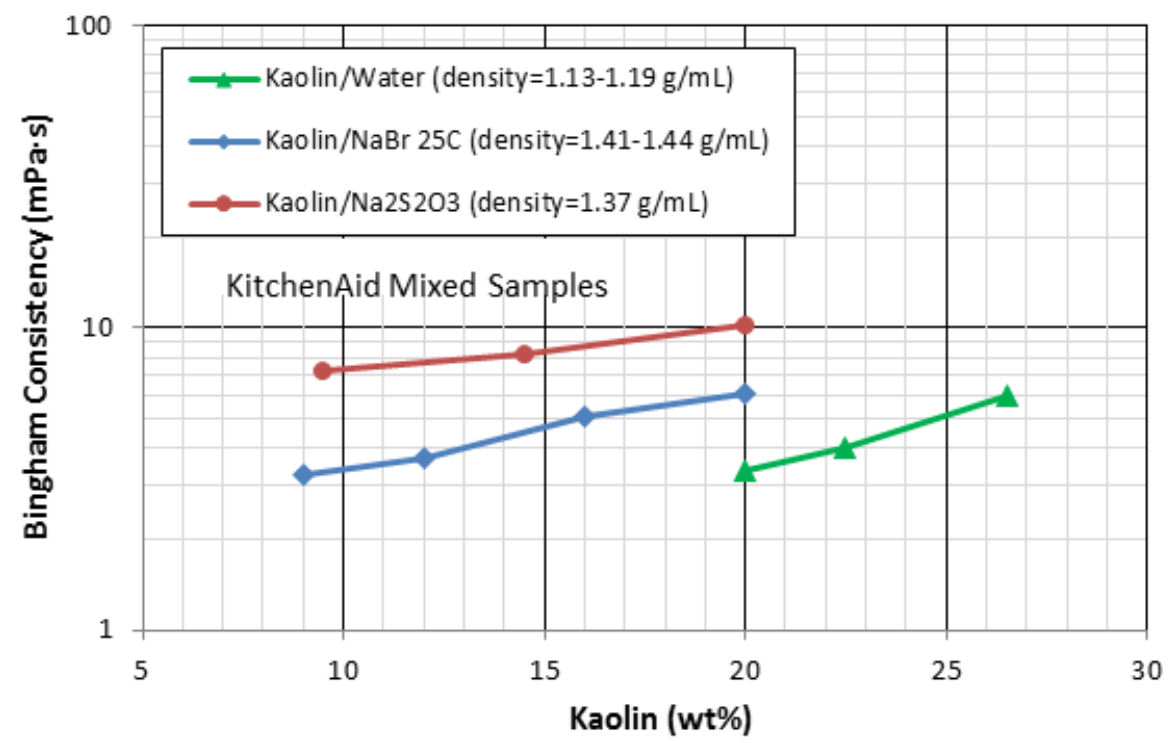

Figure 4.9. Comparison of Bingham Consistencies for Kaolin Slurries in Water and with Sodium Thiosulfate and Sodium Bromide 


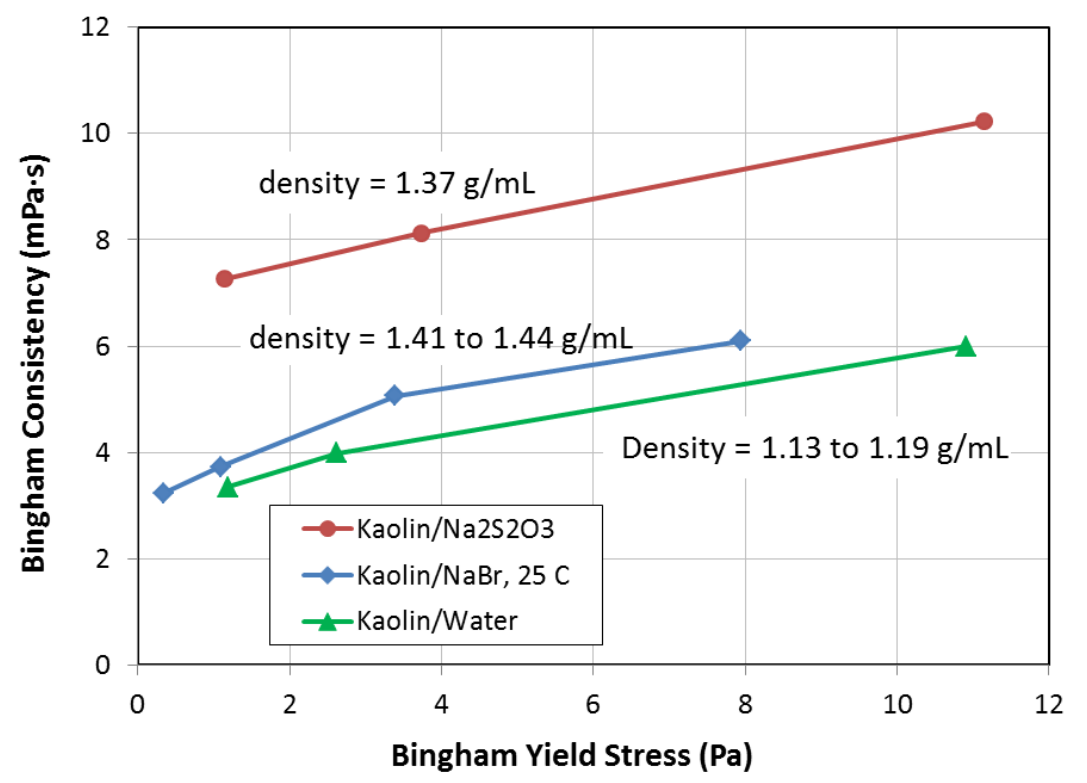

Figure 4.10. Bingham Consistency versus Yield Stress for Kaolin Slurries in Water and with Sodium Thiosulfate or Sodium Bromide

Table 4.6 shows the effect of temperature on Bingham yield stress and Bingham consistency for the recommended recipes of non-Newtonian kaolin-sodium thiosulfate simulants. The result shows essentially no effect of temperature on the Bingham yield stress and minimal temperature effect on Bingham consistency for these simulants. However, the small temperature effect on the Bingham consistency is insignificant because the variations are within an acceptable range of experimental error. In addition, there was no salt precipitation observed in the temperature stability studies described in Section 3.6. This result indicates the stability of the recommended non-Newtonian kaolin-sodium thiosulfate simulants for the potential range of test temperatures.

Table 4.6. Effect of Temperature on Bingham Yield Stress and Consistency for Slurries of Kaolin and Sodium Thiosulfate in Water

\begin{tabular}{|c|c|c|c|c|c|c|}
\hline \multirow[b]{3}{*}{$\begin{array}{l}\text { Temp } \\
\left({ }^{\circ} \mathrm{C}\right)\end{array}$} & \multicolumn{6}{|c|}{ Simulant Composition: Kaolin $/ \mathrm{Na}_{2} \mathrm{~S}_{2} \mathrm{O}_{3}$ in Pasco City Water } \\
\hline & \multicolumn{2}{|c|}{$\begin{array}{c}9.5 \mathrm{wt} \% \text { kaolin } \\
29.6 \mathrm{wt} \% \mathrm{Na}_{2} \mathrm{~S}_{2} \mathrm{O}_{3}\end{array}$} & \multicolumn{2}{|c|}{$\begin{array}{c}14.5 \mathrm{wt} \% \text { kaolin } \\
24.9 \mathrm{wt} \% \mathrm{Na}_{2} \mathrm{~S}_{2} \mathrm{O}_{3}\end{array}$} & \multicolumn{2}{|c|}{$\begin{array}{c}20 \mathrm{wt} \% \text { kaolin } \\
19.9 \mathrm{wt} \% \mathrm{Na}_{2} \mathrm{~S}_{2} \mathrm{O}_{3}\end{array}$} \\
\hline & $\begin{array}{c}\text { Bingham } \\
\text { Yield Stress } \\
(\mathrm{Pa})\end{array}$ & $\begin{array}{c}\text { Bingham } \\
\text { Consistency } \\
(\mathrm{mPa} \cdot \mathrm{s})\end{array}$ & $\begin{array}{c}\text { Bingham } \\
\text { Yield Stress } \\
(\mathrm{Pa}) \\
\end{array}$ & $\begin{array}{c}\text { Bingham } \\
\text { Consistency } \\
(\mathrm{mPa} \cdot \mathrm{s})\end{array}$ & $\begin{array}{c}\text { Bingham } \\
\text { Yield Stress } \\
(\mathrm{Pa})\end{array}$ & $\begin{array}{c}\text { Bingham } \\
\text { Consistency } \\
(\mathrm{mPa} \cdot \mathrm{s}) \\
\end{array}$ \\
\hline 20 & 1.1 & 7.3 & 3.7 & 8.1 & 11 & 10.2 \\
\hline 25 & 1.1 & 6.2 & 3.4 & 7.3 & 10 & 10.0 \\
\hline 30 & 1.1 & 5.6 & 3.5 & 6.9 & 11 & 8.5 \\
\hline
\end{tabular}

Table 4.7 presents the effect of temperature on Bingham yield stress and Bingham consistency for the recommended recipes of non-Newtonian aqueous kaolin simulants. The experiment was done in duplicate to verify the results and the testing protocol. Both data sets show essentially no effect of temperature on the Bingham yield stress and Bingham consistency for these non-Newtonian aqueous 
kaolin simulants. The small variations in the Bingham yield stress and Bingham consistency measurements are within an acceptable range of experimental error. This result indicates the stability of the recommended non-Newtonian aqueous kaolin simulants for the potential range of test temperatures.

Table 4.7. Effect of Temperature on Bingham Yield Stress and Consistency for Slurries of Kaolin in Water

\begin{tabular}{ccccccc} 
& \multicolumn{5}{c}{ Simulant Composition: Kaolin in Pasco City Water } \\
& \multicolumn{2}{c}{$20.0 \mathrm{wt} \%$ kaolin } & \multicolumn{2}{c}{$22.5 \mathrm{wt} \%$ kaolin } & \multicolumn{2}{c}{$26.5 \mathrm{wt} \%$ kaolin } \\
\cline { 2 - 7 } $\begin{array}{c}\text { Temp } \\
\left({ }^{\circ} \mathrm{C}\right)\end{array}$ & $\begin{array}{c}\text { Bingham } \\
\text { Yield Stress } \\
(\mathrm{Pa})\end{array}$ & $\begin{array}{c}\text { Bingham } \\
\text { Consistency } \\
(\mathrm{mPa} \cdot \mathrm{s})\end{array}$ & $\begin{array}{c}\text { Bingham } \\
\text { Yield Stress } \\
(\mathrm{Pa})\end{array}$ & $\begin{array}{c}\text { Bingham } \\
\text { Consistency } \\
(\mathrm{mPa} \cdot \mathrm{s})\end{array}$ & $\begin{array}{c}\text { Bingham } \\
\text { Yield Stress } \\
(\mathrm{Pa})\end{array}$ & $\begin{array}{c}\text { Bingham } \\
\text { Consistency } \\
(\mathrm{mPa} \cdot \mathrm{s})\end{array}$ \\
\hline \multirow{2}{*}{20} & 1.6 & 3.5 & 3.4 & 4.3 & 11 & 6.5 \\
& 1.3 & 3.3 & 3.3 & 4.0 & 12 & 6.1 \\
25 & 2.2 & 3.6 & 5.0 & 4.4 & 11 & 5.8 \\
& 1.3 & 3.1 & 3.9 & 3.7 & 12 & 6.0 \\
30 & 1.7 & 3.1 & 4.8 & 3.9 & 11 & 5.6 \\
& 1.6 & 3.3 & 5.2 & 4.1 & 14 & 5.8 \\
\hline
\end{tabular}

\subsection{Compatibility of Spike Simulant Particles in Non-Newtonian Slurries}

Table 4.8 shows the resuspension test results for spike particles in one slurry of kaolin and sodium thiosulfate and one slurry of kaolin in water. Because there was a very small quantity of the spike particles, an additional test was done with 100-fold higher quantity of the spike particles in the kaolinsodium thiosufate simulant to have a better opportunity to evaluate the compatibility of the spike particles and the slurry. The results in Table 4.8 show that all the slurries were easily resuspended and there is no indication of unexpected behavior such as unexpectedly strong settled layers.

Table 4.8. Resuspension Results for Spike Particles in Non-Newtonian Simulant

\begin{tabular}{c|c|c|c}
\hline & $\begin{array}{c}14.5 \% \mathrm{Kaolin} \\
24.9 \% \mathrm{Na}_{2} \mathrm{~S}_{2} \mathrm{O}_{3}\end{array}$ & $\begin{array}{c}14.5 \% \mathrm{Kaolin}^{2} \\
24.9 \% \mathrm{Na}_{2} \mathrm{~S}_{2} \mathrm{O}_{3} \\
(100 \mathrm{x} \mathrm{Spike})\end{array}$ & $22.5 \%$ Kaolin \\
\hline Day 1 & 1 & 1 & 1 \\
Day 2 & $0+$ & $0+$ & $0+$ \\
Day 3 & $0+$ & 1 & 1 \\
Day 4 & $0+$ & $0+$ & $0+$ \\
Day 7 & $0+$ & 1 & 1 \\
\hline 0 - swirl in a circular motion - heavy SS beads are not stuck to the bottom (applicable to \\
bottle 7-day test only) \\
1 - rock vertical to horizontal gently at least 20 times - heavy SS beads are not stuck to the \\
bottom \\
"+" - did not suspend at specific level but suspended 1 to 2 iterations into the next level \\
\hline
\end{tabular}




\subsection{Non-Newtonian Kaolin Slurry Particle Size Distributions}

The addition of sodium thiosulfate or sodium bromide significantly increased the Bingham yield stress of the kaolin slurries, as shown in Figure 4.8, in addition to increasing the slurry density. An overall objective of the planned demonstration tests is to compare testing results using different non-Newtonian and Newtonian fluids (Lee 2012a, 2012b, 2012c). While many previous studies have used kaolin slurries, and also bentonite and kaolin/bentonite mixtures, for waste simulants (Lee et al. 2012), there are no studies that have evaluated the suitability of kaolin slurries with high salt concentrations for use as waste simulants. For the planned demonstration tests, it is important that the addition of sodium thiosulfate does not change the kaolin slurry in an unexpected manner that makes the recipes with kaolin and salt a poor selection for a non-Newtonian waste simulant. An additional slurry characterization method that can be used to evaluate the role of salt on the slurry is to measure the PSD of the kaolin particles with and without sodium thiosulfate; a summary of these measurements is given below. The rheology results in Section 4.3 also showed a significant effect of preshearing on the rheology of the slurries. PSD measurements comparing different intensities of preshearing can be helpful in understanding how shearing in the pumps and flow system for the demonstration tests might change the rheology of the kaolin slurries. PSD results for different slurry preshearing are also shown below. More detailed PSD data are provided in Appendix C for the results shown in this section.

Figure 4.11 shows a comparison of PSDs for all the kaolin slurries where the samples were sonicated prior to the PSD measurement to disperse aggregates. Sonicated samples generally give results showing the PSD of the primary particles. Figure 4.11 shows similar PSDs regardless of whether there was no preshearing (Hand Kaolin/Sonicated) or preshearing was done with only the KitchenAid mixer (KA/KA Kaolin/Sonicated) or with the Magic Bullet (KA/MB Kaolin/Sonicated). Additionally, the hand-mixed kaolin slurry without preshearing shows essentially identical PSD to that of the KitchenAid-mixed followed by KitchenAid-presheared slurry. The results also show a more narrow distribution for the slurries with sodium thiosulfate but there was no shift in the PSD to lower or higher particle sizes with the added salt. Figure 4.12 shows a similar comparison for unsonicated slurries; the addition of sodium thiosulfate has only a minor effect on the kaolin PSD. Typically, a reduction in the PSD corresponds to an increase in the Bingham yield stress for a slurry. Accordingly, because the sodium thiosulfate did not shift the PSD of the kaolin, the addition of the salt increases the rheology of the kaolin slurries by some other mechanism such as particle attractions, or equivalently making the kaolin particles more cohesive.

Figure 4.13 shows the effect of preshearing intensity on the PSD of unsonicated slurries of kaolin in water and kaolin with sodium thiosulfate addition. These results show that preshearing the kaolin slurry with the Magic Bullet, which provides higher shearing intensity than that provided by the KitchenAid mixer, shifts the PSD to smaller sizes. A reduction in PSD is consistent with the observation of increased Bingham yield stress with the Magic Bullet preshearing. Moreover, the KitchenAid preshearing shows essentially no effect on the PSD of the kaolin slurry as compared to that of the hand-mixed slurry without preshearing. Figure 4.14 shows that sonication also shifts the PSD to smaller sizes and this shift is similar to the reduction caused by the Magic Bullet preshearing. Finally, Figure 4.15 shows that sonication does not further reduce the PSD of samples presheared with the Magic Bullet, so the Magic Bullet preshearing probably gives the smallest PSD and highest Bingham yield stress for strong preshearing. 


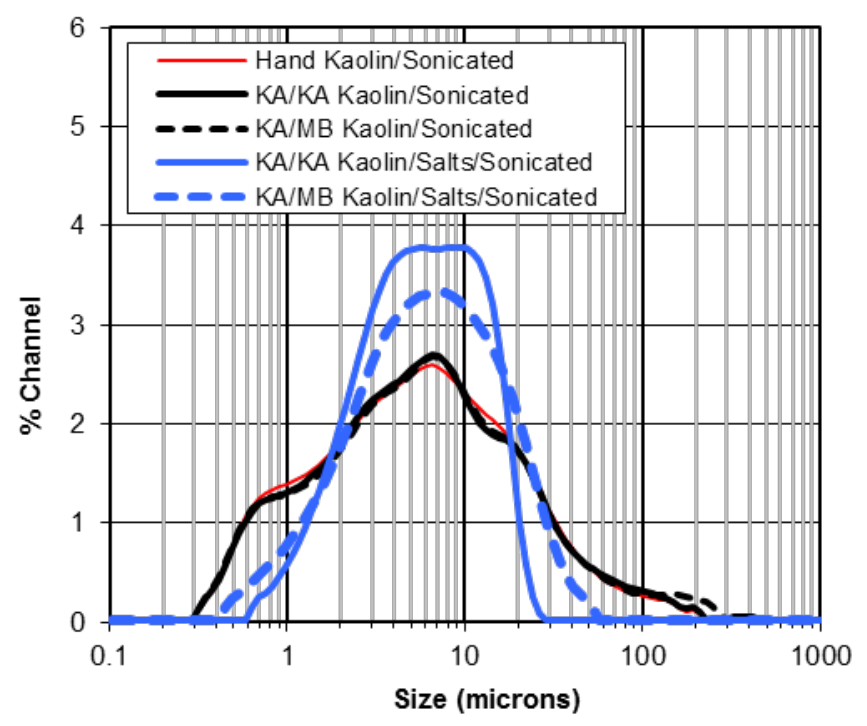

Figure 4.11. Kaolin PSDs for all Sonicated Slurries having Different Preshearing for Slurries of Kaolin in Water and Kaolin in Sodium Thiosulfate Solutions
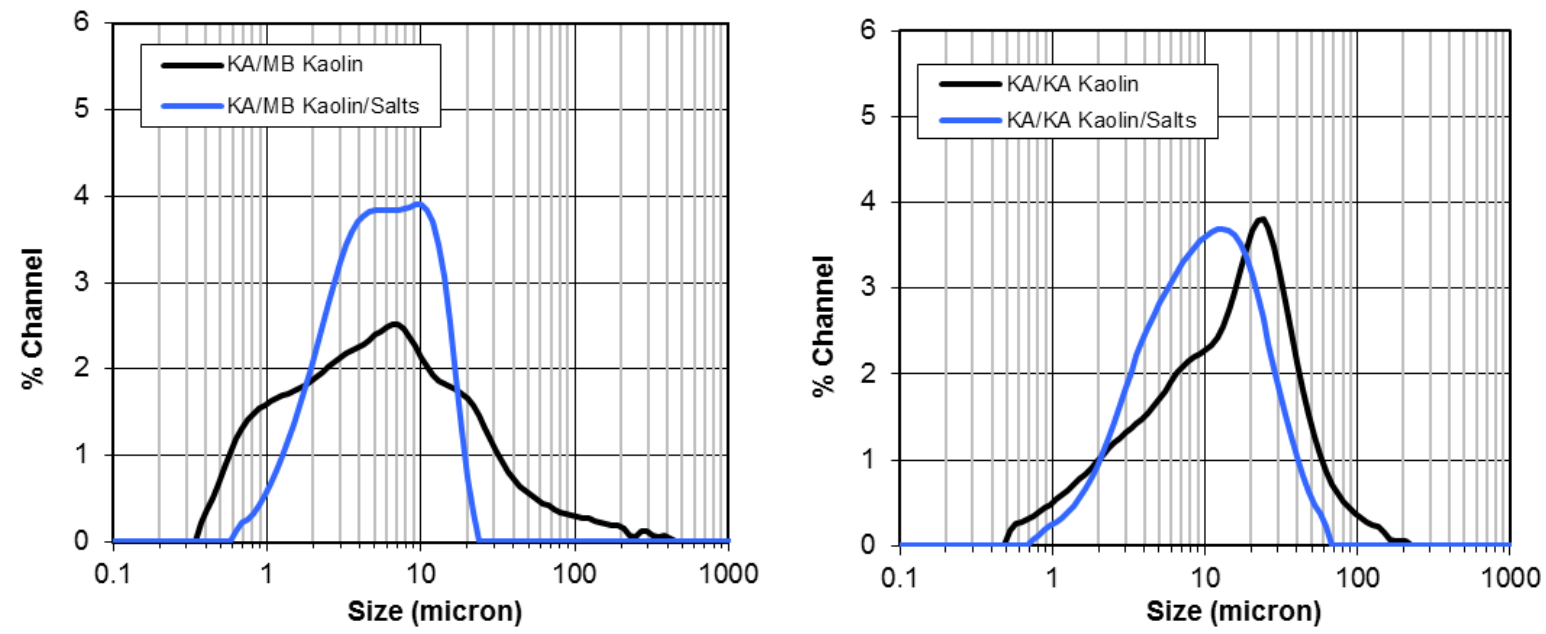

Figure 4.12. Effect of Sodium Thiosulfate on Kaolin PSDs for Unsonicated Kaolin Slurries with Different Preshearing Left: KitchenAid-Mixed/Magic Bullet-Presheared; Right: KitchenAidMixed/KitchenAid-Presheared 

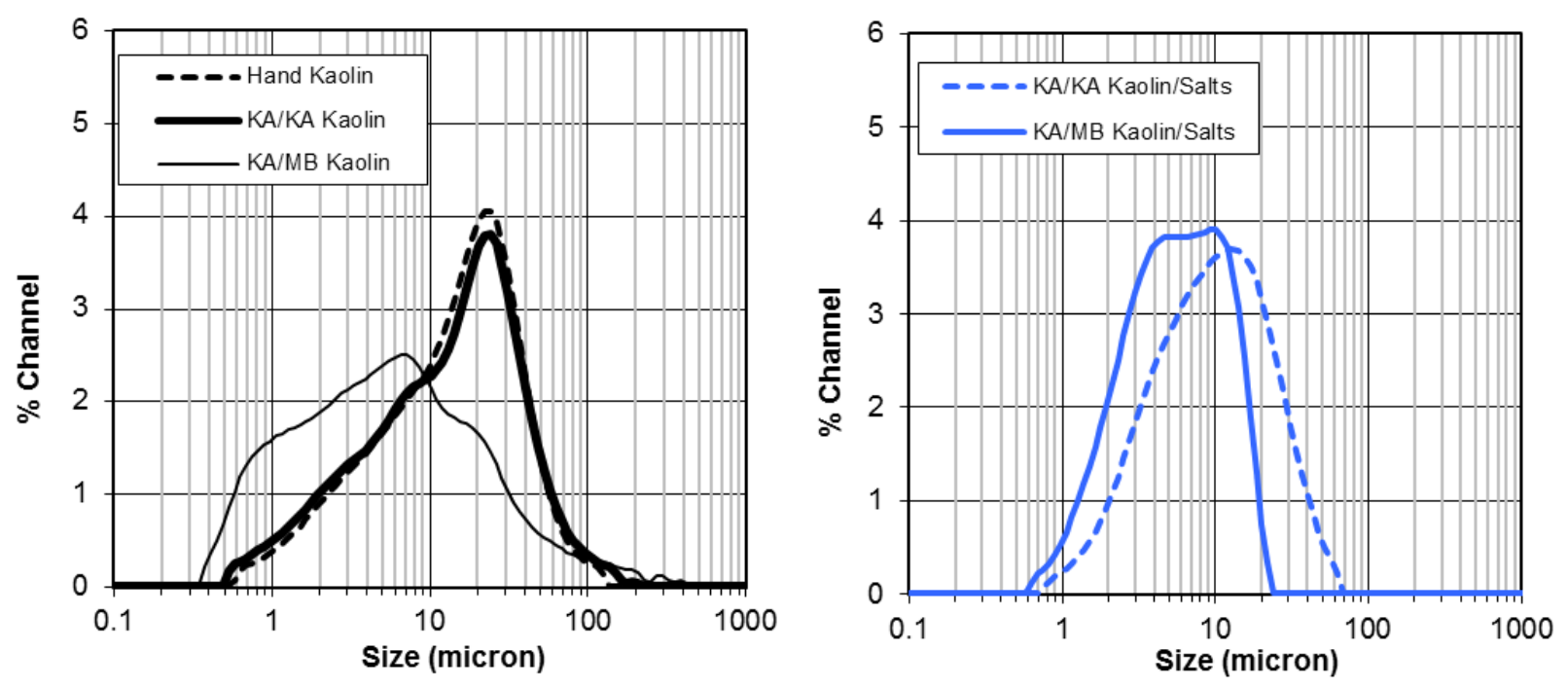

Figure 4.13. Effect of Preshearing on Kaolin PSDs for Unsonicated Slurries of Kaolin in Water (left) and Kaolin in Sodium Thiosulfate Salt Solution (right)
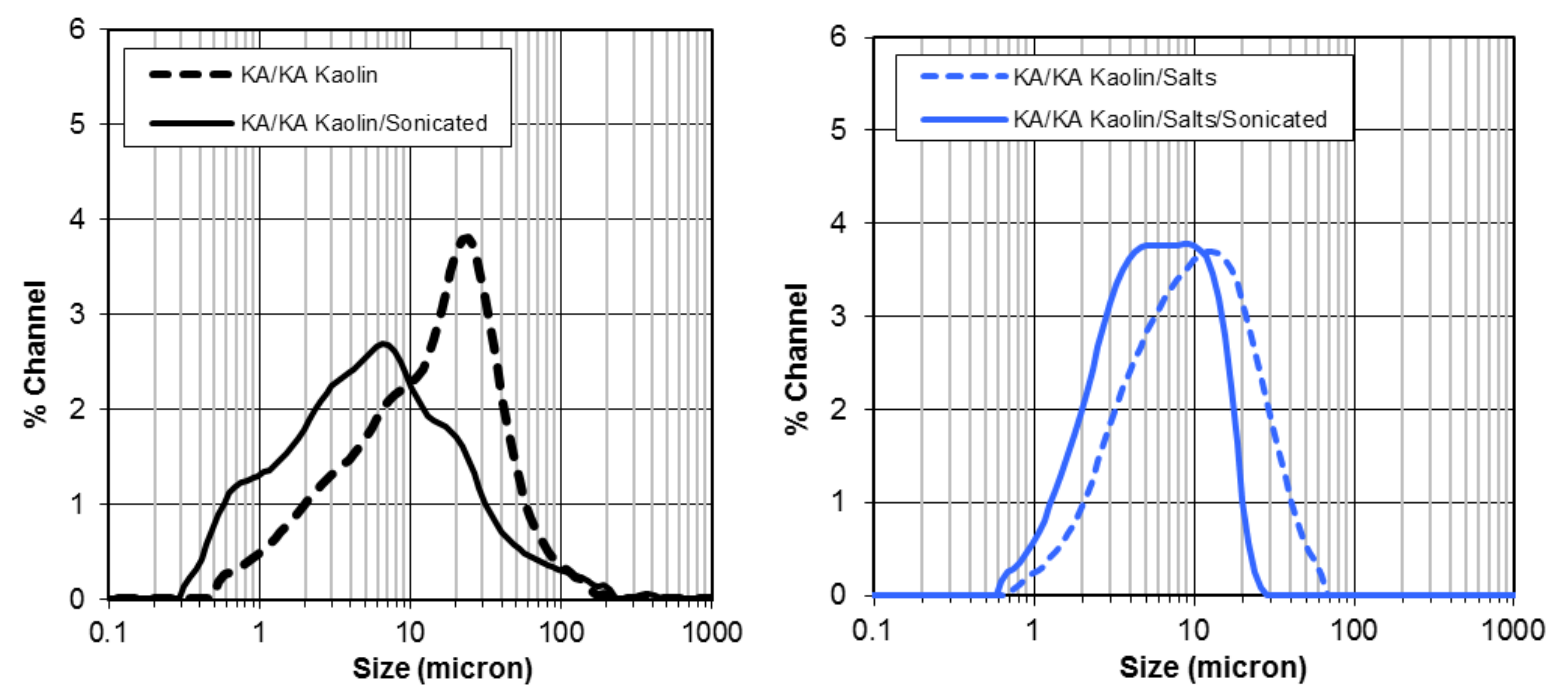

Figure 4.14. Effect of Sonication on Kaolin PSDs for Slurries of Kaolin in Water (left) and Kaolin in Sodium Thiosulfate Salt Solution (right) 


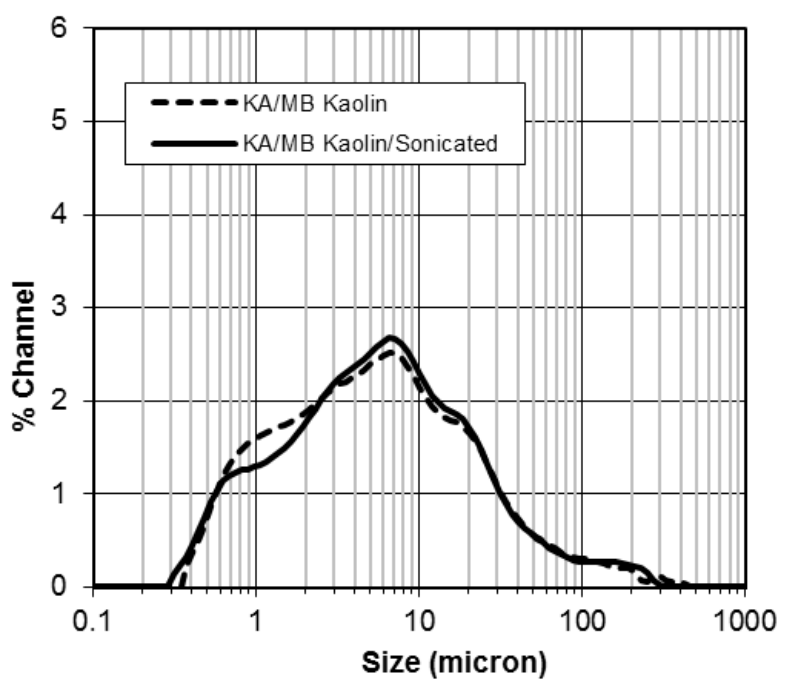

Figure 4.15. Effect of Sonication on Kaolin PSDs for Slurries of Kaolin in Water Presheared with the Magic Bullet Mixer 


\subsection{Summary and Conclusions}

This report summarizes the results of laboratory studies on small trial simulant mixtures to determine specific simulant recipes, to evaluate the compatibility of the liquids and particles, and to determine whether the simulants are stable for the potential range of test temperatures. The objective of the testing, which is focused primarily on the Newtonian and non-Newtonian suspending fluids, is to determine the composition of selected simulant materials that give the desired density and viscosity or rheological parameters.

For the Newtonian liquids, simulant recipes were developed using aqueous solutions of sodium thiosulfate or sodium thiosulfate and glycerol to match the density and viscosity targets for four of the five targets. Sodium thiosulfate was the preferred salt because it is nonhazardous and inexpensive. An aqueous solution of sodium bromide, which gives uniquely low viscosities in concentrated solutions in comparison to other salt solutions, was selected as a preferred material for a high-density/low-viscosity target. The effect of temperature on viscosity was evaluated because the glycerol/thiosulfate solutions are somewhat temperature sensitive. All of these solutions were stable (no salt precipitation after about a day) down to $10^{\circ} \mathrm{C}$.

There was only one liquid/particle compatibility issue observed during the testing, and this was when one type of the gibbsite material was added to a solution of glycerol in water (low-density/high-viscosity target). For this mixture, slurries always stayed cloudy during a day of settling, and clear liquid above a settling layer, which is the expected behavior, was not observed. This mixture would still give settled layers, and these layers were quite difficult to resuspend. This recipe was reformulated using $0.1 \mathrm{wt} \%$ sodium thiosulfate, which altered the particle behavior, and the settling and resuspension results were much improved.

For the non-Newtonian slurries, simulant recipes were developed using slurries of kaolin clay in water or kaolin clay in sodium thiosulfate solutions. For the kaolin in sodium thiosulfate solutions, the proportions of both the sodium thiosulfate and kaolin were adjusted to obtain slurries at a constant density (matching the high-density Newtonian target) for Bingham yield stresses between 1 and $10 \mathrm{~Pa}$. For the kaolin-in-water slurries, the density was not adjusted but was comparable to the low-density Newtonian target as desired. The effect of temperature on the Bingham yield stress and consistency were determined and slurries were stable (no salt precipitation after about a day) down to $10^{\circ} \mathrm{C}$. Compatibility tests with spike particles did not identify any concerns for slurries of either kaolin clay in water or kaolin clay in sodium thiosulfate solutions. PSD measurements of the kaolin slurries showed that both intense preshearing and sonication reduce the PSD of the kaolin particles and the addition of sodium thiosulfate does not shift the PSD of the kaolin. 



\subsection{References}

Adamson DJ, ML Restivo, TJ Steeper and DA Greer. 2010. Demonstration of Mixer Jet Pump Rotational Sensitivity on Mixing and Transfers of the AY-102 Tank. SRNL-STI-2010-00521, Savannah River National Laboratory, Aiken, South Carolina.

ASTM C1750-11. 2010. Standard Guide for Development, Verification, Validation, and Documentation of Simulated High-Level Tank Waste. ASTM International, West Conshohocken, PA.

Certa PJ, PA Empey, and MN Wells. 2011. River Protection Project System Plan. ORP-11242, Rev. 6, U.S. Department of Energy, Office of River Protection, Richland, Washington.

CRC. 2011. Handbook of Chemistry and Physics, 92nd Edition, WM Haynes and DR Lide Editors, CRC Press, Taylor \& Francis Group, Boca Raton, Florida.

DOE. 2011. Department of Energy Plan to Address Waste Treatment and Immobilization Plan Vessel Mixing Issues, Revision 0: Implementation Plan for Defense Nuclear Safety Board Recommendation 2010-2. Letter from Steven Chu to Hon. Peter S. Winokur, November 10, 2011.

Gauglitz PA, WC Buchmiller, JJ Jenks, J Chun, RL Russell, AJ Schmidt, and MM Mastor Jr. 2010. The Disruption of Vessel-Spanning Bubbles with Sloped Fins in Flat-Bottom and 2:1 Elliptical-Bottom Vessels. PNNL-19345 Rev. 0, Pacific Northwest National Laboratory, Richland, Washington.

Lee KP, BE Wells, PA Gauglitz, and RA Sexton. 2012. Waste Feed Delivery Mixing and Sampling Program Simulant Definition for Tank Farm Performance Testing. RPP-PLAN-51625, Rev. 0, Washington River Protection Solutions, Richland, Washington.

Lee KP. 2012a. One System Waste Feed Delivery Mixing and Sampling Program Limits of Performance and Solids Accumulation Scouting Studies Test Plan. RPP-PLAN-52005 Rev. 0, Washington River Protection Solutions, Richland, Washington.

Lee KP. 2012b. One System Waste Feed Delivery Mixing and Sampling Program System Performance Test Plan. RPP-PLAN-52623, Rev. 0, Washington River Protection Solutions, Richland, Washington.

Lee KP. 2012c. One System Waste Feed Delivery Mixing and Sampling Program Solids Accumulation Test Plan. RPP-PLAN-53193, Rev 0, Washington River Protection Solutions, Richland, Washington.

Malvern. 2007. Sample Dispersion and Refractive Index Guide Reference Manual. MAN0396 Issue 1.0 April 2007. Malvern Instruments Ltd., Worcestershire WR14 1XZ, United Kingdom.

Mewis J and NJ Wagner. 2012. Colloidal Suspension Rheology. Cambridge University Press, Cambridge, UK.

Thien MG, and RA Sexton. 2012. Waste Feed Delivery Mixing and Sampling Program Plan and Test Requirements. RPP-PLAN-41087, Rev. 1, Washington River Protection Solutions, Richland, Washington. 
Wells BE, PA Gauglitz, and DR Rector. 2012. Comparison of Waste Feed Delivery Small Scale Mixing Demonstration Simulant to Hanford Waste. PNNL-20637 Rev. 2, Pacific Northwest National Laboratory, Richland, Washington. 


\section{Appendix A}

\section{Simulant Materials Provided to Pacific Northwest National Laboratory}





\section{Appendix A}

\section{Simulant Materials Provided to Pacific Northwest National Laboratory}

Pacific Northwest National Laboratory received batches of dry simulant particles, dry salts, glycerol, and Pasco city water from Energy Solutions. The figures below show the Chain of Custody forms for these materials and give a brief description of each material. 


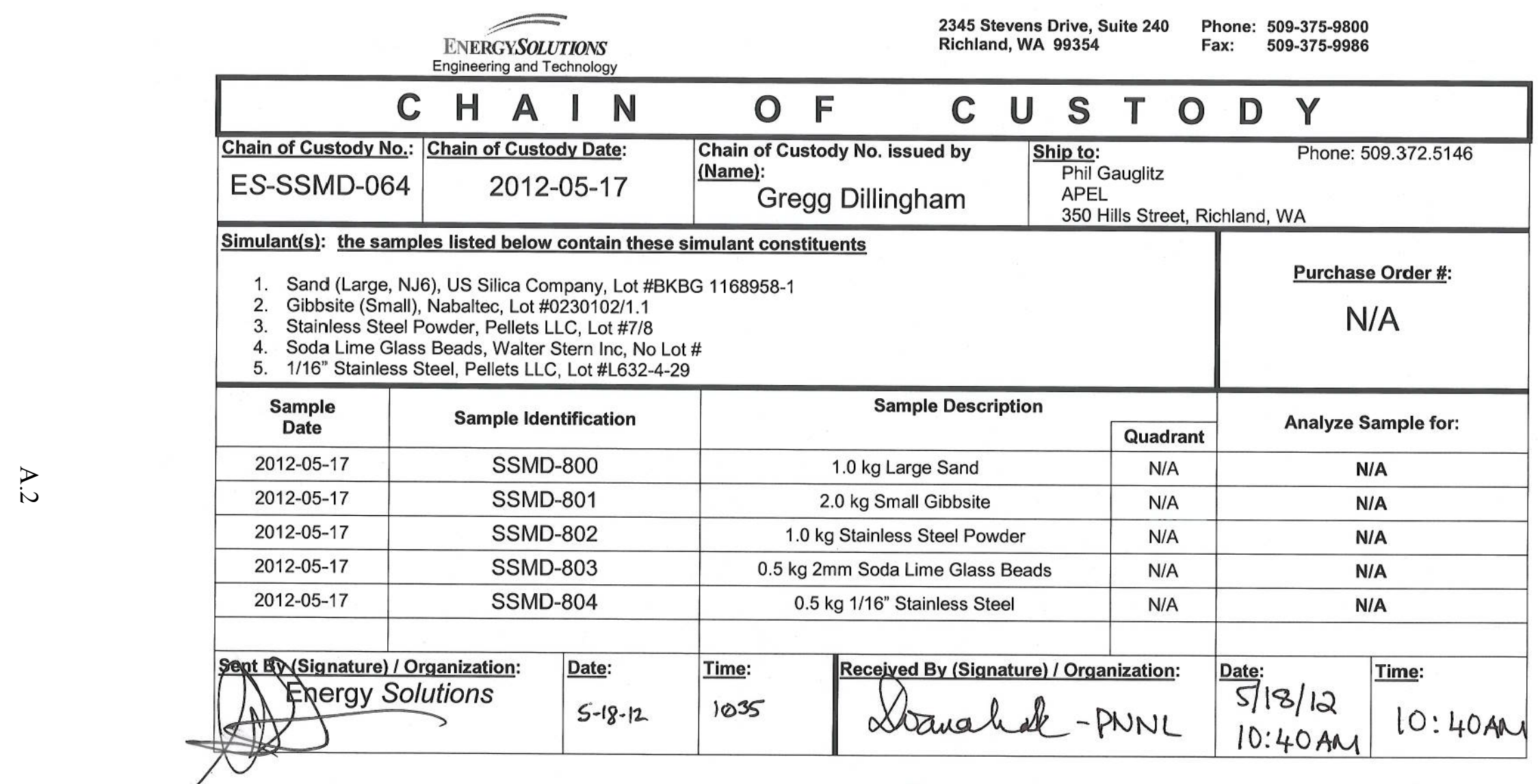

Energy Solutions SSMD Chain of Custody Form Rev1 2010-Aug-18-Wed

Return form to sender Page 1 of 1

Figure A.1. Chain of Custody Form for Sand, Gibbsite, Stainless Steel Powder and Pellets, and Soda Lime Beads 


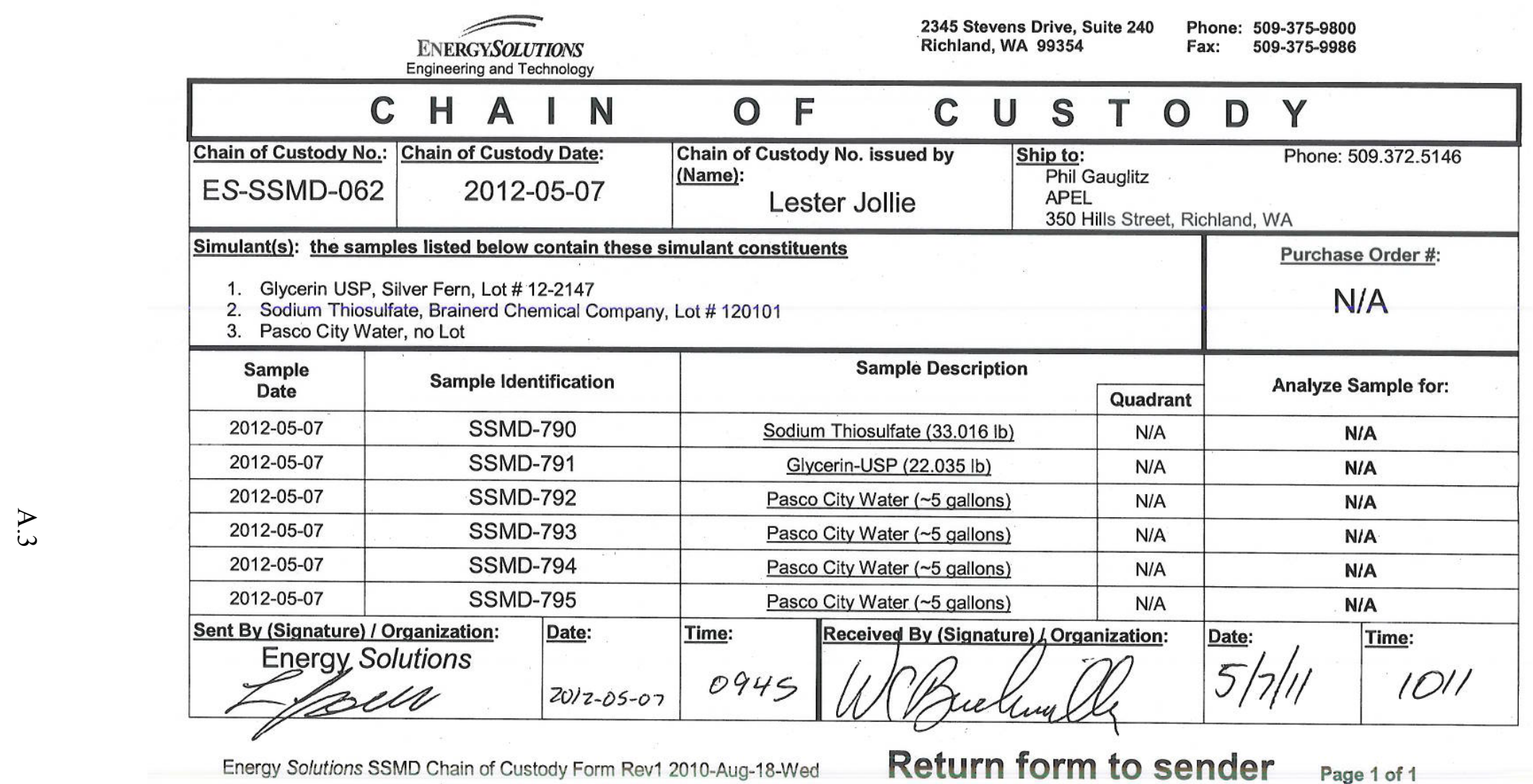

FigureA.2. Chain of Custody Form for Glycerin, Sodium Thiosulfate, and Pasco City Water 


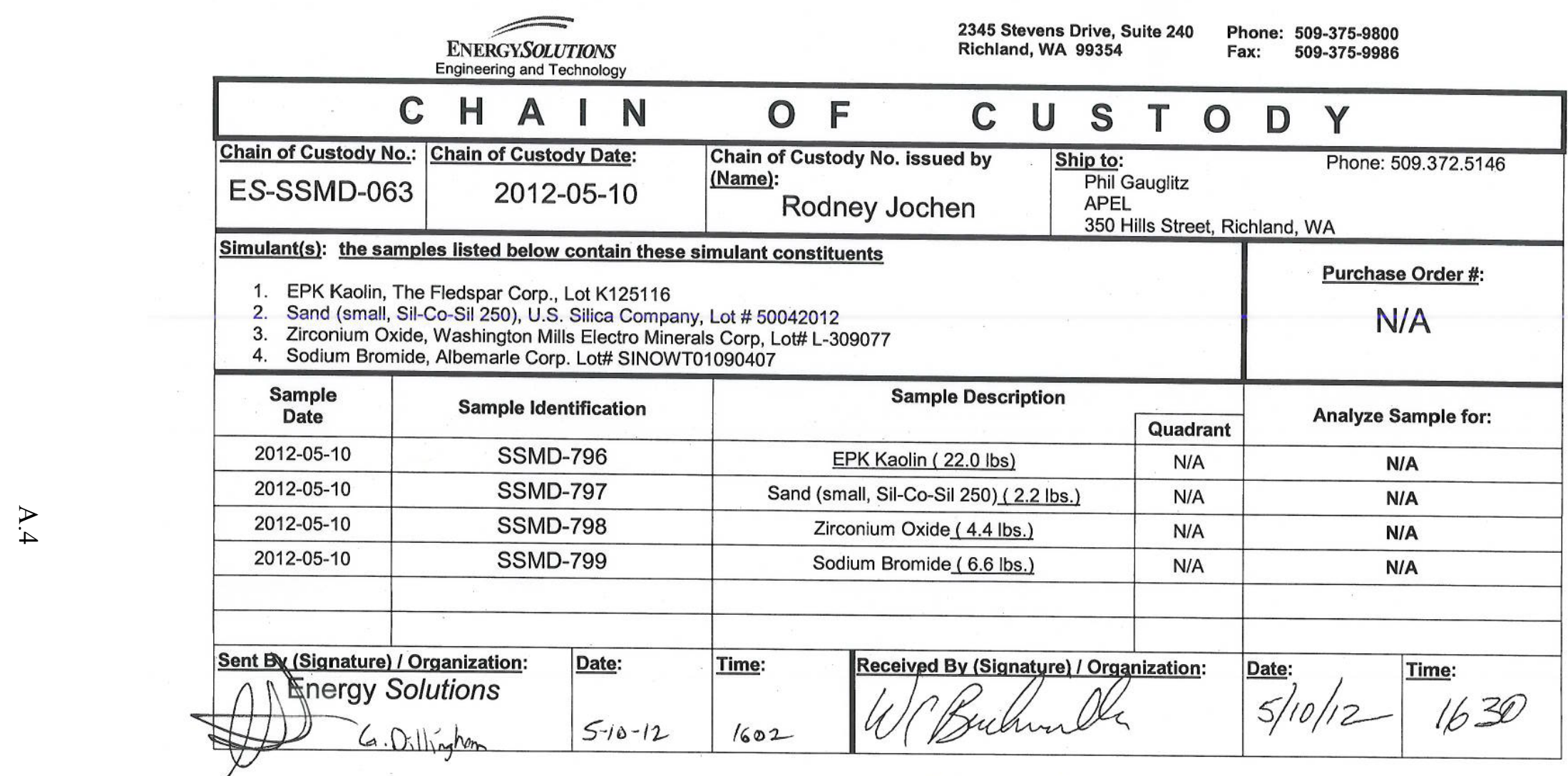

Energy Solutions SSMD Chain of Custody Form Rev1 2010-Aug-18-Wed

Return form to sender Page 1 of 1

FigureA.3. Chain of Custody Form for EPK Kaolin, Sand, Zirconium Oxide, and Sodium Bromide 


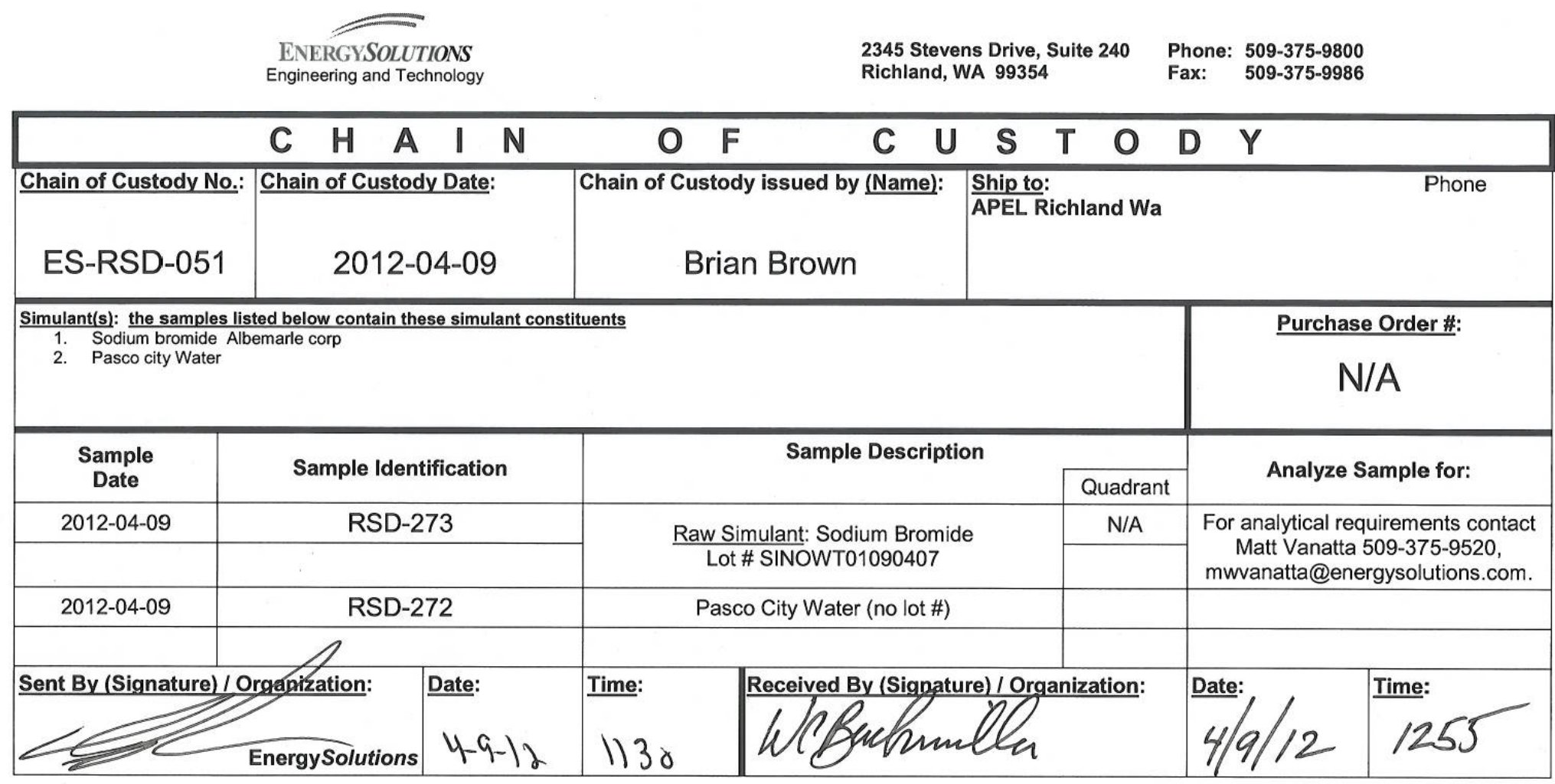

EnergySolutions RSD Chain of Custody Form Rev0 2011-06-01

Return form to sender

Page 1 of 1

FigureA.4. Chain of Custody Form for Sodium Bromide and Pasco City Water 


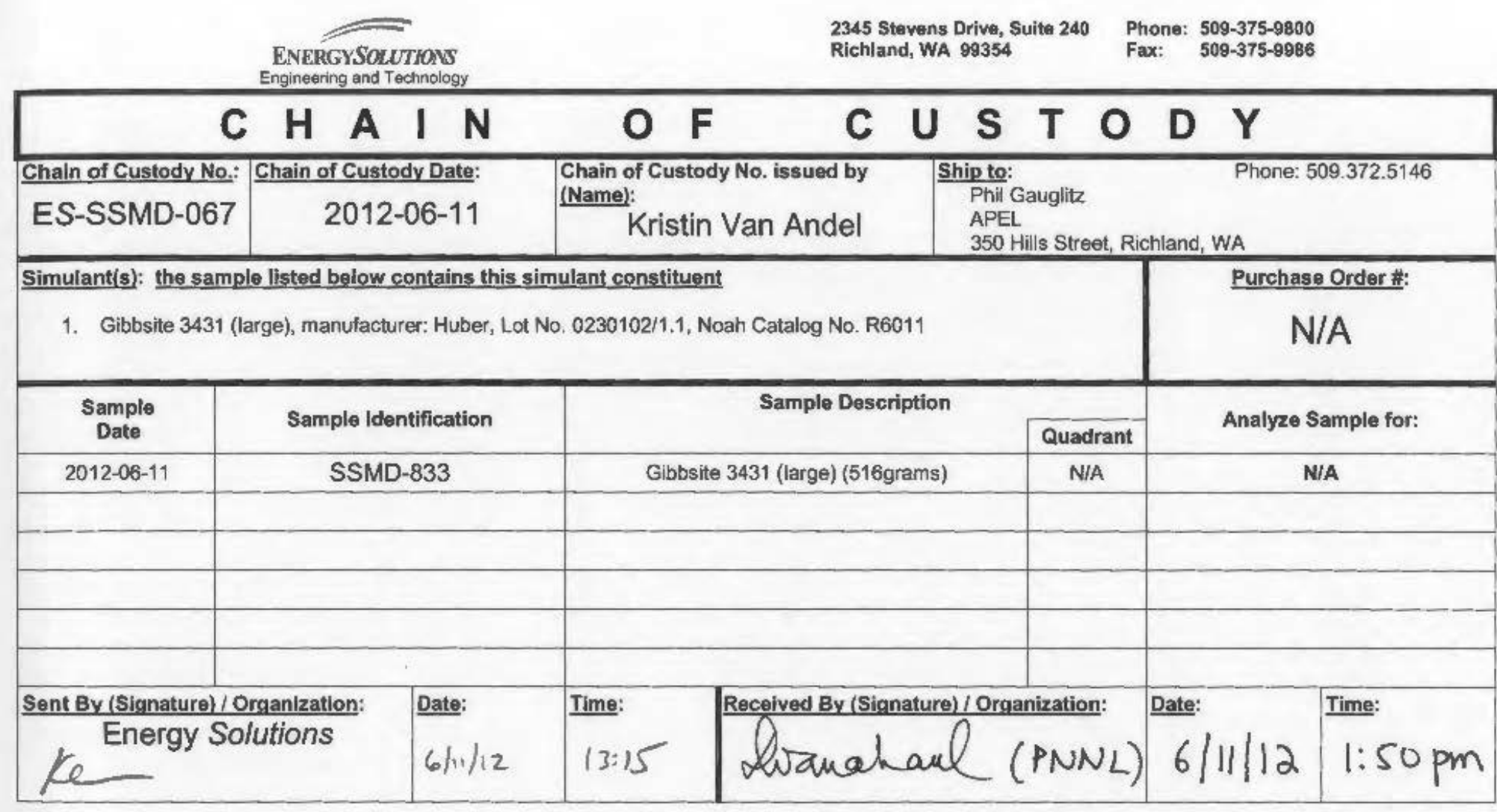

FigureA.5. Chain of Custody Form for Gibbsite 


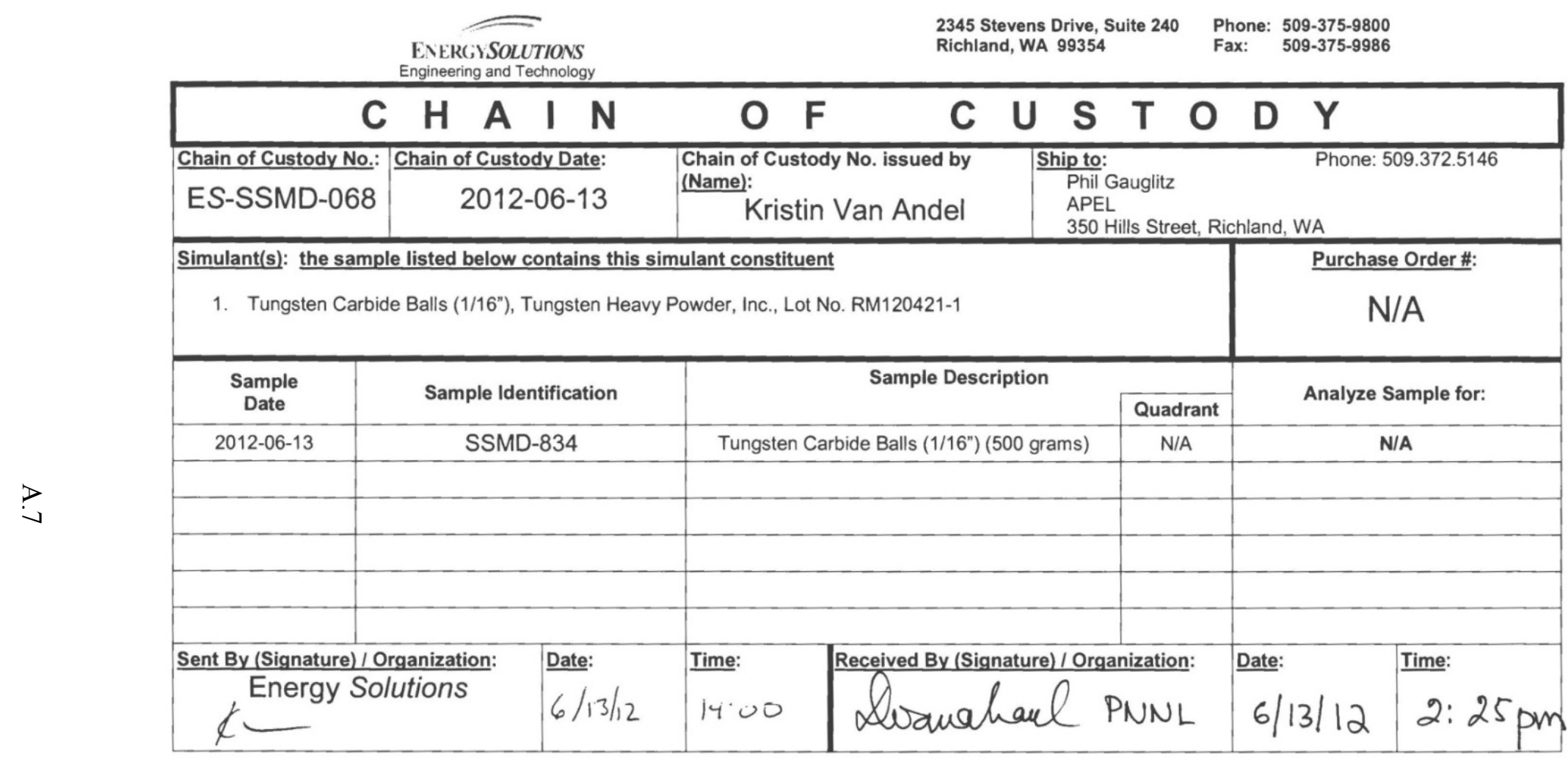

Energy Solutions SSMD Chain of Custody Form Rev1 2010-Aug-18-Wed

Return form to sender Page 1 of 1

FigureA.6. Chain of Custody Form for Tungsten Carbide Balls 

Appendix B

Rheograms for Kaolin Clay Slurries 



\section{Appendix B}

\section{Rheograms for Kaolin Clay Slurries}

The measured rheograms for the final non-Newtonian kaolin clay simulant recipes are shown below. These plots are for the second down-ramp, and this data is used to determine the Bingham yield stress and consistency provided in Section 4.

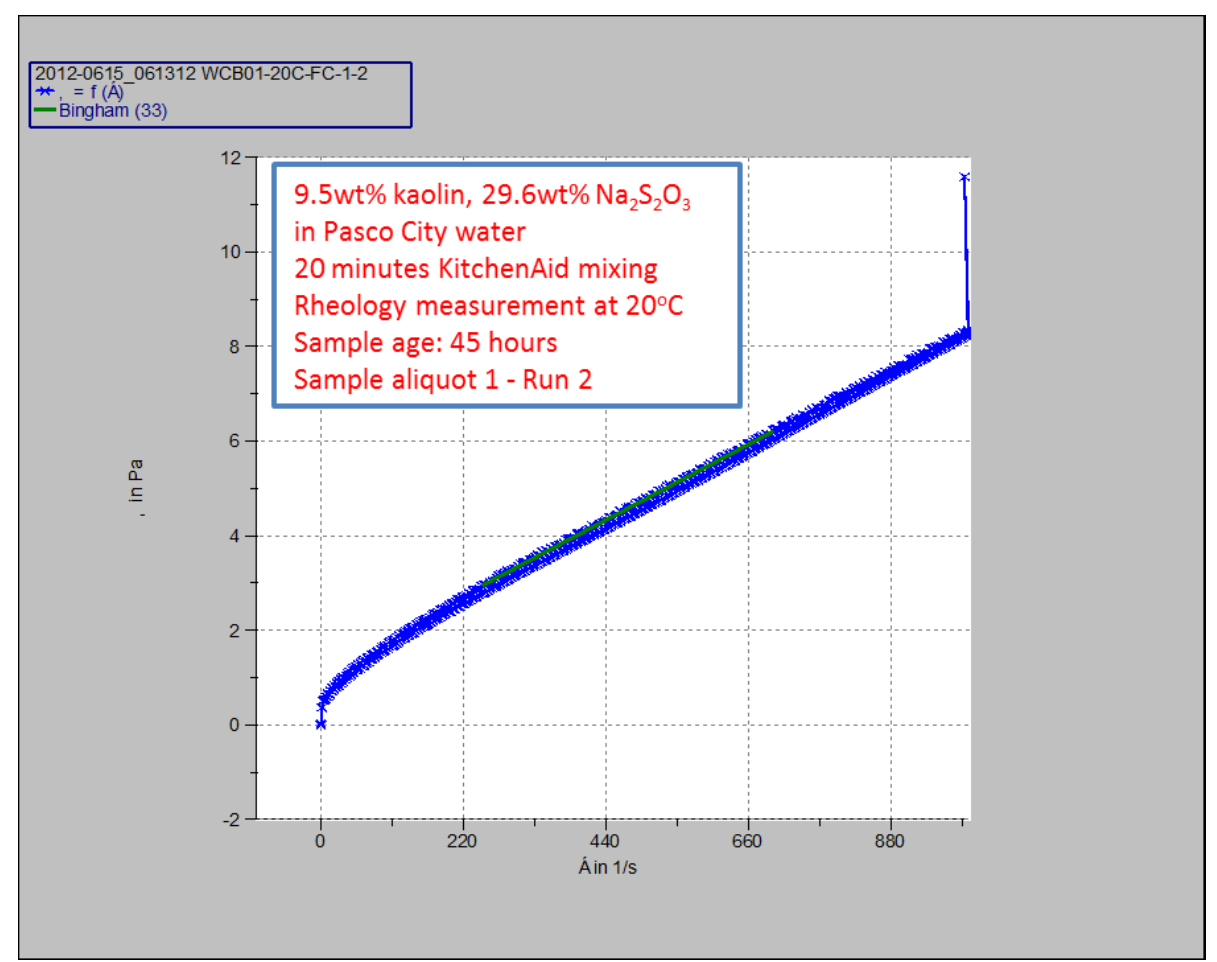

FigureB.1. Rheogram (Second Down-Ramp) for $9.5 \mathrm{wt} \%$ Kaolin and $29.6 \mathrm{wt} \% \mathrm{Na}_{2} \mathrm{~S}_{2} \mathrm{O}_{3}$ in Pasco City Water (Simulant Target Properties of $1 \mathrm{~Pa}, 1.37 \mathrm{~g} / \mathrm{mL}$ ) 


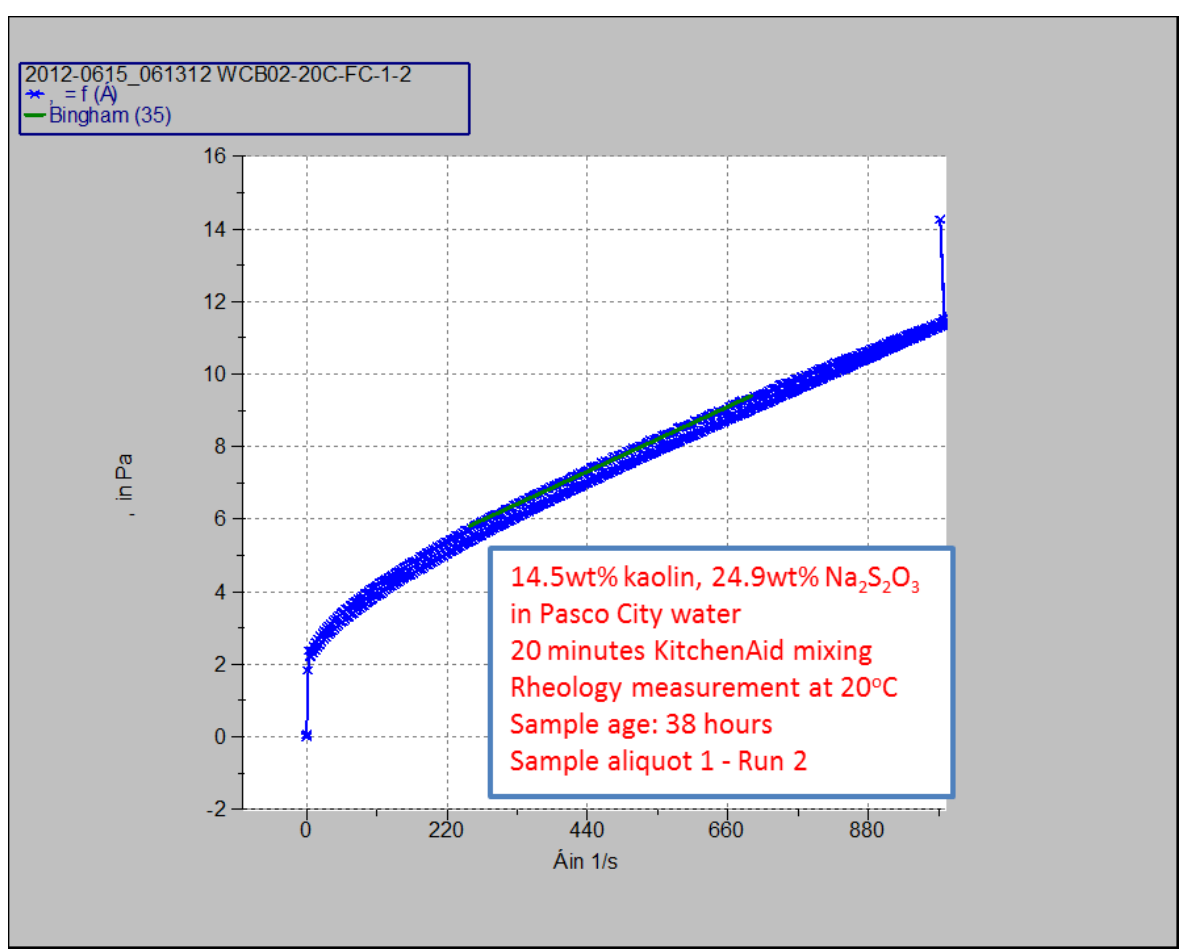

FigureB.2. Rheogram (Second Down-Ramp) for $14.5 \mathrm{wt} \%$ Kaolin and $24.9 \mathrm{wt} \% \mathrm{Na}_{2} \mathrm{~S}_{2} \mathrm{O}_{3}$ in Pasco City Water (Simulant Target Properties of $3 \mathrm{~Pa}, 1.37 \mathrm{~g} / \mathrm{mL}$ )

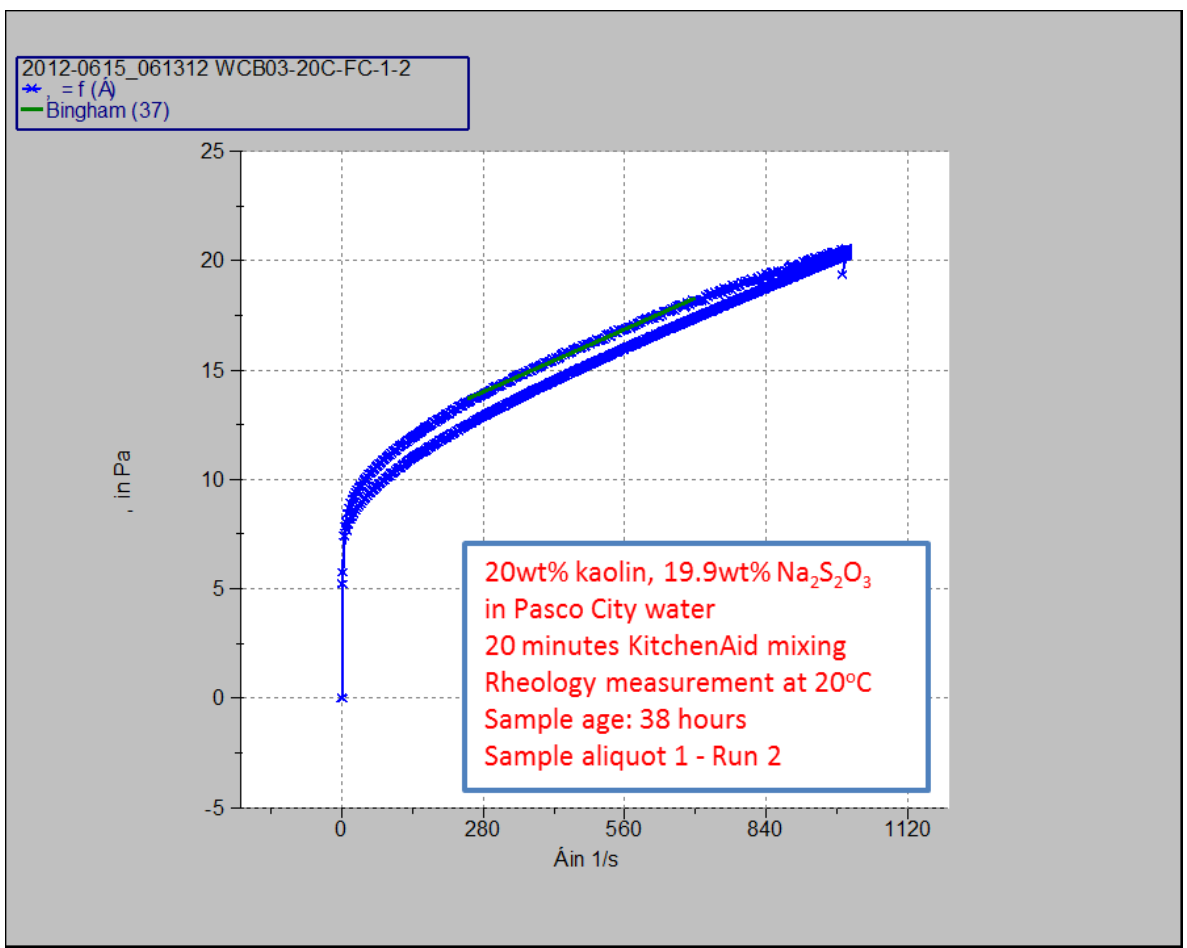

Figure B.3. Rheogram (Second Down-Ramp) for $20.0 \mathrm{wt} \%$ Kaolin and $19.9 \mathrm{wt} \% \mathrm{Na}_{2} \mathrm{~S}_{2} \mathrm{O}_{3}$ in Pasco City Water (Simulant Target Properties of $10 \mathrm{~Pa}, 1.37 \mathrm{~g} / \mathrm{mL}$ ) 


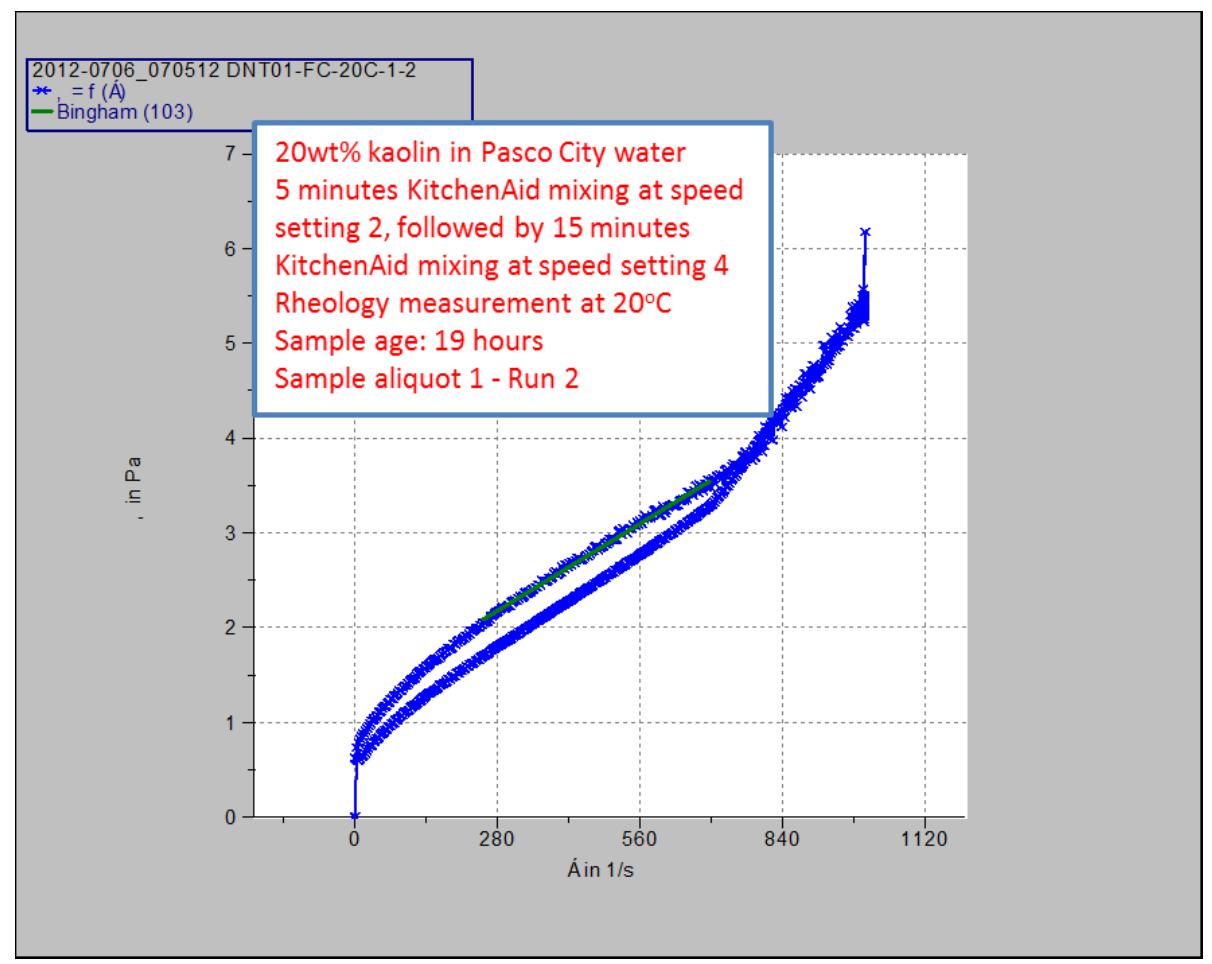

Figure B.4. Rheogram (Second Down-Ramp) for $20.0 \mathrm{wt} \%$ Kaolin in Pasco City Water (Simulant Target Properties of $1 \mathrm{~Pa}, 1.1 \mathrm{~g} / \mathrm{mL}$ )

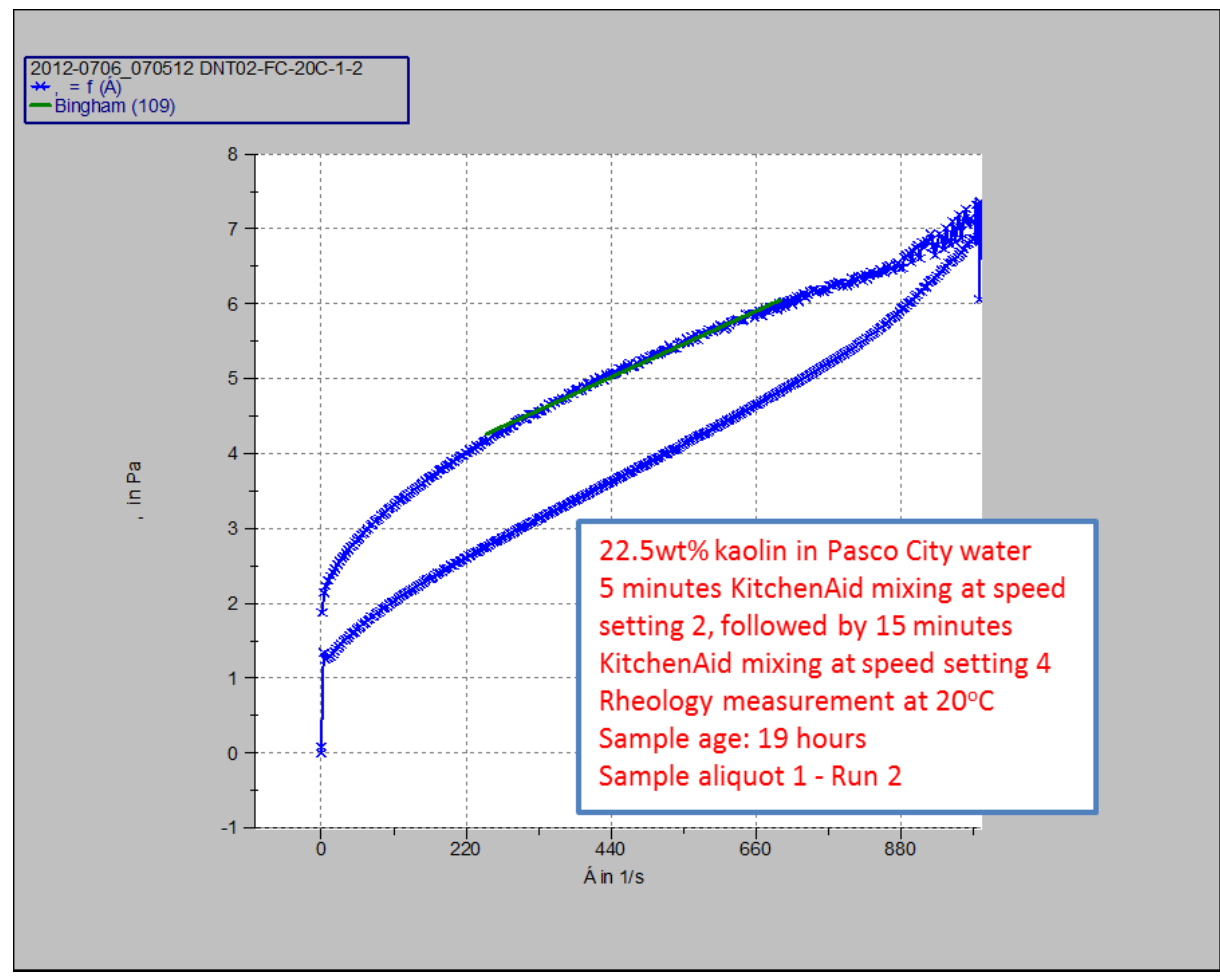

Figure B.5. Rheogram (Second Down-Ramp) for $22.5 \mathrm{wt} \%$ Kaolin in Pasco City Water (Simulant Target Properties of $3 \mathrm{~Pa}, 1.1 \mathrm{~g} / \mathrm{mL}$ ) 


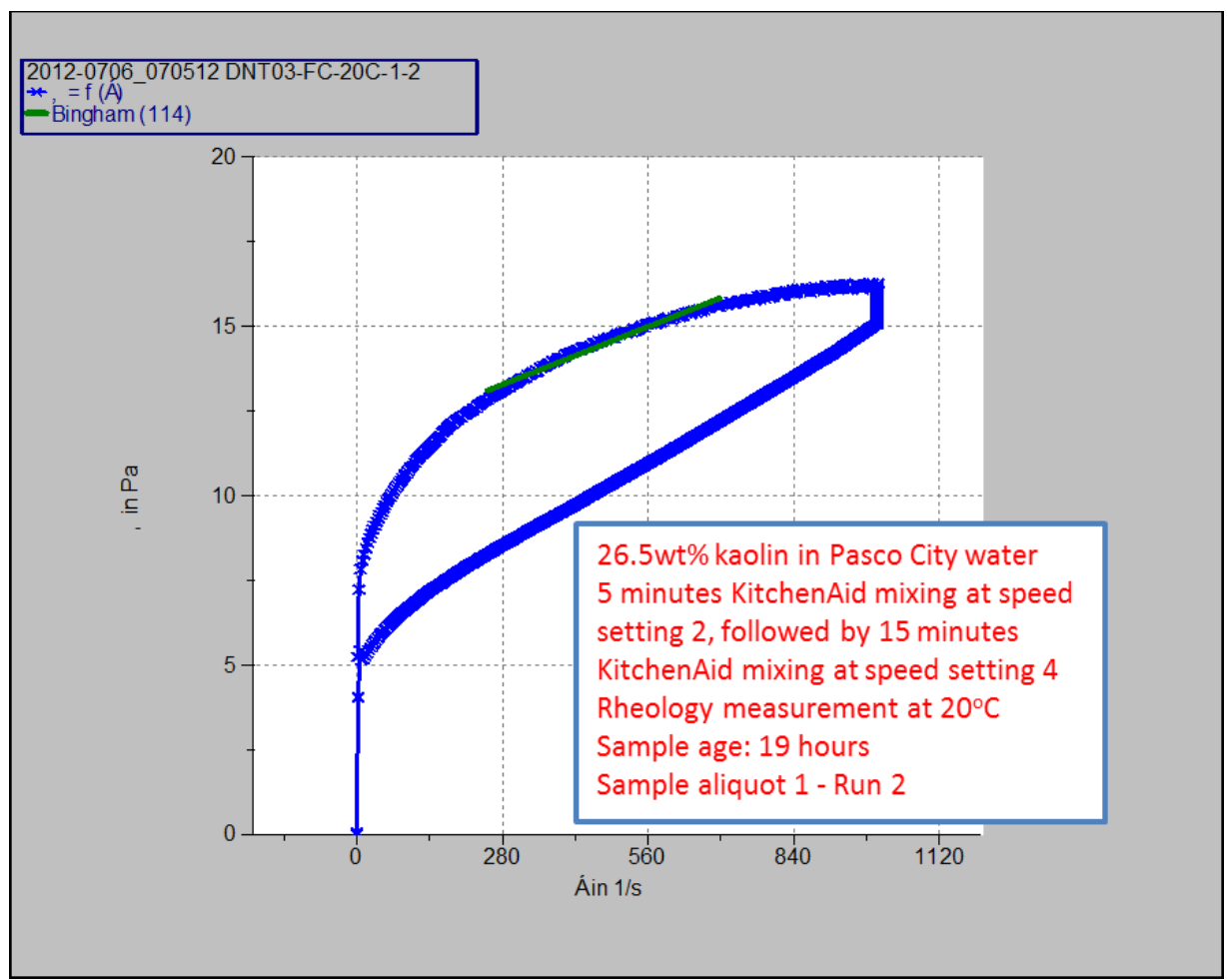

Figure B.6. Rheogram (Second Down-Ramp) for $26.5 \mathrm{wt} \%$ Kaolin in Pasco City Water (Simulant Target Properties of $10 \mathrm{~Pa}, 1.1 \mathrm{~g} / \mathrm{mL}$ ) 
Appendix C

Particle Size Distributions for Kaolin Clay in Simulant Recipes 



\section{Appendix C}

\section{Particle Size Distributions for Kaolin Clay in Simulant Recipes}

The figures below show the Microtrac instrument output for each of the kaolin slurry samples reported in Section 4. 


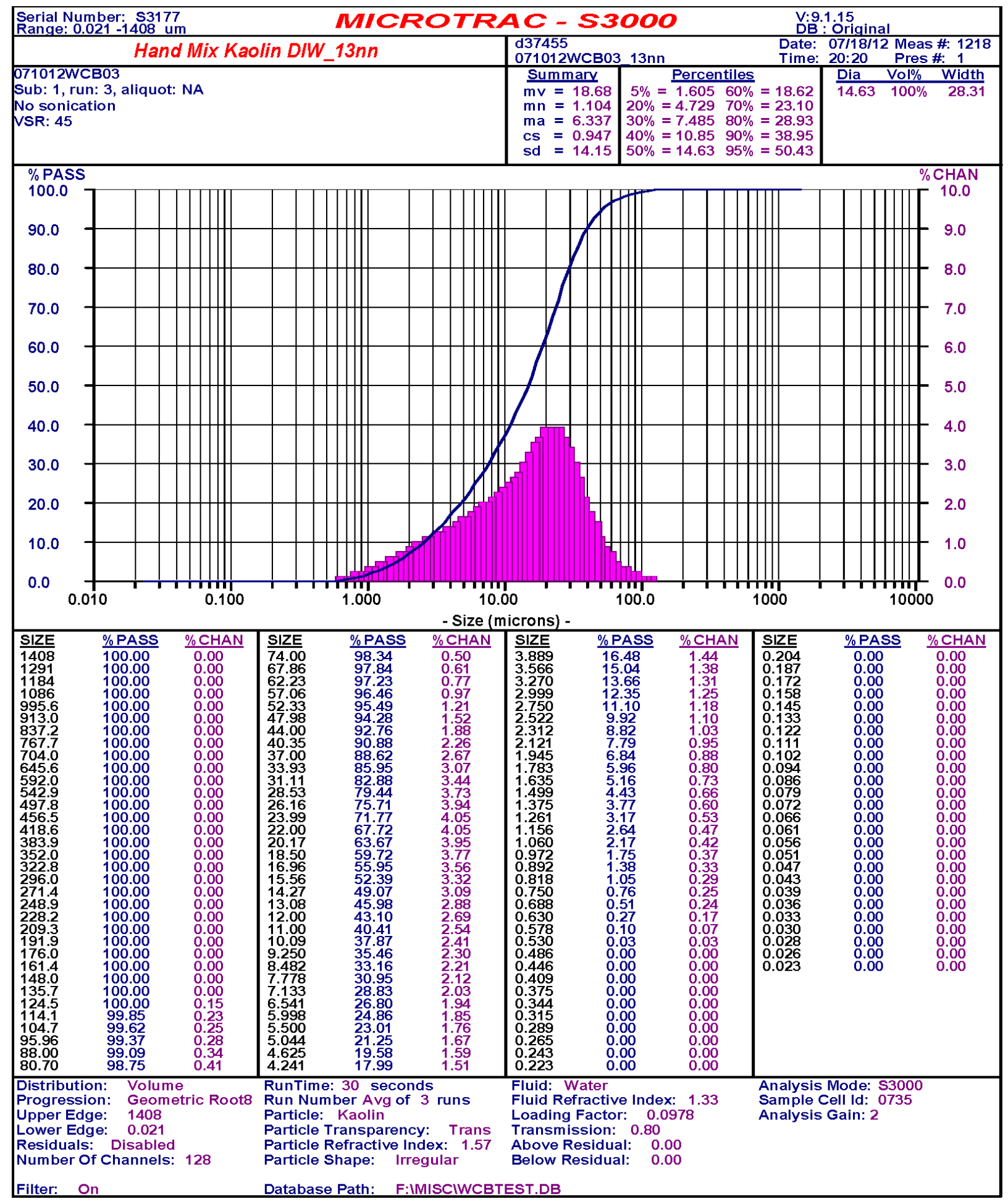

Figure C.1. Particle Size Distribution for the Hand-mixed Slurry of Kaolin Clay in DI Water without Sonication (see Hand Kaolin in Table 3.9, Section 3.6) 


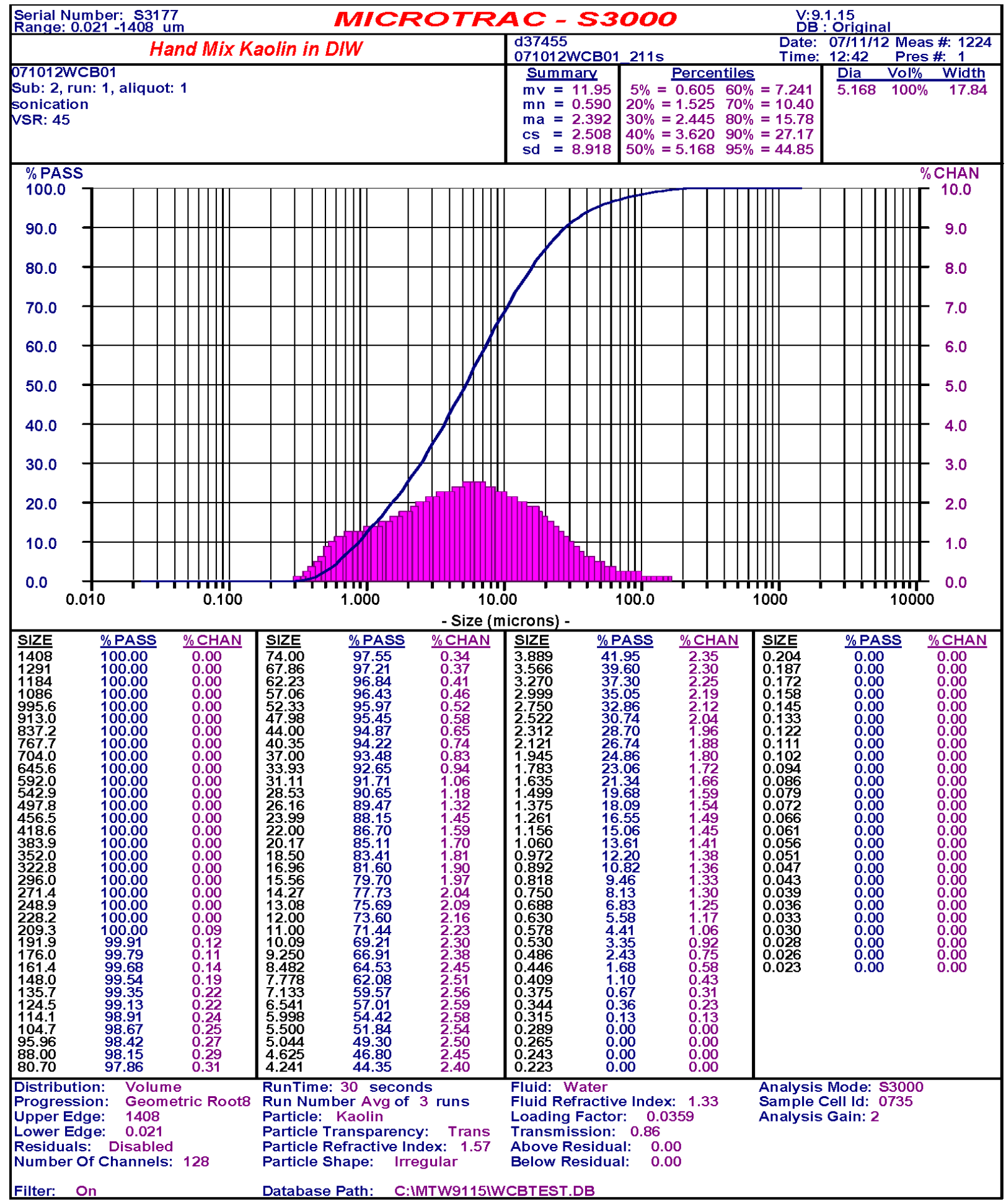

Figure C.2. Particle Size Distribution for the Hand-mixed Slurry of Kaolin in DI Water with Sonication (see Hand Kaolin/Sonicated in Table 3.9, Section 3.6) 


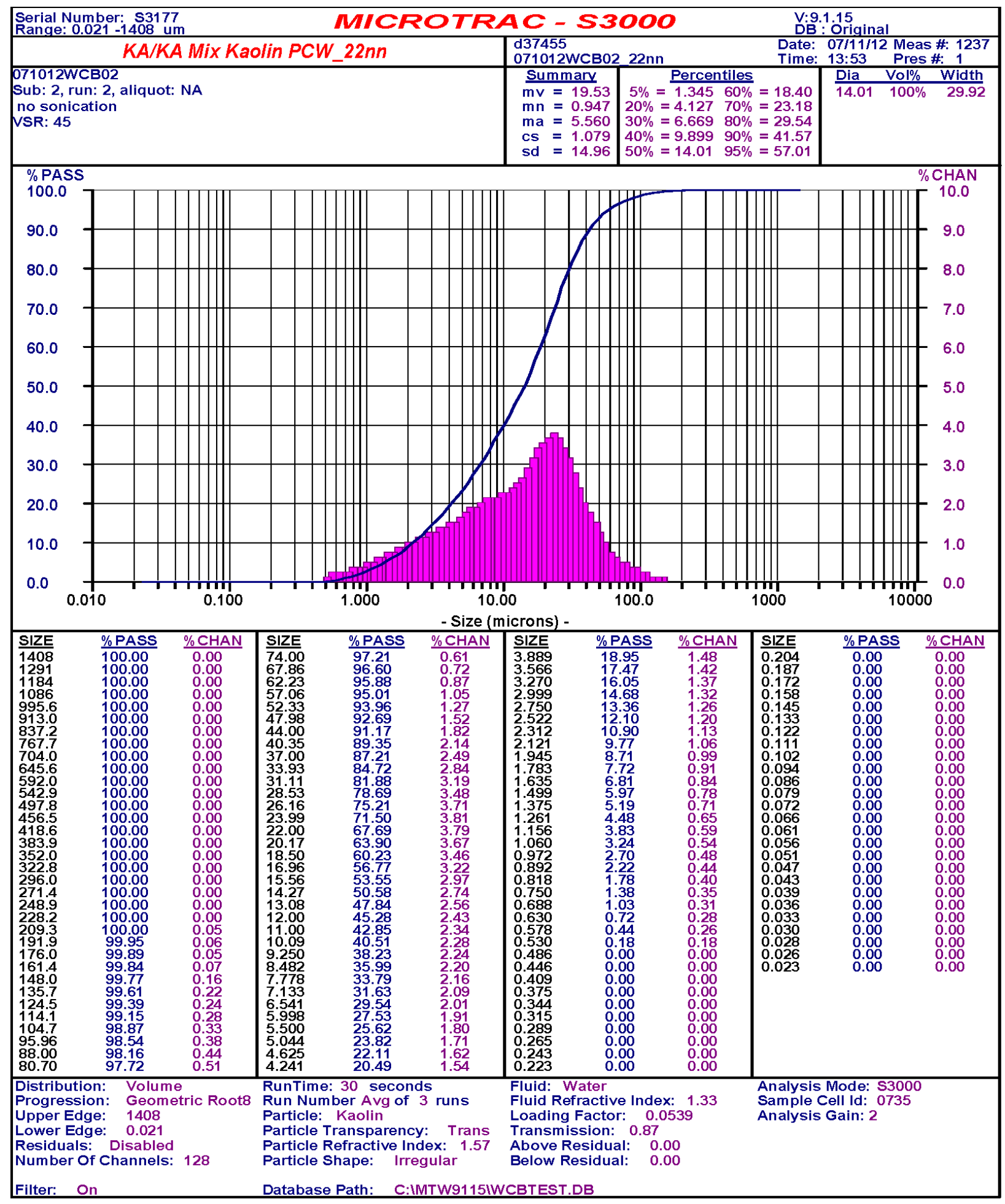

Figure C.3. Particle Size Distribution for KitchenAid-Mixed/KitchenAid-Presheared Slurry of Kaolin Clay in Pasco City Water without Sonication (see KA/KA Kaolin in Table 3.9, Section 3.6) 


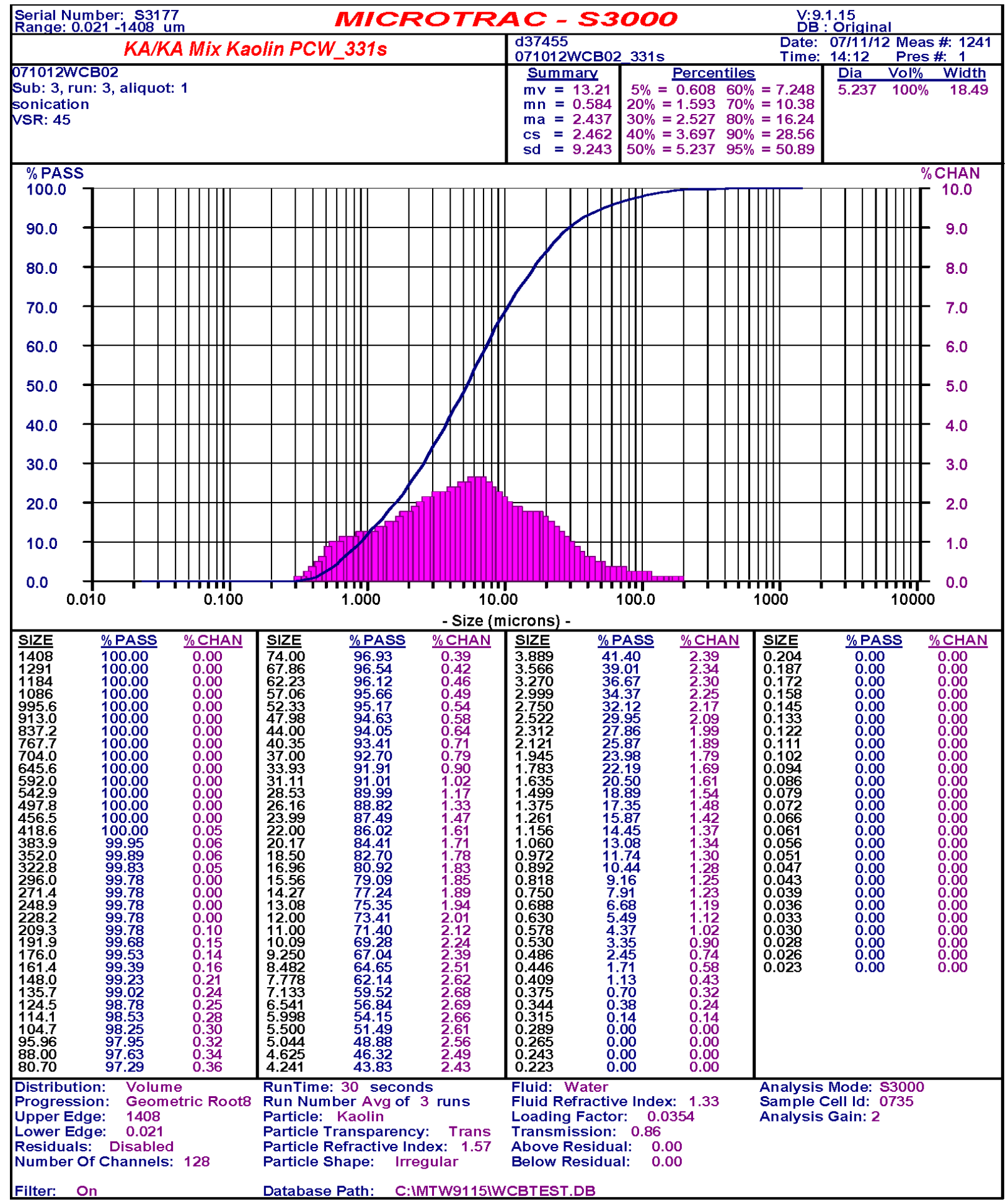

Figure C.4. Particle Size Distribution for KitchenAid-Mixed/KitchenAid-Presheared Slurry of Kaolin Clay in Pasco City Water with Sonication (see KA/KA Kaolin/Sonicated in Table 3.9, Section 3.6) 


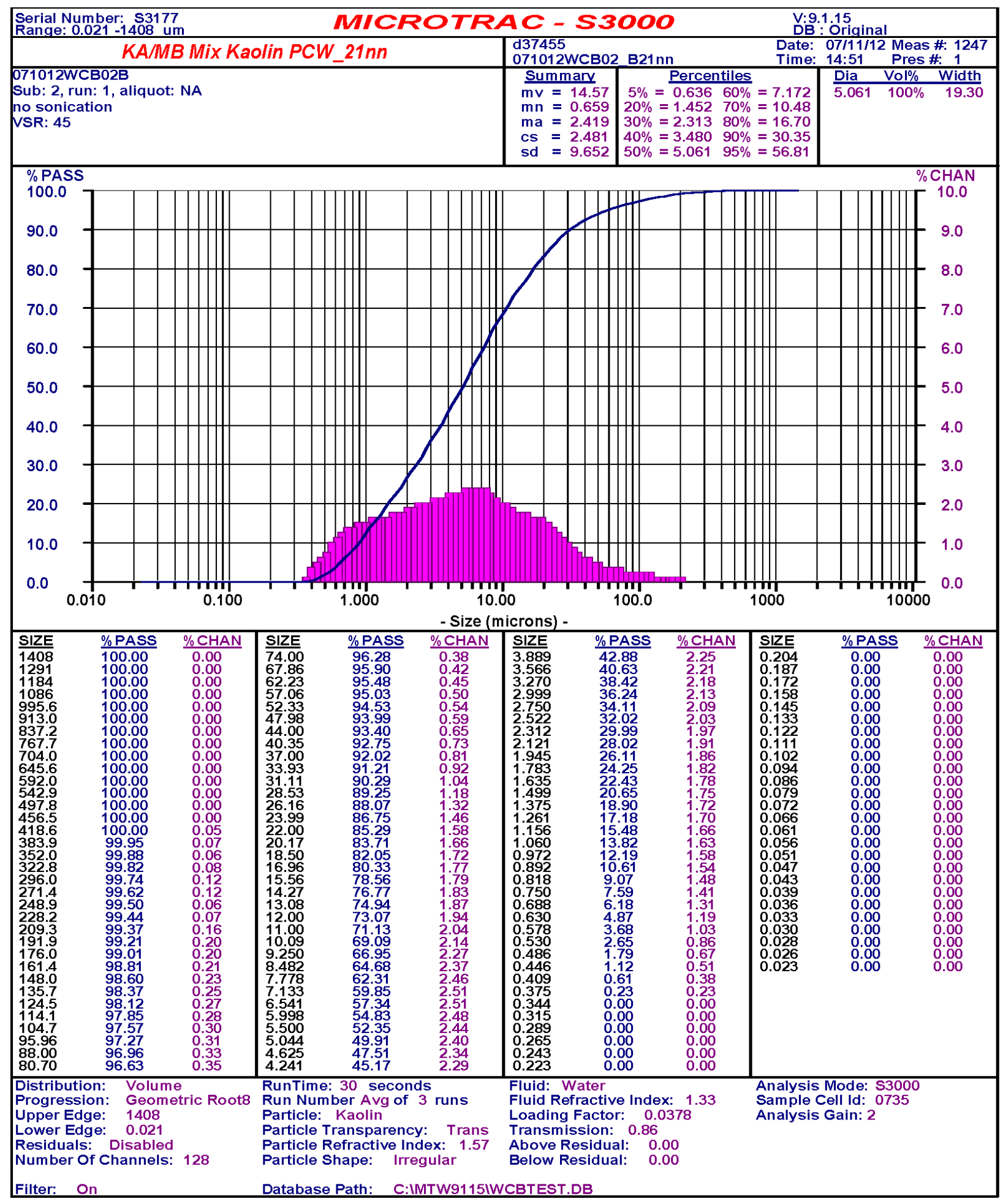

Figure C.5. Particle Size Distribution for KitchenAid-Mixed/Magic Bullet-Presheared Slurry of Kaolin Clay in Pasco City Water without Sonication (see KA/MB Kaolin in Table 3.9, Section 3.6) 


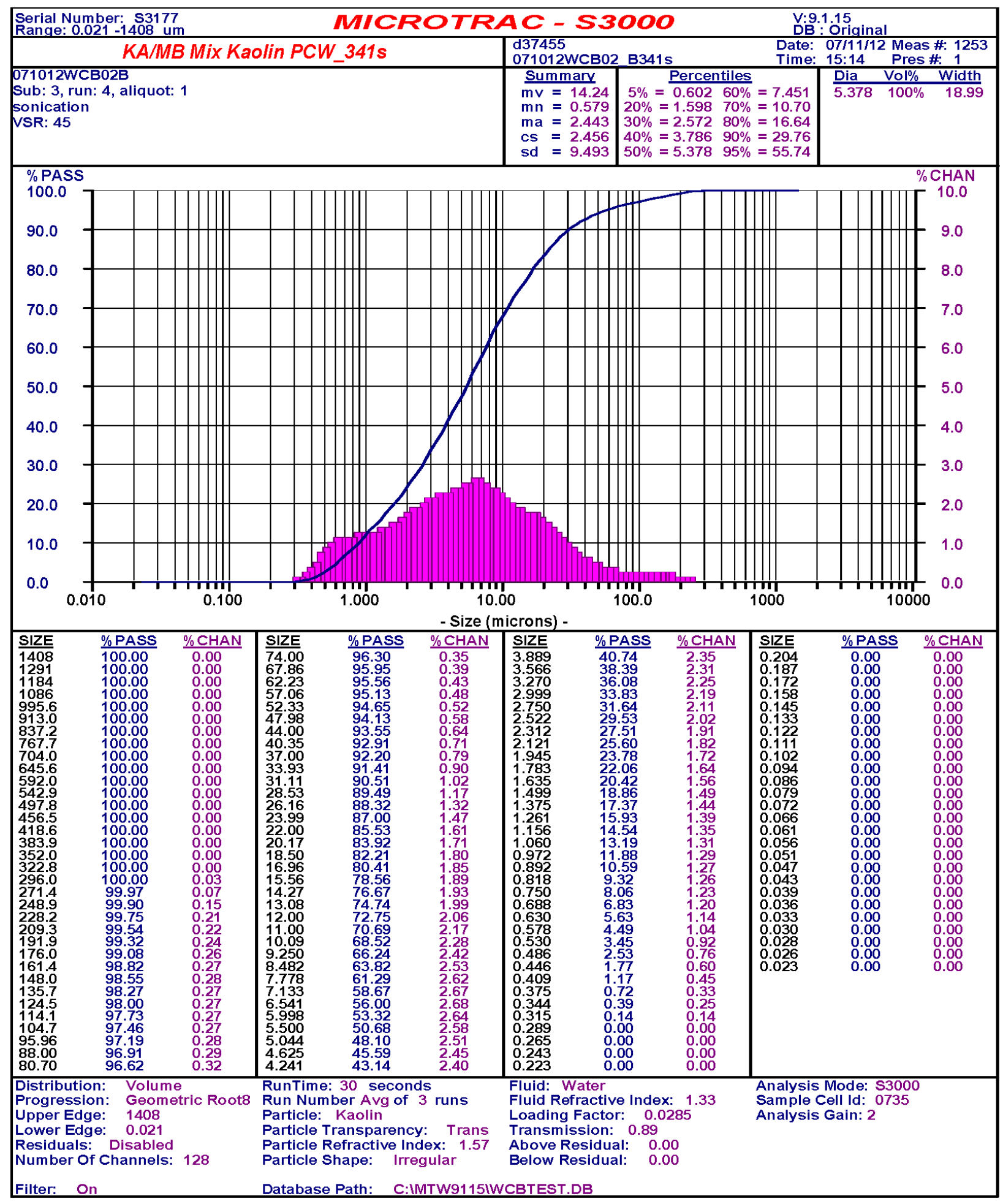

Figure C.6. Particle Size Distribution for KitchenAid-Mixed/Magic Bullet-Presheared Slurry of Kaolin Clay in Pasco City Water with Sonication (see KA/MB Kaolin/Sonicated in Table 3.9, Section 3.6) 


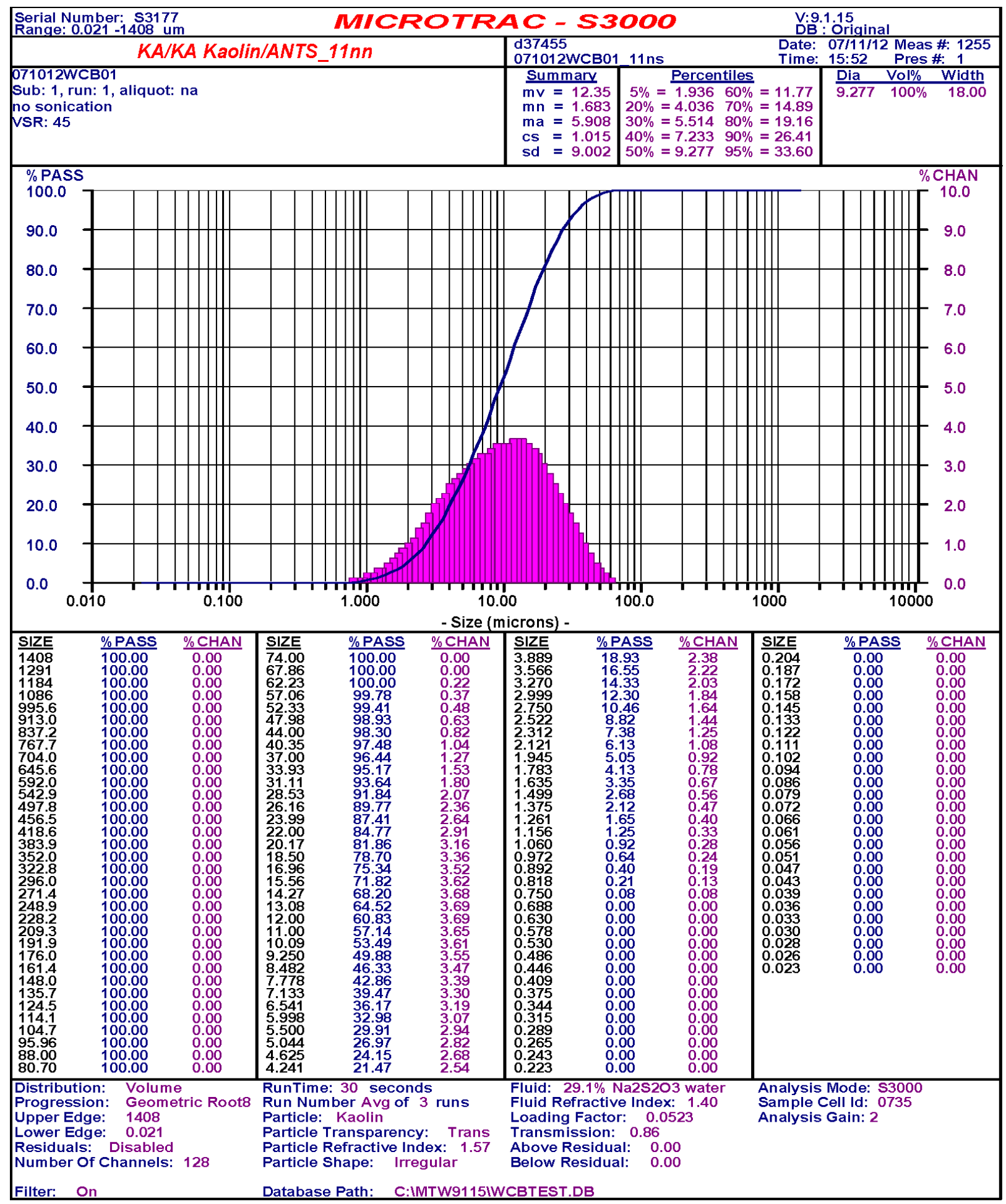

Figure C.7. Particle Size Distribution for KitchenAid-Mixed/KitchenAid-Presheared Slurry of Kaolin Clay in Pasco City Water with 24.9 wt\% Anhydrous Sodium Thiosulfate; without Sonication (see KA/KA Kaolin/Salts in Table 3.9, Section 3.6) 


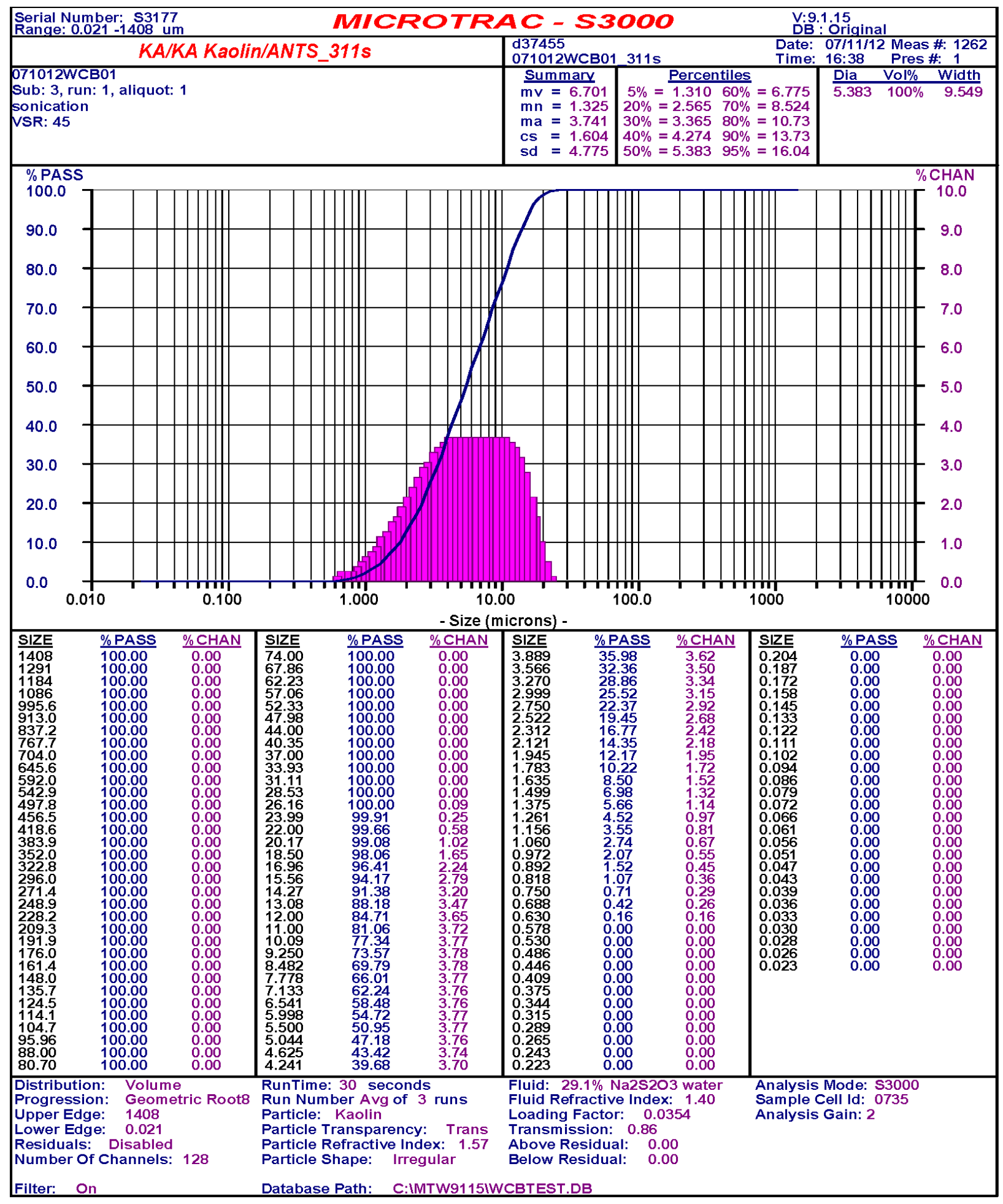

Figure C.8. Particle Size Distribution for KitchenAid-Mixed/KitchenAid-Presheared Slurry of Kaolin Clay in Pasco City Water with 24.9 wt\% Anhydrous Sodium Thiosulfate; with Sonication (see KA/KA Kaolin/Salts/Sonicated in Table 3.9, Section 3.6) 


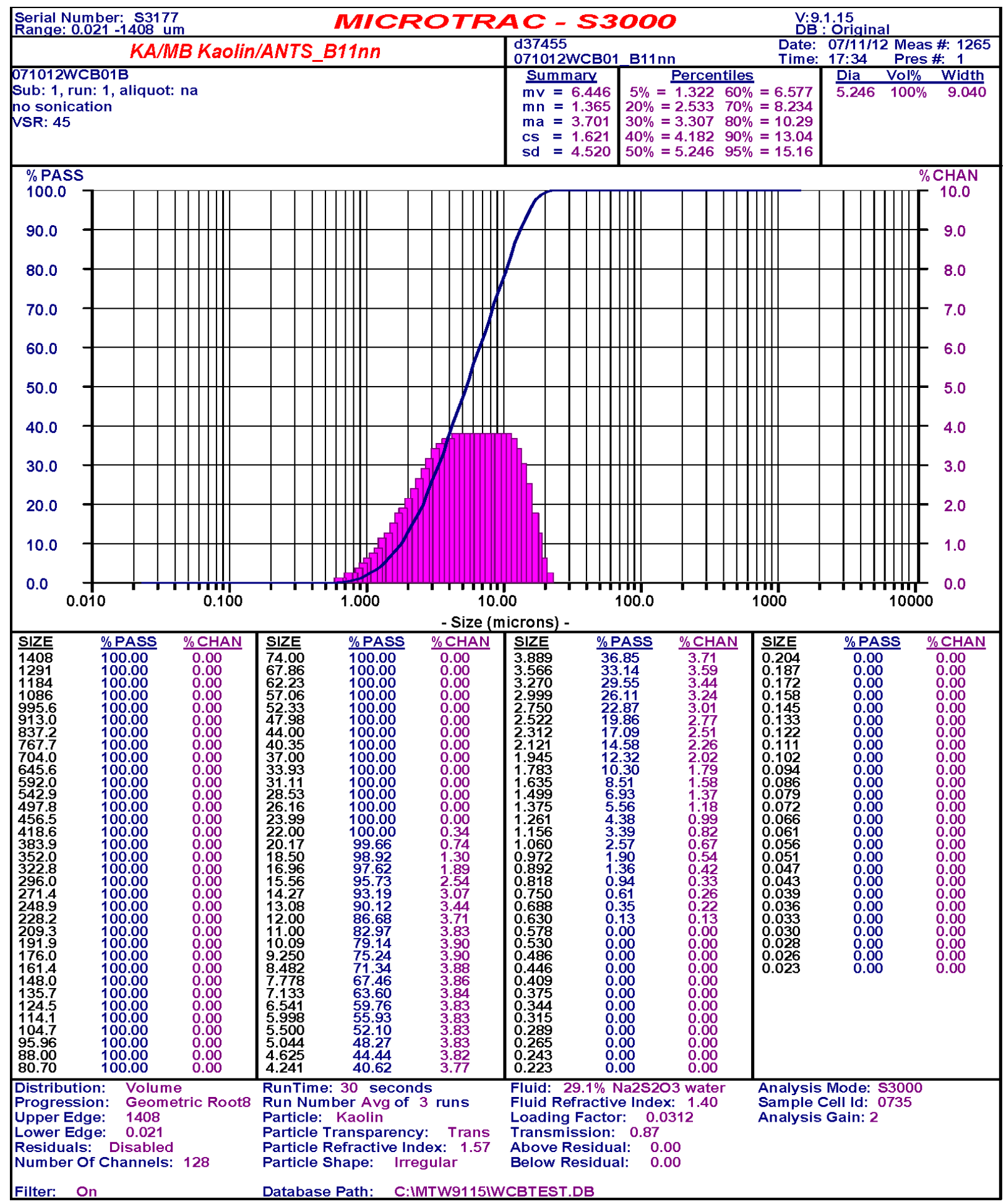

Figure C.9. Particle Size Distribution for KitchenAid-Mixed/Magic Bullet-Presheared Slurry of Kaolin Clay in Pasco City Water with $24.9 \mathrm{wt} \%$ Anhydrous Sodium Thiosulfate; without Sonication (see KA/MB Kaolin/Salts in Table 3.9, Section 3.6) 


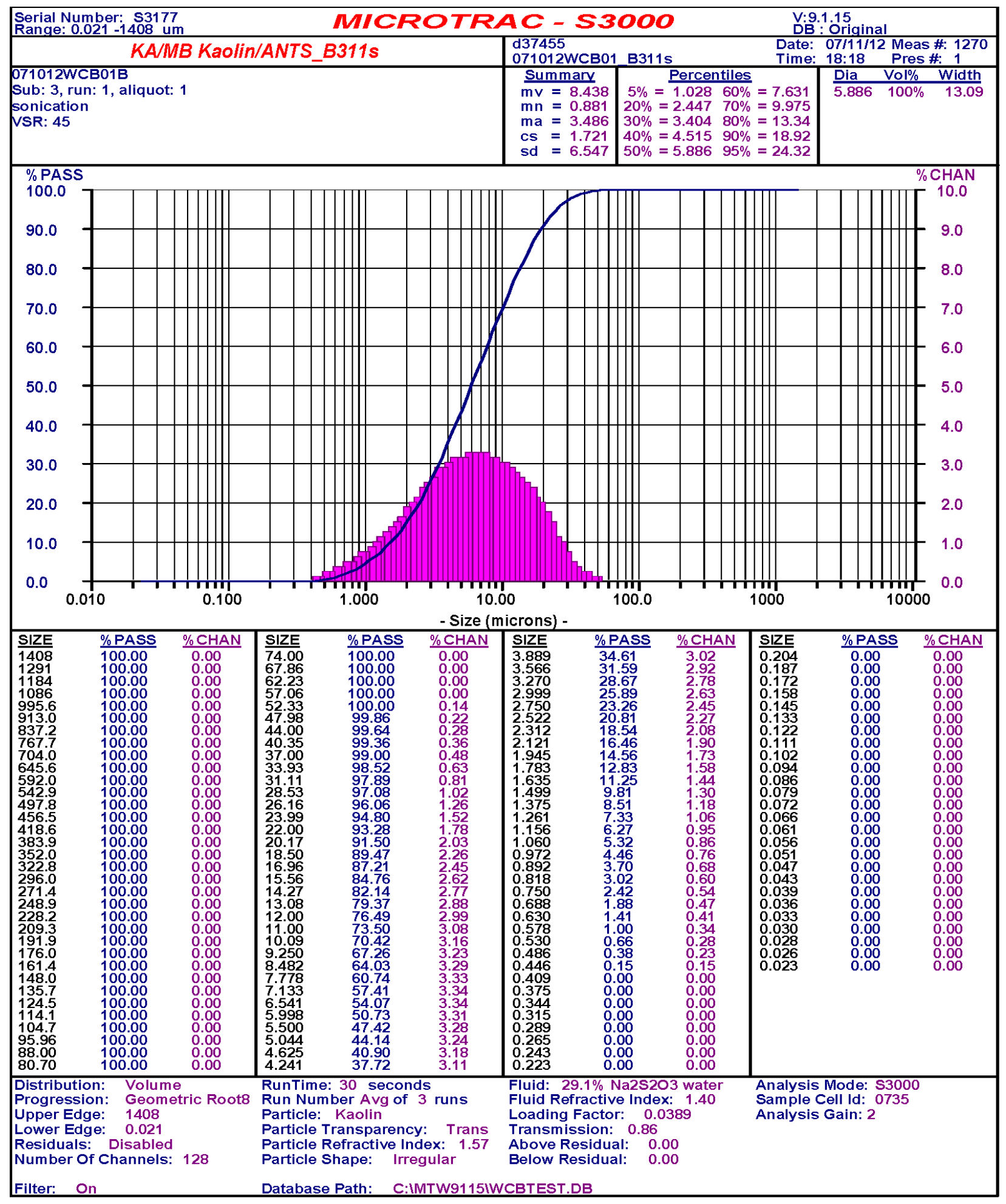

Figure C.10. Particle Size Distribution for KitchenAid-Mixed/Magic Bullet-Presheared Slurry of Kaolin Clay in Pasco City Water with 24.9 wt\% Anhydrous Sodium Thiosulfate; with Sonication (KA/MB Kaolin/Salts in Table 3.9, Section 3.6) 



\section{Distribution}

No. of

Copies

\section{OFFSITE}

DJ Adamson

Savannah River National Laboratory

Savannah River Site

Aiken, SC 29808

MR Ahrendt

Energy Solutions

2345 Stevens Drive, Suite 240

Richland, WA 99354

DW Clements

Energy Solutions

2345 Stevens Drive, Suite 240

Richland, WA 99354

MR Duignan

Savannah River National Laboratory

Savannah River Site

Aiken, SC 29808

F Dunn

Columbia Energy \& Environmental Services

1806 Terminal Drive

Richland, WA 99354

S Turner

Energy Solutions

2345 Stevens Drive, Suite 240

Richland, WA 99354

MW Vanatta

Energy Solutions

2345 Stevens Drive, Suite 240

Richland, WA 99354
No. of

Copies

ONSITE

1 DOE Office of River Protection

CK Liu H6-60

6 Washington River Protection Solutions

SE Kelly

B1-55

KP Lee

B1-55

MG Thien (3)

B1-55

TA Wooley

B1-55

12 Pacific Northwest National Laboratory

WC Buchmiller

K6-24

JA Fort

K7-15

PA Gauglitz (5)

$\mathrm{K} 7-15$

SD Rassat

K6-28

DR Rector

K7-15

DN Tran

K6-24

BE Wells

K7-15

Project Records

K7-15

1 Bechtel National, Inc.

SM Barnes

17-A

Distr.1 




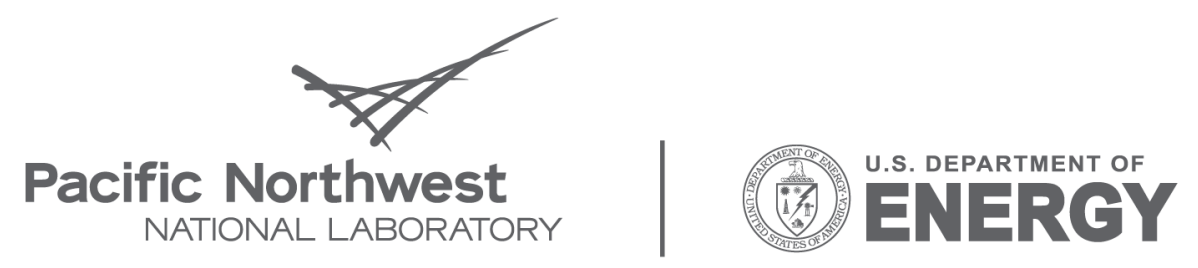

Proudly Operated by Battelle Since 1965

902 Battelle Boulevard

P.O. Box 999

Richland, WA 99352

1-888-375-PNNL (7665)

www.pnl.gov 